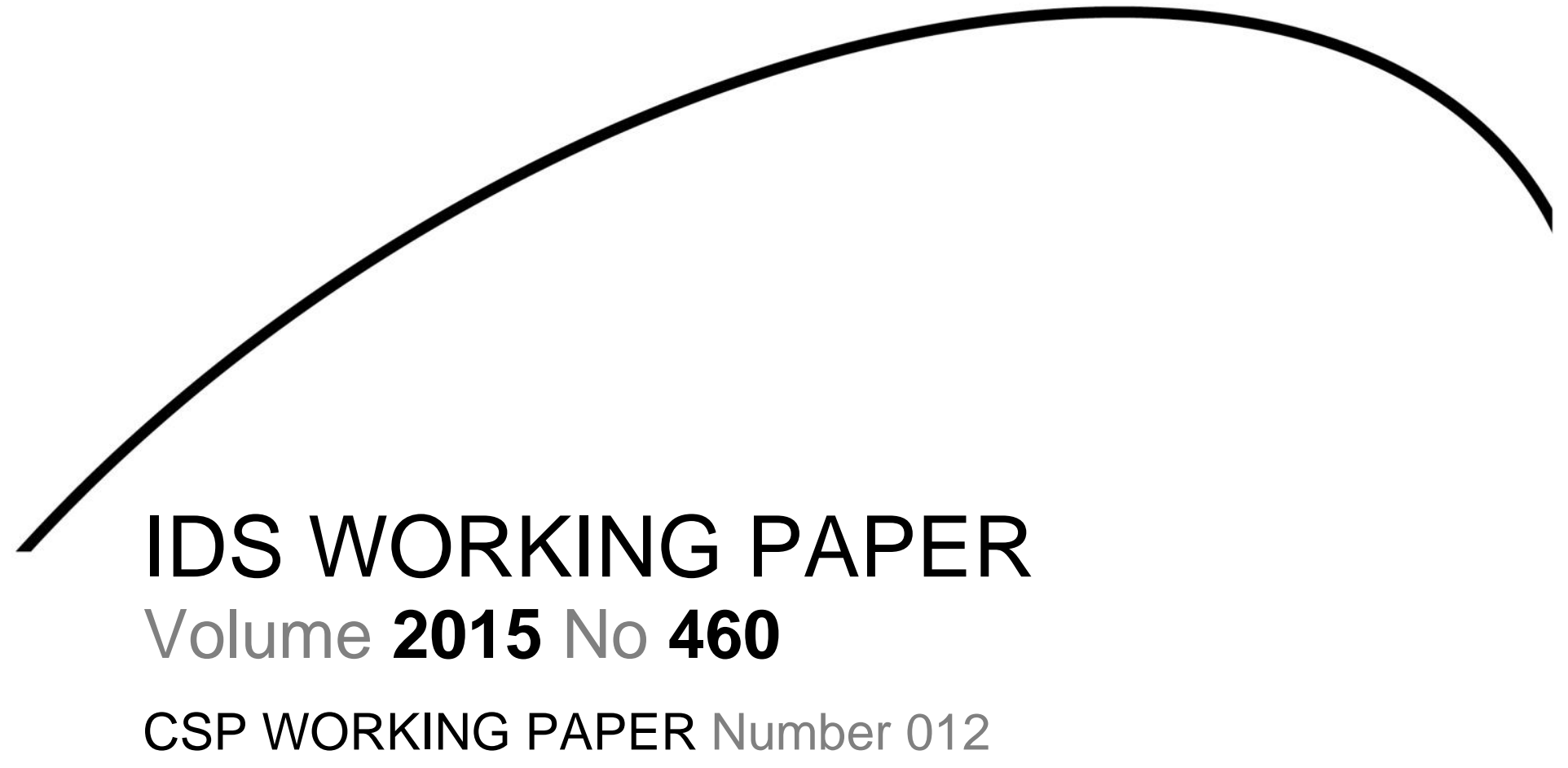

\title{
Evaluating the Targeting Effectiveness of Social Transfers: A Literature Review
}

Stephen Devereux, Edoardo Masset, Rachel Sabates-Wheeler, Michael Samson, Althea-Maria Rivas and Dolf te Lintelo

July 2015

\section{SP $\begin{aligned} & \text { Centre for } \\ & \text { Social Protection }\end{aligned}$}


The Centre for Social Protection (CSP) supports a global network of partners working to mainstream social protection in development policy and encourage social protection systems and instruments that are comprehensive, long-term, sustainable and pro-poor. We produce research on conceptual approaches; design issues, including delivery, targeting and affordability; and impacts of different social protection initiatives.

Email: socialprotection@ids.ac.uk

Web: www.ids.ac.uk/idsresearch/centre-for-social-protection

CSP WP012

CSP Working Paper series editor: Stephen Devereux

Evaluating the Targeting Effectiveness of Social Transfers: A Literature Review

Stephen Devereux, Edoardo Masset, Rachel Sabates-Wheeler, Michael Samson, Althea-Maria Rivas and Dolf te Lintelo

IDS Working Paper 460

(C) Institute of Development Studies 2015

ISSN: 2040-0209 ISBN: 978-1-78118-250-5

A catalogue record for this publication is available from the British Library.

All rights reserved. Reproduction, copy, transmission, or translation of any part of this publication may be made only under the following conditions:

- with the prior permission of the publisher; or

- with a licence from the Copyright Licensing Agency Ltd., 90 Tottenham Court Road, London W1P 9HE, UK,

or from another national licensing agency; or

- under the terms set out below.

This publication is copyright, but may be reproduced by any method without fee for teaching or nonprofit purposes, but not for resale. Formal permission is required for all such uses, but normally will be granted immediately. For copying in any other circumstances, or for re-use in other publications, or for translation or adaptation, prior written permission must be obtained from the publisher and a fee may be payable.

Available from:

Communications and Engagement Unit, Institute of Development Studies, Brighton BN1 9RE, UK

Tel: +44 (0) 1273915637

E-mail: bookshop@ids.ac.uk

Web: www.ids.ac.uk/publications

IDS is a charitable company limited by guarantee and registered in England (No. 877338) 


\section{Evaluating the Targeting Effectiveness of Social Transfers: A Literature Review}

Stephen Devereux, Edoardo Masset, Rachel Sabates-Wheeler, Michael Samson, Althea-Maria Rivas and Dolf te Lintelo

\section{Summary}

Many methodologies exist for dividing a population into those who are classified as eligible for social transfers and those who are ineligible. Popular targeting mechanisms include means testing, proxy means tests, categorical, geographic, community-based, and selfselection. This paper reviews empirical evidence from a range of social protection programmes on the accuracy of these mechanisms, in terms of minimising four targeting errors: inclusion and exclusion, by eligibility and by poverty. This paper also reviews available evidence on the various costs associated with targeting, not only administrative but also private, social, psycho-social, incentive-based and political costs. Comparisons are difficult, but all mechanisms generate targeting errors and costs. Given the inevitability of trade-offs, there is no 'best' mechanism for targeting social transfers. The key determinant of relative accuracy and cost-effectiveness in each case is how well the targeting mechanism is designed and implemented.

Keywords: targeting mechanisms; inclusion and exclusion errors; targeting costs 
Stephen Devereux is a Research Fellow at the Institute of Development Studies and the Director of the Centre for Social Protection. He works on food security, rural livelihoods and social protection in sub-Saharan Africa.

Edoardo Masset is an agricultural and development economist. Main research interests include the analysis of poverty and vulnerability, the evaluation of development interventions, and the microeconometric analysis of household surveys. Edoardo is a Research Fellow at the Institute of Development Studies at the University of Sussex and before that he worked at the evaluation department of the World Bank.

Rachel Sabates-Wheeler, a Development Economist and a Research Fellow at IDS since 2001, has worked and published in the areas of poverty analysis, social protection, graduation, targeting food security and migration in over 12 African countries. Rachel has led and been involved in a number of studies that explore understandings of risk and vulnerability, including: the Productive Safety Net Programme (PSNP), Ethiopia; the Hunger Safety Net Programme (HSNP), Kenya; the Child Support Grant (CSG), South Africa; and a number of studies on home-grown school feeding programmes in Africa.

Michael Samson is the Economic Policy Research Institute's (EPRI) Director of Research. $\mathrm{He}$ has worked on social protection policy design, implementation and evaluation projects in 35 countries in Asia, Africa, Latin America and the Pacific. He coordinated and co-led the team implementing the first-ever integrated impact assessment of the Child Support Grant in South Africa, as well as other evaluations in Africa and Asia. He has supported the design and implementation of social protection policies and programmes in Bangladesh, Kenya, Nepal, Nicaragua, Nigeria, Lesotho, South Africa, Thailand, Uganda and other countries. He lectures on the developmental impact of social protection at policy conferences and training workshops around the world.

Althea-Maria Rivas is a Postdoctoral Research Associate with the Centre for Development Studies at the University of Bath and completed her PhD in Development Studies at the University of Sussex. She specializes in peace and conflict studies and gender in Central Asia and East Africa.

Dolf te Lintelo is a Fellow in the Cities Cluster at the Institute of Development Studies at the University of Sussex. His research interests concern the politics of social policy and regulatory processes, the role of advocacy coalitions in these, and the ways in which policies structure vulnerabilities for the poor. He has a special interest in urban informal work, young people, food and nutrition security, and social protection. Much of his recent work has taken place in Eastern and Southern Africa and in South Asia. 


\section{Contents}

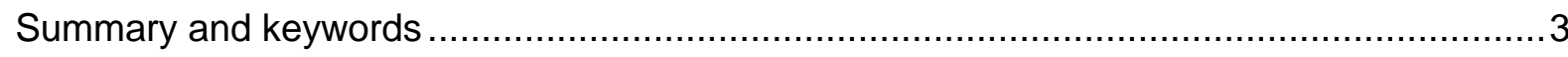

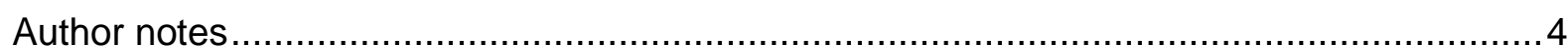

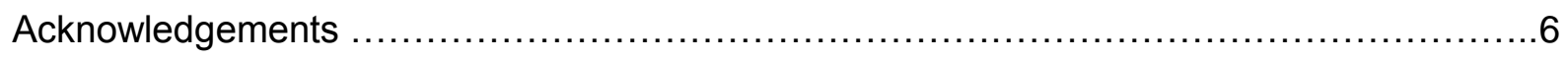

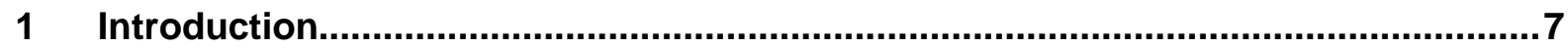

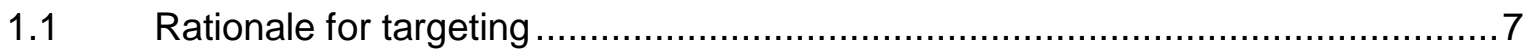

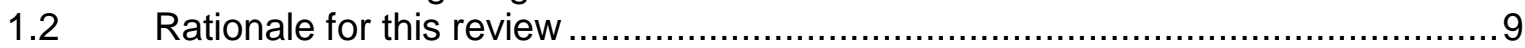

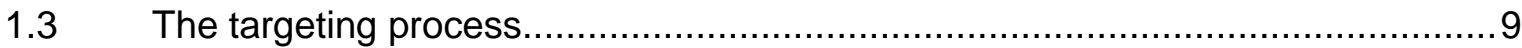

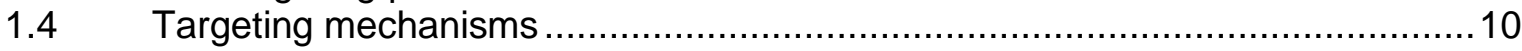

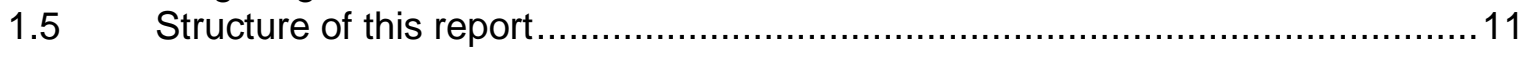

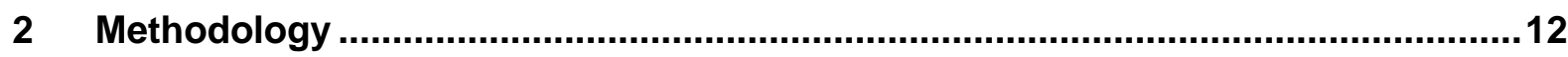

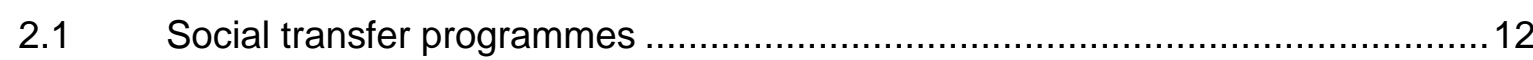

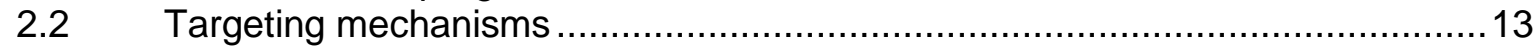

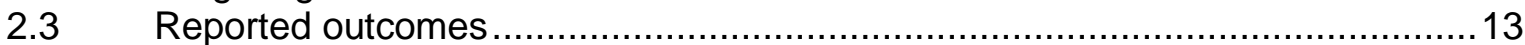

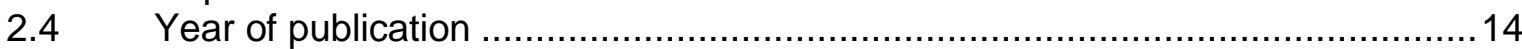

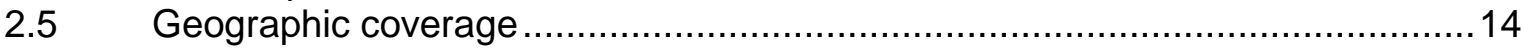

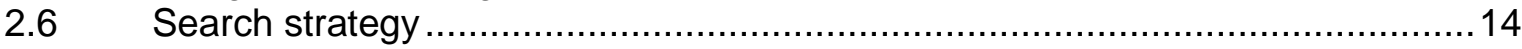

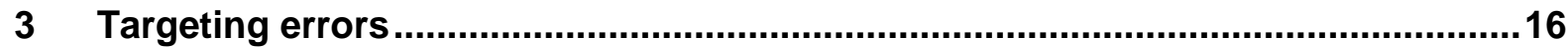

3.1 Defining targeting errors ............................................................................... 16

3.2 Overview of evidence from international experience ....................................21

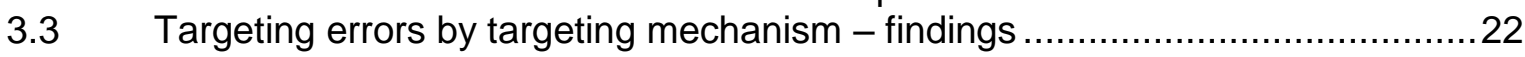

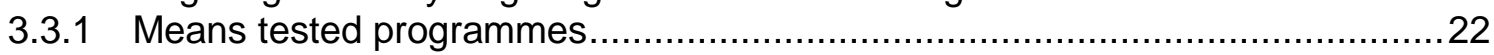

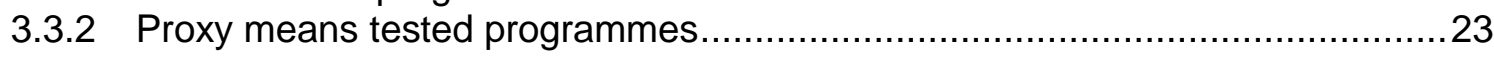

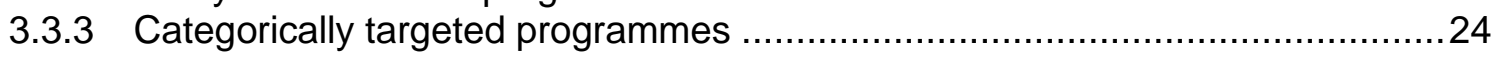

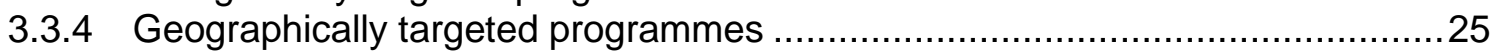

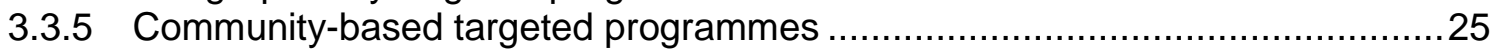

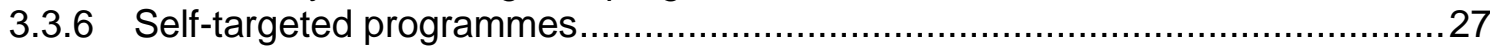

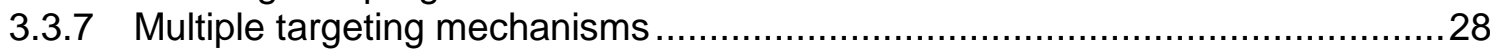

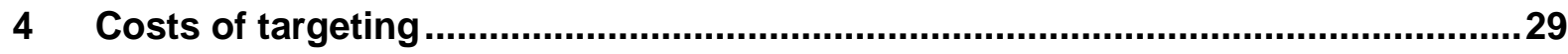

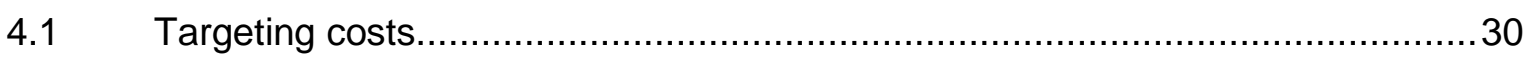

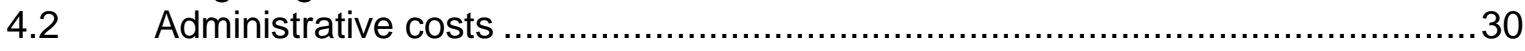

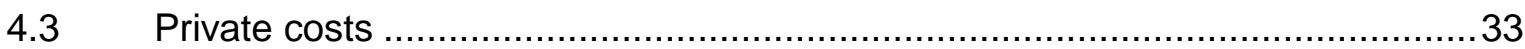

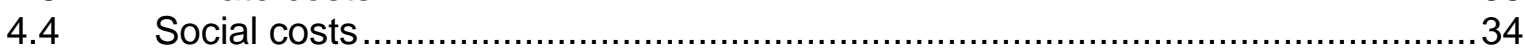

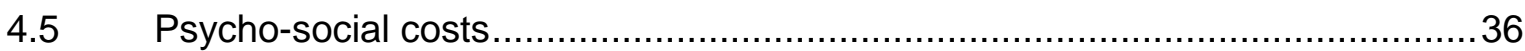

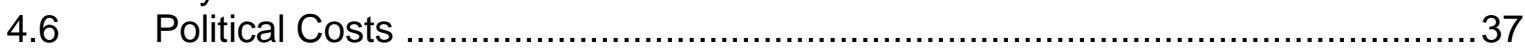

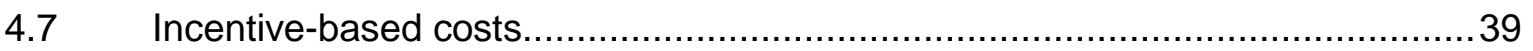

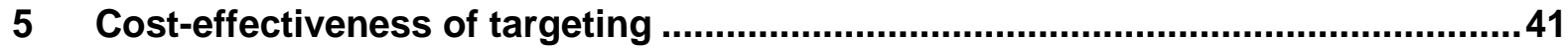

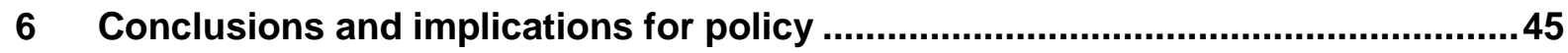

6.1 Implications for practice and research ...................................................... 46

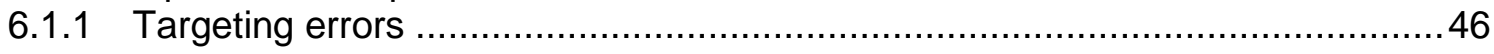

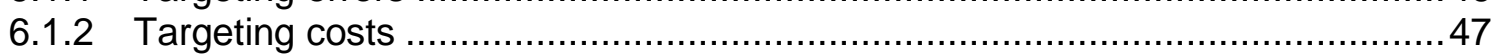

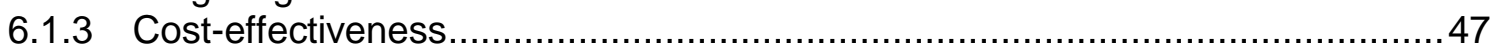

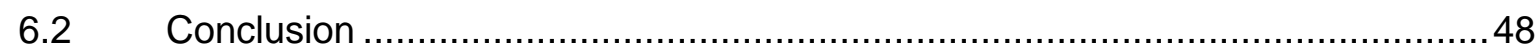

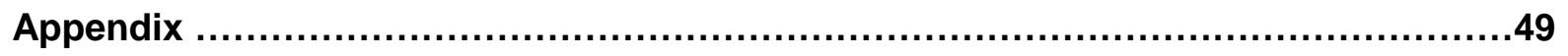

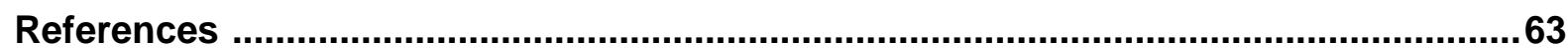




\section{Acknowledgements}

This Working Paper was originally commissioned in 2010 by the Department for International Development (DFID) as a systematic review of evidence on 'The effectiveness and efficiency of different social transfer targeting methodologies'. Four years and six drafts later, the report was accepted as a literature review, but not as a systematic review. This Working Paper is a modified version of the revised literature review, so it does not reference relevant documents that might have been published since 2011.

The authors acknowledge the financial support from 3ie/DFID that facilitated this literature review. The authors also thank Tim Conway, Heather Kindness and Matthew Greenslade (DFID) as well as two anonymous referees for insightful comments on earlier drafts. 


\section{Introduction}

Targeting can be defined as any mechanism for identifying eligible individuals and screening out the ineligible from a population, for purposes of transferring resources such as social grants or preferential access to social services.

This section discusses the rationale for targeting, explains the purpose of this literature review, introduces key concepts (e.g. 'targeting errors' and 'social transfers'), presents alternative typologies of targeting mechanisms, and outlines the structure of this report.

\subsection{Rationale for targeting}

Why target a social transfer programme? The decision is motivated by ethical notions of fairness, as well as by pragmatic considerations such as cost-effectiveness. Societies that judge existing levels of poverty and inequality as unacceptable often introduce transfers to the poor as one solution to this inequity. But governments also aim to maximise welfare under budget constraints, to use available public resources cost-effectively. Both considerations inform targeting efforts, with the balance varying from case to case.

Most social transfers aim to reduce poverty, so the obvious motivation is to provide support to people living in poverty. But this raises a series of questions. How to define poverty? Who are 'the poor'? How to identify people living in poverty? A more pragmatic reason for targeting is to contain the cost of social transfer provision within specific budget limits. This raises a different set of questions. Can all people in need be reached with a limited budget? Is it better to reach all poor people with a small social transfer, or to target the "poorest of the poor' with larger transfers? If a quota must be applied, how to do this and how to explain it to those poor people who are excluded? These are some of the conceptual and practical challenges that designers of social transfer programmes must address.

Even if social transfers are explicitly intended to alleviate poverty, they are not always targeted directly at 'the poor'. Social transfers are also given to older persons, orphans or people with disabilities, either because these 'vulnerable groups' are assumed to be deserving of support or because empirical data exists indicating that they are - on average poorer than others and need financial assistance. So these characteristics are used as proxies or indicators of poverty. What does this mean for assessing the accuracy and effectiveness of targeted social transfers? One implication is that the coverage of such programmes can be assessed in two ways:

1. In terms of their eligibility criteria (is everyone who receives a social pension over 60 years old? Is everyone over 60 receiving a social pension?)

2. In terms of the accuracy of the eligibility criteria as proxies for reaching poor people (what proportion of people over 60 years old are actually poor? What should be done to assist poor people under 60?)

It is not always clear which definition of targeting accuracy should be used - eligibility or poverty - and in fact both indicators are of interest. On the one hand, it is important to know how well a programme is performing in terms of its specific eligibility criteria. On the other hand, it is also important to know whether a social transfer is reaching people most in need. This also allows targeting outcomes to be compared across programmes using a common benchmark - people assisted who are poor. This paper reports on either indicator, or both, depending on which is reported in programme evaluations or targeting assessments. 
Even when social transfers are intended to reduce poverty, it is important to be realistic about what such programmes can achieve. Few social transfers are generous enough to lift people above the poverty line - often they raise recipients from 'extreme poverty' to 'moderate poverty' - so despite their rapidly growing popularity in recent years, they are not a solution to poverty eradication on their own. A comprehensive anti-poverty strategy needs a mix of targeted, inclusive and enabling actions.

Another powerful reason for targeting is pragmatic. Making the most efficient use of scarce public resources requires directing those resources to where they will have maximum impact. Given that all governments and development partners operate within constrained budgets, the biggest impact on poverty will be achieved by transferring resources directly to the poor. This might seem to be an argument against universal or untargeted programmes, which can be justified on other grounds (e.g. social inclusion) but are less efficient in reducing poverty, unless the costs of targeting are prohibitively high. But much depends on the scale of poverty. If $80 \%$ of a population are poor and it would cost more than $20 \%$ of a programme's budget to identify and exclude the non-poor, universal coverage would actually be more efficient than a targeted programme. Alternatively, if universal programmes are seen as 'unaffordable' but poverty is widespread, one option is to direct social transfers to the poorest of the poor (e.g. the poorest 10 or 20 percent), and to rely on other anti-poverty interventions (in agriculture, education, nutrition, health, etc) to complement social transfers and promote poverty reduction through sustainable growth in incomes.

If the policy objective is to maximise poverty reduction in a context where public resources are constrained, the policy-maker's problem is to find the optimum balance between effectiveness (reaching the intended individuals or households) and efficiency (doing so at reasonable cost). Because targeting is expensive, the most accurate mechanism (e.g. means testing every applicant) might be less cost-effective than a cheaper but less accurate mechanism (e.g. targeting a categorical 'vulnerable group', like all people with disabilities). This trade-off between targeting accuracy and targeting costs is one reason why there is no perfect targeting mechanism.

Finally, it is important not to overlook the politics of targeting (Sen 1995). Selecting one group of the population to receive public support and excluding others from benefiting is a political act, even if it is justified on 'technical' grounds such as the government's commitment to poverty reduction. For one thing, the middle-class, whose taxes contribute to financing poverty-targeted social transfers, need to give their political support for a programme that will not benefit them directly - this is one reason why governments sometimes opt for untargeted programmes, like universal free primary education. Politicians are striving to secure or sustain support, so their decisions about social transfer programmes might be overtly politicised (e.g. if they target social transfers to particular constituencies), or might be intended to address sources of social and political tension (e.g. unemployed youth, or historically neglected regions). While the overlap between political marginalisation, social exclusion and poverty is usually strong, it is never a $100 \%$ correlation.

Summing up, social transfer programmes are targeted for various reasons: to maximise their poverty reducing impact, to make most efficient use of constrained public resources, and also for political objectives: to attract or retain support of key constituencies. However, as noted above, there are often trade-offs between these objectives. Also, as will be seen below, targeting is associated with a range of errors, costs and negative consequences, which have led some to propose universal transfers rather than poverty targeted social transfers (van de Walle 1998; Mkandawire 2005).

This raises a related point - though this report does not discuss 'universal' programmes (such as a Basic Income Grant, fee-free education or a National Health Service free at the point of delivery), the line between untargeted and targeted programmes is sometimes more 
fuzzy than it appears. For instance, a social pension where eligibility is restricted only by age might be considered 'universal' in the sense that it reaches all older citizens, but only weakly 'targeted' at poor citizens because it excludes all the non-elderly poor.

\subsection{Rationale for this review}

Targeting is one of the most challenging and controversial aspects of the design and implementation of social transfer programmes throughout the world - challenging because it is almost impossible to target with $100 \%$ accuracy, and controversial because decisions about whether, how and who to target invariably raise strong feelings and heated debate.

This review aims to summarise knowledge from a selected subset of the literature on the errors, costs and secondary consequences (both positive and negative) of targeting in actual social transfer programmes in developing countries, in a comparative way across different types of programmes and different targeting mechanisms. Although other reviews of experiences with targeting exist, no comprehensive assessment has been undertaken since Coady, Grosh and Hoddinott (2004), which covered 122 social transfer programmes implemented during the period 1985-2000. Yet the past decade has seen a proliferation of social transfer programmes under the rapidly evolving social protection agenda, and a corresponding increase in the number of rigorous evaluations of the design and impact of these programmes. Without claiming to be comprehensive or exhaustive, this report offers an updated synthesis of selected thinking and evidence on targeting, and should provide a useful reference point for informing the future selection, design and implementation of targeting mechanisms for social transfer programmes.

\subsection{The targeting process}

Selecting an appropriate targeting mechanism for a social transfer programme requires taking a series of decisions, from choosing eligibility criteria to monitoring programme outcomes. Specifically, targeting social transfers involves the following series of steps.

\section{What is the aim of the social transfer programme?}

(e.g. to promote livelihoods and poverty reduction, to provide protection against livelihood shocks, or to provide support to a particularly vulnerable group)

\section{What is the aim of the targeting process?}

(e.g. to reach the poor (poverty targeting), or to direct benefits for other reasons, for example, an old age entitlement)

3. Who decides on eligibility criteria?

(e.g. programme administrators, politicians, communities)

4. What are the eligibility criteria?

(e.g. poverty, age, disability, unemployment, citizenship)

5. When does identification of beneficiaries occur?

(before delivery of social transfers, or on collection of social transfers)

6. Who identifies programme beneficiaries?

(e.g. technocrats, communities, or beneficiaries themselves)

7. What information is available to facilitate the targeting process?

(at what frequency and level of disaggregation, with what quality, at what cost?)

8. Are social transfers actually delivered to people identified as eligible - and to people who are actually poor?

(how large are the inclusion errors? how large are the exclusion errors?) 


\section{What are the financial costs of the targeting process?}

(how much programme budget was spent on identifying beneficiaries?)

\section{What are the secondary consequences of the targeting process?}

(e.g. did the exclusion of community members cause any social tensions?)

The first seven of these ten steps relate to how targeting is done; the final three steps relate to how targeting is assessed. Targeting mechanisms can be classified in terms of decisions taken under steps 1-7 above. For instance, if communities select beneficiaries this is a community-based targeting mechanism, while if beneficiaries identify themselves this is a self-targeting approach. For purposes of learning and retargeting (because people's circumstances change), regular reassessment of beneficiaries is often needed in longrunning programmes. Implementation decisions and assessment should both be part of an integrated targeting process.

The expectation informing the selection of a targeting mechanism is that decisions taken under steps 1-7 will produce good targeting outcomes in terms of steps 8-10: reasonably accurate, acceptable cost, with few negative secondary consequences. From a programming perspective, these outcomes are sometimes defined by predetermined parameters; e.g. inclusion error should not exceed $x x \%$, targeting costs should not absorb more than $x x \%$ of programme budget. From a research perspective, our interest is in comparing outcomes across alternative targeting mechanisms. Our hypothesis is that different targeting mechanisms are associated with systematic differences in terms of inclusion and exclusion errors, financial costs and secondary consequences. The focus of this evidence-based review is therefore on steps $8-10$ of the targeting process.

\subsection{Targeting mechanisms}

Any approach to targeting is based on a set of criteria that screens the eligible from the overall population. These criteria for screening applicants, and who applies the criteria, constitute different targeting mechanisms. The most common mechanisms include: means tests, proxy means tests, categorical targeting, geographic targeting, community-based targeting, and self-targeting. Box 1.1 presents three alternative classification systems. Social transfer programmes often use combinations of targeting mechanisms, either simultaneously, sequentially, or in parallel.

\section{Box 1.1 Classifying targeting mechanisms}

Slater and Farrington (2009) identify 'three main targeting approaches - poverty, social categorical and geographical; and ... a number of targeting mechanisms - communitybased, proxy indicators, means-testing, self-targeting and geographical ... Targeting approaches associated with poverty generally focus on households, and use criteria of (low) income, expenditure, consumption and assets; whilst social categorical targeting focuses on whether individuals belong to a specific social or demographic group (older people, disabled people, women, children, disadvantaged tribal or ethnic groups, etc). Typically, poverty targeting involves criteria that are continuous variables whilst social categorical involves more easily observable dichotomous indicators (i.e. people are either part of a social category - young, old, male, female, etc - or they are not). Geographical targeting selects different districts or villages or regions - often on the basis of poverty data where poverty is known to be chronic, or on the basis of other criteria (such as proneness to earthquakes, flooding etc where natural disasters are common and poverty may be more transitory'

(Slater and Farrington 2009: 6) 
The Economic Policy Research Institute (2006) describes four approaches to targeting. 'Individual or household assessments involve evaluating incomes, expenditures, assets or personal characteristics. Categorical targeting involves identifying easily distinguishable attributes that characterise poor households and the provision of benefits to those who share those traits - such as children, older people or people who live in lowincome areas. Some programmes attempt to target the poor by making the resource provided relatively unattractive - so that only the poorest will want it ... (self-targeting) ... Community targeting can involve any of these other mechanisms, but the determinations are made at a community level.'

(Samson, van Niekerk and MacQuene 2006: 55)

'According to Coady et al. (2004), the 6 main targeting methods used to identify eligible recipients for transfers include 1) Means testing, based on income, 2) Proxy means testing, based on some indicator of poverty, 3) Community-based targeting, based on local knowledge of poverty, 4) Geographical targeting based on location, 5) Demographic targeting, based on some characteristic such as age, gender, or orphanhood, and 6) Selftargeting, which is available to all who apply'

(Miller, Tsoka and Reichert 2010: 4)

This report classifies and analyses targeting mechanisms under six 'pure' categories and one 'hybrid' category:

1. Means testing: based on an assessment of income, assets or wealth of applicants (including unverified means-testing)

2. Proxy means testing: based on a weighted combination of characteristics that are believed to be highly correlated with wellbeing or deprivation

3. Categorical targeting: based on characteristics of interest to policy-makers, which might or might not be correlated with wellbeing or deprivation

4. Geographic targeting: based on location or residence (e.g. an area affected by a hazard, or a district with high poverty prevalence]

5. Community-based targeting: based on an eligibility assessment performed by the community where a programme is implemented

6. Self-targeting: based on voluntary participation or self-selection.

7. Multiple mechanisms: where more than one mechanism is used to identify programme participants, either simultaneously, sequential or in parallel.

In practice, many social transfer programmes (or most programmes, since geographical boundaries and citizenship invariably constitute first-level eligibility criteria) actually use a combination of targeting mechanisms, to refine targeting accuracy. For example, categorical programmes can either be 'universal' (all people over 60) or 'poverty targeted' (poor people over 60, combining categorical targeting and means testing). 'Multiple' targeting mechanisms are analysed as a separate category in this report.

\subsection{Structure of this report}

This report is structured around a review of empirical evidence from the literature on three key aspects of targeting - errors, costs, and cost-effectiveness. Section 2 describes the methodology we used to select documents for inclusion in this review. Section $\mathbf{3}$ focuses on 
targeting errors, and summarises recently available evidence by targeting mechanism on inclusion and exclusion errors of social transfer programmes, by design and implementation, and/or according to programme eligibility criteria and poverty. Section $\mathbf{4}$ focuses on targeting costs, broadly defined to include administrative, private, social, psycho-social, political and incentive-based costs. Section 5 extends this analysis to consider the (limited) evidence on cost-effectiveness of targeting. Section 6 discusses the implications of our findings on targeting errors, costs and cost-effectiveness, for policy and practice. Finally, an Appendix provides a table of inclusion and exclusion errors reported on programmes discussed in this report, categorised by targeting mechanism.

\section{Methodology}

Any literature review has to set its parameters. This review of literature on targeting social transfers was initially commissioned as a 'systematic review', which meant that a rigorous selection process had to be followed that necessarily excluded large numbers of publications that did not meet the search criteria and filters. First we defined the review's key search terms ('social transfer programmes', 'targeting mechanisms'), its geographic boundaries ('developing countries') and its timeframe (from 2000 onwards). Publications that met these search criteria were selected for this review if they reported on key outcomes of interest (targeting errors, targeting costs, negative and positive social consequences). Most of these studies reported data from actual programmes, but some ex ante simulations of targeting methods and outcomes were also included.

\subsection{Social transfer programmes}

Social transfers can be defined as regular non-contributory payments, in cash or in kind (e.g. food or vouchers), made by government or non-government organisations (NGOs) to individuals or households, with the objective of decreasing chronic or shock-induced poverty, addressing social risk and/or reducing economic vulnerability (adapted from Samson et al. 2006: 2).

Social transfer programmes include non-contributory welfare grants (social pensions, disability grants, child support grants, family allowances), conditional transfers (such as conditional cash transfers where benefits are conditional on compliance with household participation in education and health services, or public works projects where benefits are conditional on work), and in-kind transfers (school feeding schemes, food stamps or commodity-denominated vouchers). Since our definition of social transfer programmes specifies 'regular' payments, short-term programmes or once-off transfers (for instance, emergency relief interventions) are excluded from consideration in this review. Other interventions that share some characteristics but do not qualify as social transfers include contributory social security, microfinance, and fee waivers (Table 2.1). 
Table 2.1 List of included and excluded social transfer programmes

\begin{tabular}{|c|c|}
\hline Included & Excluded \\
\hline $\begin{array}{l}\text { Regular non-contributory cash grants } \\
\text { (or unconditional cash transfers): } \\
\text { - } \quad \text { Social pensions } \\
\text { - } \quad \text { Disability grants } \\
\text { - } \quad \text { Child benefit/ child support grant } \\
\text { - } \quad \text { Family allowances } \\
\text { Regular conditional transfers } \\
\text { - } \quad \text { Conditional cash transfers } \\
\text { - } \quad \text { Public works programmes } \\
\text { - Employment guarantee schemes } \\
\text { - } \quad \text { School feeding programmes } \\
\text { Regular in-kind transfers } \\
\text { - } \quad \text { Food stamps } \\
\text { - } \quad \text { Food subsidies } \\
\text { - } \quad \text { Regular food distribution } \\
\text { - } \quad \text { Voucher schemes }\end{array}$ & $\begin{array}{l}\text { Contributory social security schemes } \\
\text { Short-term or once-off social transfers (e.g. asset } \\
\quad \text { transfer programmes) } \\
\text { Emergency relief interventions } \\
\text { Microfinance programmes } \\
\text { Social funds/ Social action funds } \\
\text { Agricultural input subsidies } \\
\text { Education or health fee waivers } \\
\text { Public utility subsidies }\end{array}$ \\
\hline
\end{tabular}

\subsection{Targeting mechanisms}

Only targeting mechanisms used in actual social transfer programmes are included in this review. Several alternative classification systems are summarised in Box 1.1 above. For purposes of this review, six discrete targeting mechanisms were identified. Very often, targeted programmes use two or more mechanisms in combination, and this is recognised as a seventh category.

1 Means testing

2 Proxy means testing

3 Categorically targeting

4 Geographically targeting

5 Community-based targeting

6 Self-targeting

7 Multiple mechanisms.

\subsection{Reported outcomes}

The review compiles evidence on four indicators of targeting errors, costs and positive and negative secondary consequences, which are analysed comparatively across the different targeting methodologies described above. Only studies that report on one or more of these four indicators are included in this review:

1. Errors (inclusion and exclusion) in implementation

2. Targeting costs

3. Negative social consequences of targeting

4. Positive outcomes across targeting mechanisms

Targeting costs are expressed as a proportion of the programme budget. Normally only administrative costs are reported by the studies, which is a limitation. Where data are available, full targeting costs are assessed. These include: administrative costs, private costs (opportunity costs, travel costs), incentive-based costs (e.g. behavioural change to meet eligibility criteria), social costs (erosion of community cohesion), political costs (loss of political support) and psycho-social costs (stigma). 
Secondary effects and other intangible costs are not often quantified. They can nevertheless be categorised, and in this report their observed prevalence is summarised and analysed comparatively across different targeting mechanisms.

Note that we are not reviewing evaluations of the impact of social transfer programmes by targeting mechanism, because this confuses a design choice (targeting mechanism) with programme outcomes (impacts), which are determined by a broad range of design choices and implementation modalities. A programme's relative performance against its objectives cannot be attributed to its choice of targeting mechanism. Instead, we assess the effectiveness of targeting mechanisms only in their own terms: Did they reach their intended beneficiaries? Were the beneficiaries poor? What were the costs of targeting? Was the targeting cost-effective? What were the secondary consequences of targeting?

\subsection{Year of publication}

Studies published or reporting on data collected before the year 2000 are excluded, for two reasons. First, the review of targeting by Coady et al. (2004) already covers studies published in the 1990s, and there is no value-added in replicating their analysis. Second, social transfer programmes have made considerable advances during the 2000 s, partly by incorporating learning from the experiences of the 1990s, so a focus on more recent programming experience accurately captures the current state of targeting practice.

\subsection{Geographic coverage}

Only social transfer programmes implemented in developing countries were considered for this review. Our definition of 'developing country' extended to all countries that are not among the 66 countries defined as 'high-income' by the World Bank. Note that 'uppermiddle-income' countries like Brazil are included, on the grounds that a large proportion of the population in these countries live in conditions of extreme poverty.

\subsection{Search strategy}

A number of electronic databases were searched in conducting this review, covering published work, unpublished work and relevant institutional websites (Table 2.2).

Table 2.2 List of databases searched

\begin{tabular}{|l|l|l|}
\hline \multicolumn{1}{|c|}{ Published work } & \multicolumn{1}{|c|}{ Unpublished work } & \multicolumn{1}{c|}{ Institutions } \\
\hline Agris & BLDS/ELDIS/IDS & Asian Development Bank \\
Econolit & Google Scholar & DFID \\
IBSS & IDEAS & IADB \\
JSTOR & JOLIS & IFPRI \\
PubMed & International Initiative for Impact Evaluation (3le) & World Bank e-library \\
ASSA & & World Food Programme \\
Web of Science & & \\
\hline
\end{tabular}

Search terms were divided into two tiers. Tier 1 contained 16 phrases that described types of social transfer programmes, and Tier 2 contained 14 targeting-related words and phrases, including alternative targeting mechanisms (Table 2.3). 
Table 2.3. Database search terms

\begin{tabular}{|l|l|}
\hline Tier $\mathbf{1}$ & Tier $\mathbf{2}$ \\
\hline Social transfers & Targeting \\
Social grants & Targeting errors \\
Cash transfers & Targeting costs \\
In-kind transfers & Inclusion errors \\
Non-contributory & Exclusion errors \\
Conditional cash transfers & Targeting efficiency \\
Unconditional cash transfers & Targeting effectiveness \\
Social pension & Categorical targeting \\
Disability grant & Means test \\
Child support grant & Proxy indicator \\
Family allowance & Self-targeting \\
Public-works programmes & Self-selection \\
Employment-guarantee schemes & Community-based targeting \\
School feeding programmes & Geographic targeting \\
Food stamps & \\
Voucher schemes & \\
\hline
\end{tabular}

The first-stage screening generated 1,406 documents, which were inputted into EPPI Reviewer, ${ }^{1}$ then checked for duplicates and whether they met the selection criteria (in terms of geographical region, publication date, type of intervention, etc). This second-stage screening reduced the number of documents selected to 254, of which 140 were 'sure' (the document definitely met the selection criteria) and 114 were 'unsure' (the document needed further assessment).

The third-stage screening involved a full text review of the 254 documents against the four outcome indicators identified above. The reviewers made an assessment of the relevance of the research against a checklist - whether the paper quantifies targeting errors, explores the social costs of targeting, or discusses the cost-effectiveness of targeting in a rigorous and credible way. A minimum set of quality requirements (for methodological rigour) was also established - for instance, data on targeting errors should be obtained from credible sources (preferably surveys representative of the beneficiary population, with samples of a sufficient size to allow statistically significant estimates to be derived), and data on targeting costs should be obtained from reliable sources (such as project documents and monitoring forms). This process reduced the total documents finally included in this report to 85 covering about 30 programmes.

Several of these documents review evidence from multiple countries, but the majority present empirical evidence from specific social transfer programmes. All 41 countries with programmes that are explicitly discussed in this report are listed in Table 2.4 below. As noted above, these programmes all fall into one of the following types: conditional cash transfers (7), unconditional cash transfers (15), child benefit (8), disability grants (2), social pensions (9), food subsidies (4), food distribution (4), public works programmes (4), and school feeding programmes(2).

The Evidence for Policy and Practice Information and Co-ordinating Centre (EPPI-Centre) is part of the Social Science Research Unit at the Institute of Education, University of London. EPPI Reviewer is a web application that enables researchers to upload documents for screening, keywording, data extraction and analysis (http://eppi.ioe.ac.uk/). 
Table 2.4. Countries represented in this review

\begin{tabular}{|c|c|c|c|}
\hline Africa & Asia & Europe/ Central Asia & Latin America \\
\hline Botswana & Bangladesh & Albania & Bolivia \\
\hline Egypt & Brunei & Azerbaijan & Brazil \\
\hline Ethiopia & Cambodia & Bulgaria & Colombia \\
\hline Ghana & China & Estonia & Ecuador \\
\hline Kenya & India & Hungary & Jamaica \\
\hline Malawi & Indonesia & Kyrgrz Republic & Mexico \\
\hline Mauritius & Mongolia & Poland & Nicaragua \\
\hline Namibia & Nepal & Russian Federation & Peru \\
\hline Rwanda & Philippines & & Uruguay \\
\hline Somalia & Samoa & & \\
\hline South Africa & Vietnam & & \\
\hline Tanzania & & & \\
\hline Zimbabwe & & & \\
\hline
\end{tabular}

\section{Targeting errors}

This section first discusses definitions of targeting errors from the literature and proposes a broader approach, then reviews empirical evidence on targeting errors by targeting mechanism.

\subsection{Defining targeting errors}

According to the targeting literature, targeting generates two types of error: inclusion and exclusion (Cornia and Stewart 1993). Inclusion errors occur when programme benefits reach some unintended beneficiaries. Exclusion errors occur when programme benefits do not reach all of the intended beneficiaries.

1. Inclusion error is the proportion of a programme's beneficiaries who are technically ineligible. For our purposes, inclusion error is defined as the percentage of beneficiaries who receive social transfers, despite not meeting the eligibility criteria.

2. Exclusion error is the proportion of eligible individuals or households that do not receive programme benefits. For our purposes, exclusion error is defined as the percentage of individuals or households that do not receive social transfers, despite meeting the eligibility criteria.

Although these definitions are consistent with the literature, they reflect a narrow view of targeting, in two ways. Firstly, they describe targeting errors in implementation, meaning that the predefined rules for identifying and registering eligible beneficiaries are not fully met in practice (see Figure 3.1). 
Figure 3.1. Two errors of targeting in implementation

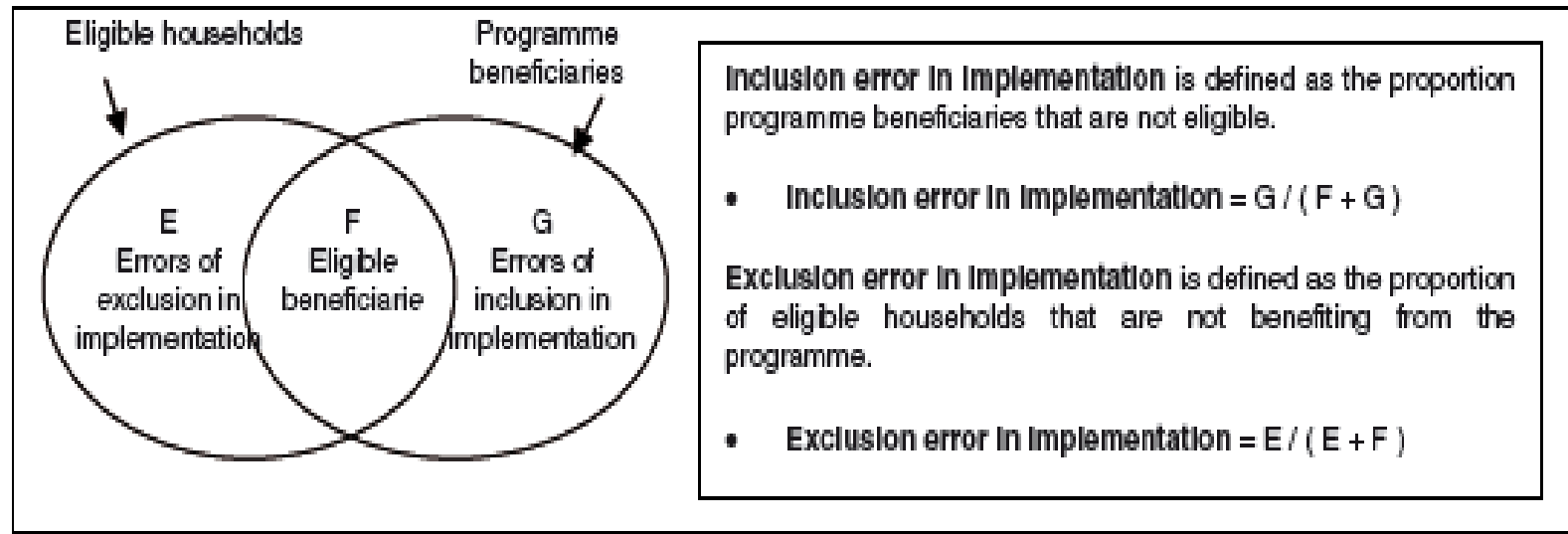

Source: Hurrell (2009). Reproduced with kind permission of Oxford Policy Management.

Secondly, if the objective of a social transfer programme is to reach poor people in order to reduce or alleviate their poverty, then the targeting strategy can generate targeting errors by design. Even if a programme reaches all its intended beneficiaries, and no-one else, inclusion or exclusion of poor people can occur, if there are 'leakages' to the non-poor (e.g. with a general food price subsidy) or 'under-coverage' of the poor because the targeting mechanism does not explicitly target the poor (e.g. a child benefit that fails to reach poor families without children). A case in point is universal pensions. If old age is taken as a proxy for poverty, then 'inclusion error by design' (leakage) refers to all people over 60 who receive a pension despite not being poor. Conversely, 'exclusion error by design' (under-coverage) refers to all people who are poor but do not receive a social pension because they are under 60 years old.

Implementation of targeting will typically result in both inclusion and exclusion errors. Inclusion errors in implementation increase programme costs by spending money on ineligible people, while exclusion errors in implementation deprive eligible individuals of resources that they might desperately need, to escape poverty or to avoid destitution or even death. Some analysts (notably Cornia and Stewart 1993) have suggested weighting exclusion errors several times higher than inclusion errors, on the grounds that the humanitarian costs of failing to assist people in need are worse than the financial costs of 'leaking' some resources to people who don't need assistance.

In practice there is an inevitable trade-off between these two errors. Assume that the poverty headcount is $30 \%$. If the budget allocated to social transfers can reach only $10 \%$ of the population, coverage is rationed and there will be under-coverage, or exclusion errors by design. As the budget increases towards $30 \%$ of the population, exclusion errors by design will fall towards zero, and if the budget allows for coverage of more than $30 \%$ of the population, inclusion errors by design (or over-coverage) will increase. Of course, even with coverage $<30 \%$ there will be some inclusion errors, and with coverage $>30 \%$ there will be some exclusion errors (except in untargeted programmes with universal access), to the extent that there is mis-targeting in implementation.

The issue of targeting errors by design - specifically, targeting the poor versus reaching all the poor - is especially pertinent on small-scale pilot projects. Many social transfer pilot projects report low inclusion and exclusion errors in implementation, but since they are operational only in some parts of the country (e.g. one or two districts) they exclude the majority of poor people in the country by design. Similarly, even a robust proxy for poverty excludes all poor people who do not meet this criterion. (If everyone over 60 years old is poor then a perfectly delivered 'universal' social pension would have zero inclusion error by design 
or exclusion error in implementation, but at national level exclusion error by design is high to the extent that there are poor citizens under 60 years of age.)

On the other hand, it might be unreasonable to expect a single intervention to reach all the poor. At national level, coverage should be assessed over all relevant programmes. A social protection system that includes social pensions, child grants, disability grants and a demandled employment guarantee scheme will probably achieve a cumulative coverage of most poor citizens.

This discussion raises five questions that must be resolved before we can assess the magnitude of different targeting errors on specific programmes.

\section{First, should targeting errors be measured in terms of eligibility criteria or poverty status? In cases where the poverty focus of categorical criteria or proxy means tests is assessed, exclusion error is defined as the proportion of poor households that do not benefit from the programme', while inclusion error is 'the proportion of programme beneficiaries that are non-poor' (Hodges et al. 2007: 13). But this implies that all targeting mechanisms should be assessed on their ability to reach the poorest members of the population. Some analysts hold this view - 'Better targeting is not seen as desirable in its own right, but rather as an instrument for reducing poverty' (Ravallion 2007: 2) - but others argue that targeting should be assessed only in terms of the programme's eligibility criteria. For instance, for a 'universal' pension that targets all people over 60 years of age, inclusion error is all pension recipients under 60 , not the percentage of recipients or people over 60 who are non-poor; and exclusion error is all non-recipients over 60 , not the percentage of non-recipients or people under 60 who are poor.}

In this review, the authors adopt the position that the targeting accuracy of social transfer programmes should firstly be assessed in terms of whether it reaches the eligible groups. ${ }^{2}$ Whether that group is a good proxy for poverty is a separate question which can in part be answered by the targeting analysis, however, the accuracy of targeting must in the first instance relate to the exact specification the programme intended to target, and secondly in terms of coverage of the poor. Although high inclusion errors (in terms of non-poor beneficiaries) are a concern with 'universal' targeting - for instance, if the objective of a social pension is to provide income security in old age, there is no reason to include older persons who are already income secure - high exclusion errors are inevitable, because no single instrument targeted at one category of beneficiaries can be expected to reach most poor people: a social protection system comprising several instruments is required. Only if a demographically targeted programme is also means tested - as with South Africa's Disability Grant (Mitra 2010) - does the recipient's poverty status also become directly relevant in assessing targeting accuracy.

\section{Second, should undercoverage in programme design be measured as a targeting error? For instance, if a social cash transfer programme targets poor rural households, should exclusion error be assessed as only poor rural households that do not receive transfers, or as all poor individuals in the country (including poor urban households) who do not receive transfers? High exclusion rates on social transfer programmes often reflect budgetary constraints, or a policy decision to concentrate resources in priority regions or on priority groups, and this is better understood as 'undercoverage' (i.e. planned exclusion by}

\footnotetext{
According to Ravallion (2007: 7): "A Type 1 error can be defined as incorrectly classifying a person as poor, while a Type 2 error is incorrectly classifying a person as not poor. A Type 1 error entails a leakage of transfers to the non-poor, while a Type 2 error implies lower coverage of the poor." But this ignores the possibility that targeting is based on other criteria apart from poverty. Consider a country where every citizen over 60 has a legislated right to a social pension, even though no older person is living in poverty and some citizens under 60 are poor. If all older persons - and only older persons receive the pension, staff would congratulate themselves on achieving $0 \%$ inclusion and $0 \%$ exclusion error, but Ravallion would assign this programme a $100 \%$ inclusion error and $100 \%$ exclusion error.
} 
design) than 'mistakes' made during a beneficiary registration process (i.e. unplanned exclusion in implementation). A review of coverage of the poor by conditional cash transfer programmes found 'significant variation ... from about $1 \%$ of the poorest decile in Cambodia to more than $60 \%$ in Brazil, Ecuador, and Mexico' - which was explained by 'the size and budget of the programs' (Fiszbein and Schady 2009: 73). We therefore differentiate between 'exclusion by design' (eligibility criteria that result in 'undercoverage' in terms of reaching all poor people) and 'exclusion in implementation' (failure to register and pay all individuals or households who meet the eligibility criteria) in reporting on targeting outcomes below.

\section{Third, if eligible individuals choose not to enrol, does this count as exclusion error?}

Exclusion errors can result from inadequate enrolment of eligible people, either because of inadequate outreach ${ }^{3}$ or because potential beneficiaries choose not to apply. In many (perhaps most) cases, some eligible households fail to enrol for the programme, although this is not often measured. (Burdin and de Melo (2009) provide a rare exception.) Failure to apply is not a targeting 'error' in terms of incorrect assessment, but it is an indicator of 'unplanned undercoverage'. In most cases, this should be counted as a form of exclusion error, because the reasons are often related to programme implementation: inadequate information or outreach, complex or costly enrolment procedures in terms of financial costs, information processing costs, waiting costs, social and psychological costs (Burdin and de Melo 2009: 144).

\section{Box 3.1. Exclusion error or failure to enrol?}

Coady and Parker (2009) model enrolment onto a programme in three stages: (1) knowledge; (2) application; (3) acceptance - the second being under the household's control while only the first and third are under the administrator's. Failure to apply is invariably related to either lack of knowledge or high costs of applying. In the case of South Africa's Child Support Grant, coverage of eligible children increased from 9\% to $58 \%$ between 2000 and 2004 - so exclusion error fell from $91 \%$ to $42 \%$ in four years - mainly due to a government campaign to enrol eligible children, and the simplification of application procedures (Samson et al. 2006: 6-7). Nepal's 'universal' Old Age Pension reaches only $77 \%$ of the age-qualified population, because of 'difficulties in establishing proof of age, delays in processing applications, difficulties in reaching remote areas of the country, and the fact that some of the wealthy do not bother to apply for a pension' (Willmore 2007: 30). Reasons for low take-up of Ecuador's conditional cash transfer programme include stigma and high transaction costs relative to the benefits provided. For some residents of Amazonia (where poverty rates are high but enrolment is very low), enrolling for the conditional cash transfer would require walking for more than a day each way, or paying up to $\$ 50$ for a motorboat ride or up to $\$ 480$ for a return flight (Fiszbein and Schady 2009: $79)$.

\section{Fourth, if eligibility numbers are not quantifiable, how should targeting errors be} measured? In some programmes, targeting errors are difficult to quantify because eligibility criteria are vaguely specified (e.g. communities are asked to identify their 'most vulnerable households'). In such cases, targeting errors can be approximated by assessing 'benefit incidence' - mapping beneficiaries against the population's poverty profile. Many studies reviewed follow this procedure (e.g. Alderman 2001; Maluccio 2009). This introduces the challenge of comparing findings across studies where different poverty thresholds were assessed, or even defining targeting errors within the same programme, where 'inclusion' and 'exclusion' errors are reported for different thresholds (e.g. the poorest $20 \%$, or the

Castaneda (2005: 11) differentiates between 'outreach' and 'application' approaches to registration, and explains the advantages and disadvantages of each. An 'outreach' approach requires extensive surveys to identify and register eligible beneficiaries, but an 'application' approach invites anyone who believes they are eligible to apply to be registered. 'Outreach' methods are considered to be more comprehensive but also more expensive to implement. 
poorest $40 \%$ ). (Note that community-based targeting can generate targeting outcomes that are quantifiable. For instance, if communities are asked to identify all 'female-headed households' or 'orphans', inclusion and exclusion errors should be assessed in terms of these eligibility criteria.)

Fifth, should a programme's impact on poverty be considered as an indicator of targeting success? This review argues against this position. 'A number of factors cloud the relationship between targeting performance and total impact on poverty, including aspects of program design, implementation and the context in which a program operates' (Ravallion 2007: 2-3). This review focuses on the accuracy and cost-effectiveness of mechanisms for identifying and reaching poor and/or eligible people (individuals or households) rather than the impact of social transfer programmes on poverty. Therefore, we do not consider the class of targeting measures that are based on benefit incidence, or the 'concentration curve': 'the cumulative share of transfers going to the poorest $p \%$ of the population ranked by household income per person' (Ravallion 2007: 5). Such measures include: (1) the share of transfers going to the poorest $x x \%$ of households; (2) the normalised share; and (3) the concentration index. Our analysis focuses on who benefits from social transfer programmes, not on the size of the benefits transferred.

This analysis allows us to identify not two but four errors of targeting - inclusion (I) and exclusion $(E)$ error both in terms of eligibility $(E)$ and in terms of poverty $(P)$.

1. Inclusion error by eligibility (error in implementation) $\left(\mathbf{I}_{\mathbf{E}}\right)$ is the proportion of a programme's beneficiaries who do not meet the eligibility criteria but do receive social transfers.

2. Exclusion error by eligibility (error in implementation) $\left(E_{E}\right)$ is the proportion of eligible individuals or households in a programme area who do meet the eligibility criteria but do not receive social transfers.

3. Inclusion error by poverty (error by design) ( $\left.\mathbf{I}_{\mathbf{P}}\right)$ is the proportion of a programme's beneficiaries who meet the eligibility criteria and receive social transfers but are not poor.

4. Exclusion error by poverty (error by design) $\left(E_{P}\right)$ is the proportion of individuals or households in a programme area who do not meet the eligibility criteria and do not receive social transfers but are poor.

\section{Four types of targeting error ${ }^{4}$}

\begin{tabular}{|c|c|c|}
\hline Errors & $\begin{array}{c}\text { Eligibility Criteria } \\
\text { (in implementation) }\end{array}$ & $\begin{array}{c}\text { Poverty } \\
\text { (by design) }\end{array}$ \\
\hline Inclusion & $\begin{array}{c}\mathbf{I}_{\mathbf{E}} \\
\text { (Recipient, not eligible) }\end{array}$ & $\begin{array}{c}\mathbf{I}_{\mathbf{P}} \\
\text { (Recipient, not poor) }\end{array}$ \\
\hline Exclusion & $\begin{array}{c}\mathbf{E}_{\mathrm{E}} \\
\text { (Non-recipient, eligible) }\end{array}$ & $\begin{array}{c}\mathbf{E}_{\mathbf{P}} \\
\text { (Non-recipient, poor) }\end{array}$ \\
\hline
\end{tabular}

To illustrate these four errors, consider the example we have discussed previously, of a universal social pension, where eligibility is open to all individuals 60 years of age and over.

4 We are indebted to Heather Kindness for proposing this diagrammatic formulation of the four types of error examined in this literature review. 
1. Inclusion error by eligibility $\left(\mathrm{I}_{\mathrm{E}}\right)$ is all social pension recipients under 60 .

2. Exclusion error by eligibility $\left(E_{E}\right)$ is all individuals aged 60 and over who do not receive a social pension.

3. Inclusion error by poverty $\left(\mathbf{I}_{\mathbf{P}}\right)$ is all social pension recipients who are not poor.

4. Exclusion error by poverty $\left(E_{P}\right)$ is all individuals under 60 who are poor.

Four targeting errors with social pensions for all individuals aged 60 and over

\begin{tabular}{|c|c|c|}
\hline Errors & Eligibility Criteria & Poverty \\
\hline Inclusion & Recipients under 60 & Non-poor recipients \\
\hline Exclusion & $\begin{array}{c}\text { Non-recipients aged 60 } \\
\text { and over }\end{array}$ & Poor non-recipients \\
\hline
\end{tabular}

\subsection{Overview of evidence from international experience}

Coady et al. (2004) compared targeting outcomes on over 100 programmes, using a povertybased performance measure: 'the percentage of benefits accruing to either the bottom 40 percent or 20 percent of the national income distribution'. Based on this indicator, they reached the following key conclusions (Coady et al. (2004: 2-3).

1. Targeting can work: On average, targeted programmes 'provide approximately $25 \%$ more resources to the poor than would random allocations'.

2. Targeting does not always work: About $25 \%$ of programmes were regressive - 'a random allocation of resources would have provided a greater share of benefits to the poor'.

3. No single targeting mechanism works best in all contexts: ' 80 percent of the variability in targeting performance was due to differences within targeting methods and only 20 percent was due to differences across methods'.

4. Targeting mechanisms can be ranked by performance: (1) Transfers accruing to the poor increase most from self-targeting on public works (by $40 \%$ ), followed by geographic targeting (34\%), and means testing (30\%). (2) Proxy means tests achieve a smaller propoor benefit ( $8 \%)$ and along with community-based targeting, and categorical targeting of children, achieve highly variable results. (3) Categorical targeting of older persons, community bidding on social funds, and self-targeting (based on consumption) performed worst on average.

5. Implementation is the single most important determinant of targeting success: Targeting improves with implementation capacity (proxied by national income), government accountability, and inequality levels. Multiple targeting methods improves targeting accuracy, by about $15 \%$ for each additional method used.

The last point is well illustrated by Ndihme Ekonomika, a means tested cash transfer programme in Albania, where targeting failures in implementation confounded the attribution of targeting errors in design. 
leakage and undercoverage rates show that there are problems of targeting in addition to inadequacy of program's design and resources. More than half of the beneficiaries are non-poor families. Targeting coefficients are positive but near to " 0 ": even though the program is designed to support poor families, it is approaching to be untargeted.

(Mangiavacchi and Verme 2009: 12)

Grosh and Leite (2009: 176) conclude that: 'it is more difficult to target narrowly in countries with very low incomes'.

\subsection{Targeting errors by targeting mechanism - findings}

The review of targeting errors that follows is organised around alternative targeting mechanisms, as defined in section 2.1.2 above.
1. Means testing
2. Proxy means testing
3. Categorical targeting
4. Geographic targeting
5. Community-based targeting
6. Self-targeting
7. Multiple mechanisms

It is important to note that some of the case studies cited below may have subsequently refined or changed their targeting methodology, while some of these programmes have also implemented one or more rounds of retargeting, that have reduced the targeting errors reported here.

\subsubsection{Means tested programmes}

It is axiomatic that there is a trade-off between targeting accuracy and administrative costs of targeting (Besley and Kanbur 1990). Means testing is the most data-demanding (and most expensive) targeting mechanism, and is assumed to be the most accurate. Yet despite their putative potential for accurate identification of poor beneficiaries in theory, means tested programmes in practice display high errors of exclusion and inclusion in implementation (see Table A1.1 in Appendix 1).

The 'Ndihme Ekonomika' (NE), a cash transfer programme in Albania that supports about $20 \%$ of the population, targeted urban households with no other source of income, and rural households with small landholdings. These tests accurately identified the poor, with low leakages to the non-poor - only $10.1 \%$ of the richest $80 \%$ of households received NE assistance. However, exclusion errors in implementation were high, with $62.6 \%$ of households in the poorest quintile not receiving NE benefits. This was due to a $25 \%$ cut in the government's budget allocation to NE, which imposed a hard budget constraint on local communes that administered the programme and resulted in substantial exclusion of eligible households (Alderman 2001).

In China, the Minimum Livelihood Guarantee Scheme (MLGS) fails to reach $71 \%$ of poor households, while $40 \%$ of recipients have incomes above the income threshold for eligibility (Ravallion 2007). In the Krygyz Republic, two-thirds (69\%) of households in the poorest quintile do not receive the Unified Monthly Benefit, and more than half the programme beneficiaries are from wealthier quintiles (Tesliuc 2004). In Azerbaijan, 88.5\% of households in the poorest quintile do not receive Children Benefits - none at all in the poorest decile (many of these households have no resident children) - while $86.3 \%$ of beneficiaries come from wealthier quintiles (Habibov and Fan 2006). 


\subsubsection{Proxy means tested programmes}

Proxy means tests are popular on conditional cash transfer programmes (mainly in Latin America), but have also been used to identify beneficiaries for social welfare programmes (e.g. in Colombia) and food subsidies (e.g. in Egypt), especially in contexts where incomes are difficult to assess. In Mongolia, a proxy means test was preferred to an income-based means test 'due to the informal nature of much of the economy, particularly among the herding population in the rural areas as well as among many of the urban poor' (Hodges et al. 2007: 10).

How accurately a proxy means test identifies the poor depends on which proxies are applied, how they are weighted, as well as how rigorously the beneficiary identification process is implemented. In Brazil and Ecuador, conditional cash transfers excluded $45 \%$ and $33 \%$ of poor households respectively (see Table A1.2), one reason being that the conditions are applied to children but the poorest households often have no resident children (Fiszbein and Schady 2009). In Colombia, a proxy means test (comprising indicators of housing, access to public services, education levels, employment status, household composition) determines eligibility for a range of social welfare benefits, and misclassification of poor households as non-poor (exclusion error) is fairly low at $19 \%$, while misclassification of non-poor households as poor (inclusion error) is somewhat higher at 31\% (Castañeda 2005). In Egypt, a proxy means test was modelled for a food subsidy programme which predicted an exclusion error of $28 \%$ of poor households and an inclusion error of $16 \%$ (Falkingham and Namazie 2002).

A rare case where predicted and actual targeting errors can be compared is the Child Money Programme (CMP), Mongolia's conditional cash transfer programme. Initially, a proxy means test was applied, 'based on a set of indicators for various household characteristics to generate a score, which would determine the eligibility of applicant households' (Hodges et al. 2007: 10). Analysis of the proxy means test formula before implementation predicted high exclusion error (42\%) and inclusion error (38\%), because of poor choice of proxy indicators. When the CMP was actually implemented, exclusion error was lower than predicted $(21 \%)$ but due to 'serious shortcomings in implementation' inclusion error was much higher, with more than half the beneficiary households (57\%) living above the Minimum Subsistence Level. The CMP also allows a rare opportunity for comparison of alternative targeting mechanisms, because in 2006 the proxy means test was dropped and the grant became a 'universal' entitlement for all children under 18 years of age. As expected, exclusion error fell dramatically (to $8 \%$ ), mainly poor households without children, or children living outside a family (e.g. street children), or because of barriers to access (e.g. lack of documents) by poor families. Also as expected, inclusion error increased (to 65\%) when the proxy means test was lifted, with almost two-thirds of beneficiaries being non-poor (Hodges et al. 2007).

In a recent paper, Kidd and Wylde (2011) provide a review of the strengths and weaknesses of PMT targeting. Conducting econometric simulation exercises for Bangladesh, Indonesia, Rwanda and Sri Lanka, their paper is the first to attempt an in-depth analysis of PMT targeting. They show that exclusion and inclusion errors vary between $44 \%$ and $55 \%$ when $20 \%$ of the population is covered and between $57 \%$ and $71 \%$ when $10 \%$ is covered. In other words, the smaller the target group in terms of coverage, the higher the errors. They conclude that proxy means tests are subject to considerable inaccuracy due to a range of challenges, related to (1) the imperfect correlation between multiple proxies and household consumption, (2) the inaccuracy of national household survey, (3) sampling errors in household survey design and, (4) difficulties on verifying the actual value of proxies. These are all relevant concerns, however, they do not only apply to PMT targeting, but to a range of targeting methods that rely on heavy data collection. While Kidd and Wylde do highlight many of the weaknesses of PMT, they do not provide a comparative perspective to other targeting mechanisms so it is impossible to determine the relative efficiency of PMT targeting over other forms of targeting. 


\subsubsection{Categorically targeted programmes}

Programmes using categorical targeting typically identify proxy indicators of poverty or vulnerability, often demographic categories such as older persons (social pensions), people with disabilities (disability grants), and orphans or 'vulnerable children' (child allowances). As noted above, targeting errors on categorically targeted programmes can be assessed either in terms of whether beneficiaries (and non-beneficiaries) meet the eligibility criteria or whether beneficiaries (and non-beneficiaries) are poor. Both options are discussed here, according to data availability (Table A1.3).

Categorical targeting tends to be associated with high inclusion and exclusion errors in terms of the poverty profile of beneficiaries. For instance, a 'universal' social pension is 'mildly progressive in its targeting because households with elderly members are somewhat poorer than average, but a substantial share of the benefits would go to the non-poor because many of the elderly live in households that are not poor' (Grosh and Leite 2009: 176). Grosh and Leite calculate that $80-88 \%$ of older persons live in non-poor households in Kyrgyzstan, Niger, Panama and Yemen. Conversely, $78-80 \%$ of poor households in these countries have no elderly members, so a universal social pension would generate both inclusion and exclusion errors of approximately $80 \%$.

The evidence reveals that social pensions are generally effective at reaching older persons, but relatively inaccurate in targeting the poor. One global review of 'universal' social pension programmes found that Bolivia, Mauritius and Samoa have achieved $100 \%$ coverage of their eligible group; Botswana, Namibia and Mexico City have very low exclusion error (4\%, $7 \%$ and $6 \%$ respectively, defined as beneficiaries as a percentage of the age-qualified population), while only Brunei and Nepal reach less than $90 \%$ of their age-qualified population (Willmore 2007). In terms of inclusion error, an assessment of the Old Age Allowance in Bangladesh found that $24 \%$ of households receiving the grant did not have a member aged 60 or above (Slater and Farrington 2009). However, old age was found to be a weak proxy for poverty in Azerbaijan. An assessment of the poverty status of social pensioners found high inclusion error by design ( $86 \%$ of beneficiaries were not in the poorest income quintile) and even higher exclusion error by design (95\% of persons in the poorest quintile were not benefiting from the programme) (Habibov and Fan 2006).

Three disability grants in Azerbaijan recorded similarly high targeting errors by design (when assessed against poverty). Very few households in the poorest quintile benefited from these grants, suggesting that there is little correlation between an individual's disability and their household's income. This is also true for student scholarships, grants for war veterans and grants for decorated civilians, military and government personnel (Habibov and Fan 2006).

In several Eastern European transition economies (Poland, Hungary, Bulgaria, Estonia, the Russian Federation) categorical targeting is politically more acceptable than means testing, but an assessment of categorical benefits such as child allowances and subsidies on public services for older citizens and public sector workers found that most poor citizens do not fall into these categories, so exclusion errors (by design) are high, ranging from $57 \%$ in Hungary (where $43 \%$ of poor households receive some social assistance), to $94 \%$ in Poland (where only $6 \%$ of poor households receive social assistance). Since these categories are crude proxies for poverty, inclusion errors are also high, peaking at $92 \%$ in Bulgaria, meaning that almost all non-poor households receive social assistance (Fox 2003).

A range of cash and food transfer programmes that target women in Bangladesh specify categories of women who are eligible - female-headed households, adults aged between 18 and 49 years, illiterate persons. Although most programme participants satisfied the age eligibility and illiteracy criteria (with inclusion errors ranging from $3 \%$ to $11 \%$ ), the majority of households (over $60 \%$ in three of the programmes) were not female-headed, suggesting that 
this criterion was not strictly enforced during beneficiary registration procedures (Ahmed 2009).

Ghana's Livelihood Empowerment Against Poverty (LEAP) programme targets 'ultra-poor' labour-constrained households, but for political reasons (to avoid all LEAP benefits being disbursed in geographically isolated and politically marginal regions) a uniform proportion of beneficiaries was selected across all administrative districts. This effectively imposed a quota which resulted in exclusion errors (under-selection) in poor districts and inclusion errors (over-selection) in wealthier districts. Across all rural districts more than a third of eligible households were excluded by the quota (exclusion error $=36 \%$ ). In urban centres, the quota resulted in almost three times as many non-poor as poor beneficiaries being registered (inclusion error $=73.4 \%$ ) (Ellis 2009).

\subsubsection{Geographically targeted programmes}

Geographical targeting is most effective in contexts where poverty rates are high and poverty is spatially concentrated, as Handa and Davis (2006) explain:

poverty rates among targeted communities in Nicaragua and rural Mexico are around $70 \%$. In these situations the additional cost of individual targeting has been shown to yield little in terms of efficiency ... as the program expands to less poor areas geographic targeting may no longer be viable and the relative benefit of household targeting will increase.

(Handa and Davis 2006: 11)

Related to this is the 'granularity' issue: the poverty targeting accuracy of geographical targeting generally improves, the smaller the area where blanket coverage is applied. Typically there is not enough information to do this, as household surveys might report disaggregated poverty incidence to province level, but not to districts or communes. This problem can be resolved by 'small area estimation', but again this demands data that may be available only infrequently - e.g. by combining LSMS-type sample surveys with census data (which is typically available only every 10 years) for each individual.

Nonetheless, geographically targeted programmes are associated with relatively high inclusion and (especially) exclusion errors by design, because even if some regions within a country are poorer than others on average, physical location is a weak proxy for individual poverty, and poor households tend to be scattered throughout the country. As Manasan and Cuenca (2007: 8) observe: 'geographically targeting works best when poverty differs across regions but is similar within regions'. But geographic targeting also ignores the population distribution, and especially the concentration of people in urban centres. For example, if $20 \%$ of urban residents are poor this can exceed the numbers of poor people in remote rural districts where $70+\%$ of residents are poor, but the urban poor tend to be overlooked by programmes that target on headcount poverty rates by district.

In Vietnam, anti-poverty programmes are targeted at communes officially designated as poor or remote. Few non-poor people live in these communes, so inclusion error is low $(7.7 \%)$. However, 'the vast majority of poor people in Vietnam do not live in an officially designated poor or remote commune' (Minot and Baulch 2002: 36), so exclusion error is extremely high (80.5\%) (Table A1.4).

\subsubsection{Community-based targeted programmes}

Community participation in selecting beneficiaries has the advantage of drawing on local knowledge of individual circumstances, thereby avoiding the cost of individual assessment mechanisms and the inaccuracy of categorical or geographic targeting. Specifically, community-based targeting is asserted to: (1) improve the accuracy of beneficiary 
identification (by reducing information asymmetries); (2) reduce the costs of identifying eligible beneficiaries; (3) improve the social acceptability of targeting decisions (by transferring ownership of these decisions to the community); (4) contribute to community mobilisation. On the other hand, involving communities in targeting runs the risk of 'elite capture' of programme benefits (much depends on whether community structures are genuinely democratic, inclusive and accountable), ${ }^{5}$ they require small, cohesive communities (where everyone knows each other and no sub-groups are socially marginalised by the majority), and they are difficult to scale up from the community to the regional or national level.

This review draws a distinction between delegation and devolution in community-based targeting, as elaborated by Conning and Kevane (2002).

A center or principal delegates responsibility for candidate selection and benefit delivery to local community groups when the principal contracts to use the delegated intermediary agent's better information and access to local networks to carry out the principal's objectives. ... By way of contrast, when the center devolves responsibility to local communities, it transfers not only resources but also responsibility for setting the criteria by which eligibility and assistance level will be judged.

(Conning and Kevane 2002: 381)

In short, either communities identify beneficiaries based on criteria pre-defined by administrators ('delegated community-based targeting'), or communities select beneficiaries based on their own criteria ('devolved community-based targeting'). Each approach has different implications for targeting outcomes and for comparability of targeting accuracy. Under 'delegated' approaches it is possible to compare targeting outcomes against administrative approaches, because the eligibility criteria are clear and absolute. Under 'devolved' approaches, targeting outcomes are not comparable across communities, because they are based on relative assessments - so the poorest $10 \%$ in a rich community may well be better off than the poorest $10 \%$ in a rich village.

An additional complication arises when a quota is applied, as when communities are asked to identify 'the poorest $20 \%$ of households'. This approach is commonly adopted by NGOs faced with binding budget constraints. Setting such a stringent quota tends to generate high exclusion errors (by design) - if poverty in the community is $60 \%$ then a $20 \%$ quota will only reach a maximum of one-third of the poor.

\subsubsection{Delegated community-based targeting}

On Malawi's Social Cash Transfer programme communities were asked to identify households that were 'ultra-poor' and labour-constrained (defined as dependency ratio>3, or no working aged adult, or the adult has a chronic illness or disability). This 'delegated' approach proved effective in terms of outreach, reaching over $90 \%$ of households in the poorest expenditure quintile (exclusion error by design $<10 \%$ ). But a quarter of beneficiaries were not labour-constrained (inclusion error in implementation (against eligibility criteria) $=24 \%$ ) (Miller et al. 2010).

Peru's 'Glass of Milk' subsidy programme had high exclusion errors in terms of reaching poor people, because the target groups that local communities were asked to identify were narrowly specified and not always directly related to poverty status: poor children (44\% of households with children aged 3-11), households with pregnant or lactating women, and

5 A review of evidence on community-based and community-driven development initiatives found that: "The targeting of poor communities and poor households within communities is markedly worse in more unequal communities, particularly when the distribution of power is concentrated within elites" (Mansuri and Rao 2004: 55). 
people with tuberculosis. Half of all poor households did not benefit from this programme (51.4\%), but exclusion error was lower among poor households with children under 7 years old (38.2\%). Inclusion error, however, was low (16.8\%) (Stifel and Alderman 2003).

Save the Children's 'Community-Managed Targeting and Distribution' methodology (CMTD) has been used to identify beneficiaries for general food distributions in several countries. Proxies for food insecurity are derived from qualitative research in each local context, and usually include thresholds for land and livestock ownership. The CMTD methodology generated low inclusion errors in terms of meeting the administratively-defined eligibility criteria - only $5-12 \%$ of beneficiaries in Tanzania and $10-13 \%$ in Zimbabwe were 'inappropriately targeted' (Mathys 2004: 4) (Table A1.5).

\subsubsection{Devolved community-based targeting}

Two programmes in our review devolved responsibility for identifying beneficiaries to communities. On Malawi's Agricultural Input Subsidy Programme communities were asked to identify their most vulnerable members. Criteria included: being elderly, weak and vulnerable; orphans, widows and female-headed households keeping orphans; "households with multiple problems'; disabled; household head is chronically ill or household is caring for sick people.

An assessment of beneficiaries' poverty status found that inclusion error by design was extremely low, at $5 \%$. Using a social mapping technique, '95\% of the targeted households for agricultural inputs were poor' (Mgemezulu 2008: 84). However, exclusion error in implementation was very high, at $67 \%$, not because the targeting mechanism was weak but because budget constraints resulted in substantial undercoverage of eligible households. 'Ideally these households should have been included because they satisfy the selection criteria. However, due to limited quota only $33 \%$ of the deserving households were targeted' (Mgemezulu 2008: 84).

Rwanda's 'Vision 2020 Umurenge Programme' (VUP) uses a 'traditional' social mapping process at village level called 'Ubudehe' to classify households into a number of wealth categories (usually six). It then takes all households in the bottom two wealth categories, applies land ownership as a criterion, and labour to identify which households were eligible for Direct Support and which were eligible for Public Works employment. However, access to Public Works was also rationed because of budget constraints. A comparison of the 'social poverty' mechanism against findings from a household poverty survey found that inclusion error (households in the bottom two 'Ubudehe' categories that were above the 'extreme income poverty line' or the 'extreme human poverty line') was $21.1 \%$. Exclusion error was much higher, at $60.0 \%$, because large numbers of extremely income poor or human poor households are clustered in the third 'Ubudehe' wealth category, but these households are not included on the VUP because of budget constraints (Asselin 2010). It should be noted that this data only considers eligibility numbers, not actual beneficiary numbers, and does not take account of other targeting criteria (land ownership) and rationing of Public Works.

\subsubsection{Self-targeted programmes}

The most common application of self-targeting is on public works programmes, where the labour requirement and a low wage rate combine to deter non-poor individuals from applying for work opportunities. However, where poverty is widespread and employment opportunities are limited, these screening mechanisms are inadequate and public works employment is often rationed, so inclusion and exclusion errors can both be higher than predicted.

In Ethiopia, where the poverty headcount stood at approximately 24 million in 2006 (34\% of the population), the Productive Safety Net Programme (PSNP) reached about 8 million people, or roughly one-third of the poor - an 'inherent exclusion rate' in implementation (Sharp, Brown and Teshome 2006: 21) of at least 67\% - because of limited resources. The PSNP combines self-targeting with government-defined indicators of food insecurity - it is 
targeted at food insecure rather than poor households, with 3+ months of food shortage in the previous year being the indicator of food insecurity. An assessment of targeting accuracy in 2006 found that ' $88 \%$ of beneficiaries and $70 \%$ of non-beneficiaries reported experiencing three or more months of food shortage in the preceding year', so inclusion error was $12 \%$ and exclusion error was 70\% (Sharp, Brown and Teshome 2006: 23) (Table A1.6).

The PSNP exemplifies the problem of 'under-coverage' (which is common not only on selftargeted programmes) - where exclusion does not reflect a failure of the targeting mechanism, but inadequate resources to reach all poor people. Since the PSNP reaches only one-third of poor Ethiopians, a more relevant indicator of its poverty targeting accuracy would consider where beneficiaries are located on the income distribution: are they drawn from the 'poorest of the poor', are they clustered close to the poverty line, or are they scattered randomly among the poor? Assessing this adjusted poverty incidence rate would require shifting the poverty line downwards for the specific purpose of PSNP assessment, to calculate more realistic inclusion and exclusion errors, or disaggregating poverty data and looking at inclusion and exclusion errors by decile.

\subsubsection{Multiple targeting mechanisms}

Many social transfer programmes use a combination of two or more targeting methods or mechanisms, either simultaneously (e.g. individuals must satisfy both a categorical age test and an income test to qualify for a means tested social pension), or sequentially (e.g. poor geographical areas are identified, then poor households are selected within these areas), or in parallel (i.e. different mechanisms are used to target different beneficiary groups for the same programme). Multiple mechanisms complicate the assessment of targeting accuracy, because it is not possible to attribute targeting errors to any single mechanism (Table A1.7).

\subsubsection{Simultaneous mechanisms}

A study of Uruguay's National Social Emergency Plan, a social cash transfer that applied both a means test and a proxy means test ${ }^{6}$ found that $21.6 \%$ of eligible households did not apply for the programme, mainly because of various transactions costs incurred in the application process (Burdin and de Melo 2009). Means tests and proxy means tests are not only administratively complex to implement, they also add more complexity and costs for applicants than other targeting mechanisms such as categorical, geographic, or selftargeting.

South Africa's Disability Grant requires all applicants to pass both a means test and a disability test. Though inclusion and exclusion errors on the programme are substantial, at $17 \%$ and $49 \%$ (based only on the disability test), they compare favourably with international experience: 'disability targeting error rates are comparable to those of disability programs in developed countries with more administrative capacity' (Mitra 2010: 19). Two studies in the United States, one based on medical checks and the other on self-reported disability, found inclusion and exclusion error rates of $19 \%$ and $48 \%$, and $20 \%$ and $60 \%$, respectively. Inclusion errors on South Africa's Disability Grant by poverty status are low at $5 \%$; but exclusion by poverty is very high at $89 \%$, because of the stringent application of disability eligibility tests.

\subsubsection{Sequential mechanisms}

Many unconditional and conditional cash transfers use 'sequential' mechanisms, first defining the geographical boundaries of the programme (e.g. rural areas, or the poorest districts), then identifying eligible households by applying a proxy means test or community-based

6 Applicants first completed an income declaration form (the means test), then government officials visited each household and scored them on a list of characteristics (the proxy means test). Out of 131,000 applicants, about 80,000 were admitted into the programme on the basis of their proxy means test scores (Burdin and de Melo, 2009: 148). 
targeting. A review of 38 conditional cash transfer programmes found that: 'About two thirds of countries use geographic targeting; about two thirds use household targeting, mostly via proxy means testing; and many countries use both. Moreover, many programs use community-based targeting or community vetting of eligibility lists to increase transparency' (Fiszbein and Schady 2009: 70).

\subsubsection{Parallel mechanisms}

Nicaragua's conditional cash transfer, 'Red de Proteccion Social', uses two targeting methods in different areas:

Nicaragua's RPS used two targeting approaches for selecting beneficiaries: In most comarcas selected for the first phase, where about 80 percent of households fell below the poverty line, all households were eligible for the program (... about 6 percent were later excluded based on their resources). In a smaller number of comarcas where poverty rates were lower, household eligibility was assessed with a proxy means test that identified households above and below the poverty line. In these comarcas, the average poverty rate was 75 percent, meaning that about 25 percent of households were excluded... In comarcas where geographical targeting was employed, almost all poor and extremely poor households received benefits. The 'undercoverage' rate (households that were defined as poor but did not receive benefits) was only about 3 percent, while the 'leakage' rate (households in geographically-targeted comarcas defined as non-poor but receiving program benefits) was only 14 percent. In household-targeted comarcas, undercoverage was estimated as 3 percent and 10 percent among extremely poor and poor households, respectively, while leakage was similarly estimated to be 17 percent and 6 percent, respectively.

(Adato 2008: 15)

As might be expected, exclusion errors were lower under geographical targeting than household targeting, but inclusion errors were also higher when poor households were targeted using a proxy means test, which is rather surprising. ${ }^{7}$

This use of differentiated targeting is a logical strategy, given different characteristics of the population in different locations. It is unusual for multiple mechanisms to be used on a single programme, but this case suggests that such a strategy should be considered more often.

\section{Costs of targeting}

The process of targeting often requires a large amount of information to be collected though this varies by targeting mechanism - in order to identify the eligible and screen out the ineligible. This can absorb a substantial portion of the programme's budget. Targeting is often perceived as a costly activity, and the more accurate it is, the more expensive it is Besley and Kanbur (1990) hypothesised that targeting costs rise faster than targeting accuracy. Any assessment of targeting cost-effectiveness must weigh up this 'trade-off' between rising expenditure against improved accuracy in terms of the identification of the 'correct' (i.e. eligible) beneficiaries. 


\subsection{Targeting costs}

Apart from the direct administrative costs of targeting, targeting may have a number of secondary effects on both the targeted and untargeted populations, some of which introduce other forms of costs. Secondary effects can be positive, as for example when social transfers made to one vulnerable category (older persons) also benefit another vulnerable category (children) (Case and Deaton 1998). Targeting may generate other secondary benefits, such as sensitising local populations to the disadvantage faced by particular groups, or - if community-based targeting is used - involving communities in decision-making processes about policy interventions that are intended to benefit them.

However, many secondary effects of targeting are negative. Sen (1995), for example, mentions information distortions (people acting as poor in order to obtain benefits); incentive distortions (beneficiaries and would-be beneficiaries losing motivation to work); social stigma (beneficiaries who 'depend on handouts' losing the respect of their neighbours); and politicisation (manipulation of targeting for political gain).

A full cost analysis of targeting should cover all these costs and consequences. This chapter reviews the available evidence on administrative costs, private costs (travel costs, opportunity costs, etc.), social costs (e.g. erosion of community cohesion), psycho-social costs (such as stigma and loss of self-esteem), political costs (loss of political support) and incentive-based costs (e.g. behavioural change to meet eligibility criteria).

A poverty-targeted scheme can be evaluated using the benchmark of a comparable universal programme. Which option is more cost-effective, a social benefit targeted to the poor or transfers provided universally? The answer depends partly on the costs of targeting, which in turn are determined by a range of political, social, institutional, administrative and economic factors.

Targeting involves a range of public, private and indirect costs, which vary from country to country and depend on the targeting method chosen. The direct financial cost is the administrative expense incurred by the managing authority in implementing the targeting mechanisms. Private costs include both financial expenses and other resources and opportunities foregone by applicants and others complying with the targeting requirements. Indirect costs include political, economic, social and psycho-social losses.

Many of the studies analysed in this literature review recognise a broad range of costs imposed by targeting. Ferreira-Coimbra and Forteza (2005: 697) cite 'large administrative costs, corruption, distortions of incentives to save, and social stigma.' Dutrey (2007) lists indirect costs including loss of political support, stigmatisation, incentive gaps, lost social capital/cohesion, corruption and clientelism. Samson et al. (2006) consolidates similar typologies from the targeting literature into a framework including the full range of targeting costs reviewed in this study. The following sections synthesise the assessments of costs by type: administrative, private, social, psycho-social, political and incentive-based.

\subsection{Administrative costs}

Targeting systems require people, skill, time and money. A means test, for example, will often require repeated verification of the income or assets of households in order to decide whether they should receive benefits. The dynamics of poverty in many countries significantly increase the cost of targeting. When people move in and out of poverty frequently, appropriate targeting requires regular assessment of the targeting criteria. Baulch's (2002: 22) literature review reports estimates of the administrative costs of the targeting process in Latin American social transfer programmes, which range between 6\% and $9 \%$ of total programme costs. Similarly, Grosh, del Ninno, Tesliuc and Ouerghi (2008, 
Table 4.2) report targeting costs in the range of $0.6 \%$ to $6.3 \%$ of total programme costs, for eight social transfer programmes in Latin America and Eastern Europe. Targeting can absorb most of a programme's administrative budget, but Grosh et al. (2008) found that administrative costs averaged only $8.5 \%$ of total costs for 25 cash or near cash programmes, so targeting is rarely prohibitively costly.

Van der Berg, Siebrits and Lekezwa (2010: 12) provide similarly low figures, estimating administrative costs of targeting at 3-8\% of the value of transfers, and acknowledging that costs increase with attempts to increase targeting accuracy. They point out that the fixed costs of targeting may undermine the cost-effectiveness of providing very small benefits. Baulch's literature review (2002: 22) likewise identifies that varying approaches to targeting will incur different administrative costs, with finer targeting requiring higher administrative costs. Administrative costs are determined by two factors: (1) the intensity of targeting and other related administrative procedures (measured as cost-per-beneficiary), and (2) the scope of the targeting process, measured as the total number of participants in the programme. If the intensity effect is sufficiently smaller than the scope effect, finer targeting will be less expensive than universal approaches (Sluchynsky 2009: 211-212).

Castañeda and Lindert (2005) provides one of the few studies that explicitly estimates the direct administrative costs of targeting, but this only covers the household interview costs associated with the registration process, and using both unverified and proxy means testing. The estimates exclude the cost of system design and implementation, as well as hardware and the various case management responsibilities associated with targeting. The measured direct targeting costs are low - ranging between $0.7 \%$ and $1.4 \%$ of benefit values. The costs are summarised in Table 4.1 below.

Table 4.1. Targeting interview costs in Latin America

\begin{tabular}{|l|c|c|c|c|}
\hline \multirow{2}{*}{ Country } & \multirow{2}{*}{$\begin{array}{c}\text { People } \\
\text { registered } \\
\text { (millions) }\end{array}$} & \multicolumn{2}{|c|}{ Interview cost } & \multirow{2}{*}{$\begin{array}{c}\text { Cost per benefit } \\
\text { targeted (\%) }\end{array}$} \\
\cline { 3 - 5 } & Urban & Rural & \multicolumn{2}{|c|}{$\$ 8.40$} \\
\hline Chile (Ficha CAS) & 5.6 & \multicolumn{2}{|c|}{$1.3 \%$} \\
\hline Colombia (SISBEN) & 27.0 & $\$ 1.80$ & $\$ 2.90$ & $0.5 \%$ \\
\hline Costa Rica (SIPO) & 1.0 & $\$ 4.20$ & $\$ 7.00$ & $0.9 \%$ \\
\hline Mexico (Oportunidades registry) & 36.9 & $\$ 4.90$ & $\$ 6.80$ & $0.7 \%$ \\
\hline Brazil (Cadastro Unico) & 29.0 & & $\$ 3.90$ & $1.4 \%$ \\
\hline
\end{tabular}

Source: Castañeda and Lindert (2005: 42)

There is a frequent recognition in the literature that means testing (including proxy means testing) is more costly than categorical targeting and possibly community-based approaches. Targeting costs in a sample of middle-income countries averaged $4 \%$ of total programme costs, but ranged between $25 \%$ and $75 \%$ of total administrative costs (Grosh and Leite 2009: 5). Ha, Chai and Alviar (2010: 5) argue that verified means testing is expensive in terms of administrative costs but also requires linkages to the tax system which is challenging in developing countries. Administrative costs are higher if the targeting approach requires timeconsuming and difficult verification processes. Coady and Parker's (2009: 24) literature review identifies widespread misreporting by households of socio-economic characteristics that determine their eligibility for the Oportunidades programme. Benfield (2007: 7) notes that high administrative costs of targeting may reduce the resources available to finance the benefits.

These relatively high costs of means testing (including proxy means testing) influence governments' decisions on the choice of targeting mechanisms. Coady and Parker (2009: 5) 
point out the choice of a first-stage self-targeting approach in Mexico's Oportunidades programme was influenced by the relatively high costs of proxy means testing in an urban environment with a low percentage of eligible households. Schady (2002: 2) points out that geographic targeting likewise appeals to programme designers because of its administrative simplicity, which also makes it relatively inexpensive to implement. Standing (2007) argues that benefits from universal security schemes (such as categorical social pensions) are administratively simple and low-cost, as has been demonstrated by Namibia's social pension: 'The costs are equivalent to about 30 US cents per person per month, also remarkably low by comparison with other systems' (Standing 2007:21).

Conning and Kevane (2002: 378) argue that community-based approaches may be less expensive to administer because "community groups may have better information for identification of needs, and households may in turn have less incentive or opportunity to provide false information on assets, income or shocks.' Self-targeting and community based approaches are identified as low-cost options when analysts focus only on the on-budget administrative costs of the respective programmes.

The limited available literature suggests that the administrative costs of targeting vary substantially by methodological approach, but few studies have attempted to rigorously quantify the full range of administrative costs, particularly the common off-budget costs that accompany some of the schemes.

This review found one study that carefully compared the direct targeting cost of different methodologies on a consistent basis, using an approach that combined fieldwork with simulation analysis. The study corroborates this review's findings of the data limitations for the analysis of targeting costs.

There is little quantitative literature on the costs of targeting and one major constraint to cost estimation is that programme budgets and expenditure reports do not generally provide breakdowns by process (i.e. the costs of programme design, M\&E, targeting, etc.). Neither donor budget and expenditure formats nor implementing agency ERP reports provide budget or expenditure breakdowns that allow us to understand which resources have been used specifically for targeting. The lack of data on targeting costs limits our ability to compare different targeting options.

(Watkins 2008: 14)

The figure below depicts the total costs of alternative targeting approaches simulated for Zambia, broken down into the direct financial costs of targeting and estimates for the opportunity costs of the time contributed by uncompensated community officials and households. 
Figure 4.1. Simulated costs of alternative targeting approaches for Zambia

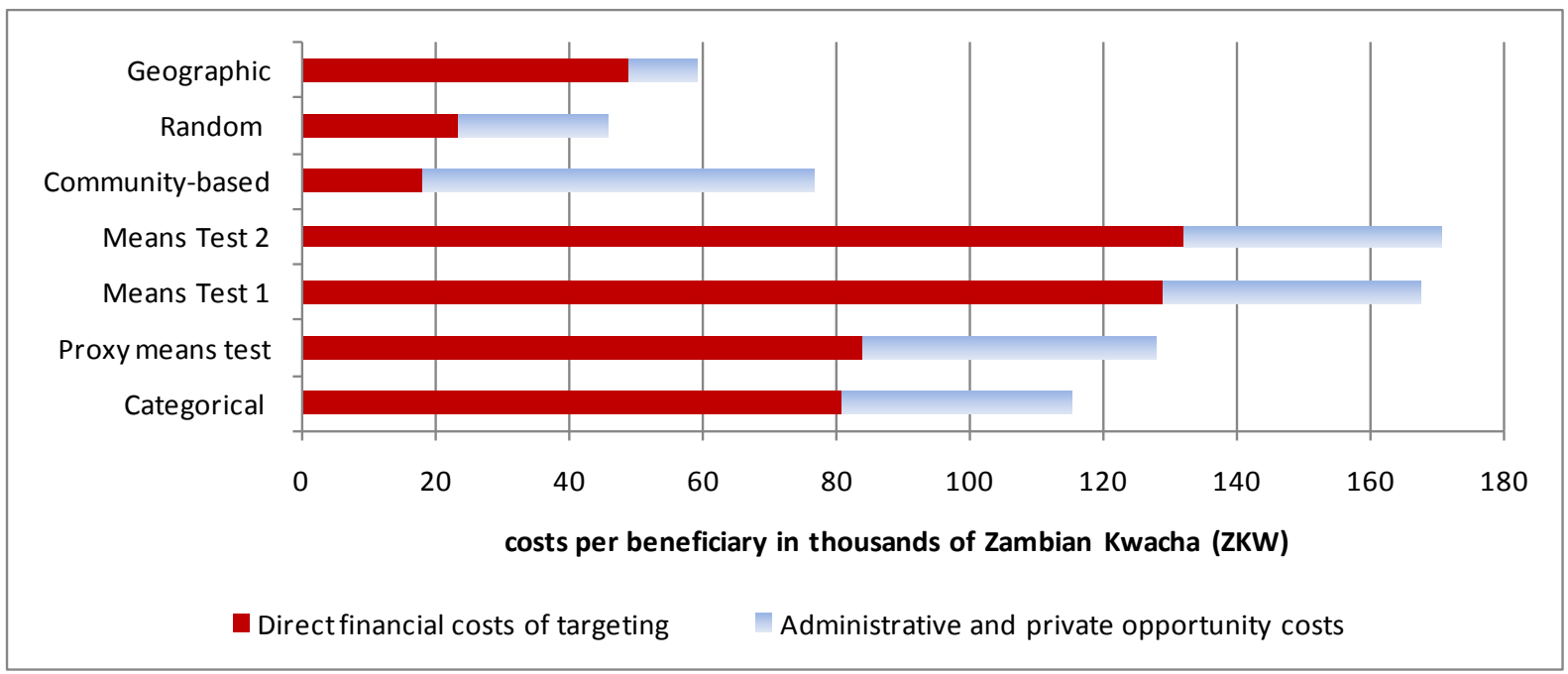

Source: Authors' calculations with data from Watkins (2008: 51$)$.

The costs Watkins simulates are influenced by a number of strong assumptions. First, he assumes a very low opportunity cost (equal to the daily rural wage rate for unskilled labour) for volunteers and community officials not financially compensated by the programme. This disproportionately favours the cost measure for community-based targeting. Second, he adopts the more expensive survey-outreach approach for categorical targeting, with associated high training costs, even though the more cost-effective on-demand registration approach is typically adopted for this targeting methodology in most countries. Third, the geographic targeting approach assumes a new survey must be conducted, rather than employ an existing household survey. Fourth, the analysis assumes a very high accuracy for means testing (80-90\%), while acknowledging 'the accuracy of means testing is unknown' (Watkins 2008: 52). While these may or may not be appropriate in Zambia's case, as with any simulation approach, the results depend critically on these assumptions. The relative costs of targeting approaches in other countries may vary substantially, depending on the assumptions reflecting the appropriate institutional contexts.

Finally, in cases where a single targeting mechanism is used to target multiple benefits, it is appropriate to think differently about assigning targeting and administration costs to each programme. Examples include Brazil's Cadastro Unico, Colombia's SISBEN and India's BPL card. Crudely, if a 'single registry' is used to target three social transfers to one household, one-third of the targeting costs should be assigned to each programme.

\subsection{Private costs}

Private costs arise as potential beneficiaries expend resources to comply with the programme's targeting criteria. Sometimes the process is perceived to be too difficult to navigate alone. Potential beneficiaries incur direct costs in order to demonstrate their eligibility. Private costs include expenses for transportation to apply for benefits, time expended in transit and in queues (with the associated loss of income or other foregone opportunities) and the fees for obtaining necessary documentation. Coady and Parker (2009: 6 ) recognise that private costs associated with the targeting process can both reduce the net benefits to participating households as well as create a self-selection process which can exclude eligible participants for whom private costs exceed the expected [present value of the] benefits.

Corruption on the part of administering authorities increases the private costs to participants who must pay bribes or non-statutory fees to secure their entitlements. Programmes without 
transparent targeting mechanisms fail to provide 'claimable' entitlements and increase the risk of corruption.

For example, a study of social pension payments in Karnataka, India found that 'high transaction costs are incurred during an application process that involves producing several proofs and certificates to be submitted to a village accountant. The study shows that a not insignificant share of applicants (especially illiterate [older] persons and widows) choose to rely on a middleman to prepare their applications, help arrange the required certification, and file the claim' (Sluchynsky 2009: 207). Different types of programmes impose varying kinds of private costs.

For means-tested programmes, the main costs involve time and transportation to what is usually an on-demand registration centre, and the costs of obtaining certification to verify compliance with the eligibility requirements. Hunter and Adato (2007: 53-54) describe the findings from interviews with caregivers eligible for but not receiving the Child Support Grant in South Africa. Applicants share their perceptions that the grant is difficult to secure, with transport costs to the relevant government offices ranging from R16 (US\$2.30) to R26 (US\$3.70) and multiple trips usually required. Uncertainty about application success and long processing delays can reduce the expected value of benefits. ${ }^{8}$

For community based targeting approaches, potential participants often meet with community members in extended exercises aimed at identifying the poorest and most vulnerable, imposing the opportunity cost of the productive activities foregone through engagement in the process (Lembani 2006: 23).

Conditional programmes - including traditional conditional cash transfer programmes that impose human capital investment requirements as well as public works programmes - have much higher private costs, if the compliance with the associated conditionalities is considered as part of the targeting process. For example, requiring hard labour for low wages in order to screen out the non-poor is a typical self-targeting mechanism in public works programmes. This review, however, does not include these costs in the framework on targeting costs.

Self-targeting requires time costs, because these approaches often use queuing as a filter (Lembani 2006: 23).

Arguing against targeting in general, Standing (2007: 29) argues that more universal approaches leave relatively little scope for bureaucratic abuse, discretionary behaviour or petty corruption, reducing the burden of private costs on beneficiaries.

\subsection{Social costs}

Social costs from targeting include a possible deterioration of community cohesiveness and the potential erosion of informal support networks. Mgemezulu (2008: 75) reports that community members are reluctant to target because they fear future repercussion from the excluded. The poorest often depend on better off households, who are more likely to be excluded in the targeting process, and they may reciprocate by not providing assistance to the included poor in the future.

Targeting creates a clear division between beneficiary and non-beneficiary households, potentially increasing social tension and reducing productive cooperative behaviour $(\mathrm{Ha}$, Chai and Alviar 2010: 4; Slater and Mphale 2008: 10). In particular, community-based

8 In the years after Hunter and Adato (2007) was published, the government substantially streamlined the application process, reducing documentation requirements and rolling out a system for same-day registration in many offices across South Africa. 
approaches are vulnerable to nepotism and other forms of elite capture, undermining social cohesion and breeding resentment ('hatred') within participating communities (Ha, Chai and Alviar 2010: 5). Conversely, Standing (2007: 29) argues that universal benefit schemes (such as categorical social pensions) can build social solidarity, strengthen community and social cohesion, and may even assist in developing a sense of national pride. However, no empirical evidence is provided that demonstrates these effects.

Adato (2000: 31-32) identifies a number of social costs from targeting processes in Progresa, a large conditional cash transfer programme in Mexico. Non-beneficiaries, for example, expressed their resentment at being excluded by resisting payment of their school fees. For example, the school director in Querétero reported this response to a request for school fees: 'Ask those who receive Progresa first.' Poverty targeting produces envy and division, with non-beneficiaries self-excluding themselves from participation in community activities more generally because of their exclusion from Progresa. This may have a substantial negative impact on social capital erosion. 'One or more of these problems was reported in approximately $80 \%$ of the focus groups, and $75 \%$ of the doctors' interviews (some more serious than others).'

Jaspars and Maxwell (2008) warn that the backlash to targeting food aid can result in or exacerbate violent conflict within the communities and reduce human security. This can include physical attacks, looting and theft, and the conflict is more prevalent when community members are not consulted. In Somalia in 2007, for instance 'WFP reported 15 major security incidents at food distributions, in which 10 militia were killed, 10 civilians were killed, and 350 metric tons of food remain unrecovered from looting' (Jaspars and Maxwell 2008: 25). In this context, the World Food Programme (WFP) faces a difficult dilemma. They worry that community leaders will skew food distribution towards politically aligned groups. But if the WFP does not consult with local stakeholders, the perceived lack of transparency increases the risk of backlash.

There are fewer distinctions across methodologies in terms of social costs. Coady (2006: 14) highlights the issue of proxy means testing in Mexico causing 'substantial social conflict within communities.' Hodges et al. (2007: 30) reports that the administrative processes for Mongolia's Child Money Programme had created tensions among families. Conning and Kevane (2002: 378) point out that community-based targeting approaches may 'lead to, or increase, conflict and divisions within the community'.

The social context for targeting appears to be a significant factor in determining the extent of social costs. Handa and Davis (2006: 11) suggest that Progresa's experience indicates that 'individual targeting in small communities with high poverty rates can lead to social conflict within the community'. Mathys (2004: 24) points out that tensions about targeting are intensified when communities perceive that the allocated benefits are wholly insufficient for addressing the critical vulnerabilities.

Even simulation exercises meant to identify appropriate design issues can impose social costs. Chinsinga (2005: 721) reports that community members in Malawi resented the simulation of targeting exercises, perceiving these to make a mockery of their poverty. Researchers and non-governmental organisations in Malawi raise expectations but have rarely adequately delivered, leading to resentment of outsiders by poor communities.

Lack of transparency appears to be a central theme, as a factor that raises social costs. In his assessment of the agricultural input subsidy programme in Malawi, Mgemezulu (2008: 87) reports that lack of transparency contributed to community perceptions that local leaders and extension workers had stolen coupons meant for the community. Secrecy in targeting approaches increased suspicion and mistrust. In one village, resentful members destroyed benefit vouchers. In another the community leader was murdered. Community leaders 
subsequently decided to distribute benefits universally among members, avoiding the tension and resentment associated with exclusion.

In the very different context of Progresa in Mexico, Adato (2000: 18) attributes some of the tension, conflict and social division described above to community members lacking an understanding of the basis for some households receiving benefits and others being excluded. Poverty reinforces a common identity that supports social solidarity, and the new and artificially imposed distinctions between beneficiaries and non-beneficiaries create resentment.

Mechanisms that introduce rights of redress to social transfer programmes may reduce social costs, by increasing the perceived legitimacy of targeting approaches. Mgemezulu (2008: 90) notes that the destruction of input vouchers and the murder of an official in Malawi reflect community members' frustrations with legitimate channels of redress, and intensify long-term tensions because of the time it takes for the resulting social scars to heal. Castañeda and Lindert (2005) suggest that providing potential beneficiaries with a 'voice' in the targeting process can increase their empowerment within the community and reduce social costs.

Pritchett, Sumarto and Suryahadi (2002: 25) report that communities address this problem of social cost with more universal approaches to distribution. Even when Indonesia's rice distribution programme allocated rations based on the number of eligible households according to centrally established poverty targeting guidelines, in practice community leaders allocated a more limited quantity to nearly twice the number of eligible households, rejecting the national guidelines for targeting the poorest. 'Community leaders argue that the targeted distribution of this central government benefit is inconsistent with the spirit of community solidarity and self-help. The village heads point out that, if everyone is expected to contribute their labour to community projects, then everyone should also benefit from the unexpected windfall of assistance from the central government' (Pritchett, Sumarto and Suryahadi 2002: 41).

When Chinsinga (2005: 19-20) tested community attitudes to alternative targeting mechanisms for safety net programmes in rural Malawi, his findings echoed those from Mexico and Indonesia. 'The sentiment that everybody is poor was apparently motivated by the fear that the selection process would either create or exacerbate social tensions in the communities. This fear consequently put communities on the defensive arguing, "we are all poor and we all need assistance".'

\subsection{Psycho-social costs}

Potential psycho-social costs from targeting include stigma and the exacerbation of negative self-perceptions grounded in the participants' experience with the programme. While the provision of transfers can improve economic independence and reduce the impact of stigma, policy stances that reinforce negative stereotypes could increase the psychological costs of the targeting process. Self-targeting frequently employs stigma to discourage non-poor (and even poor) people from taking up the benefits. Stecklov, Winters, Todd and Regalia (2006) report that, in Mexico, where census data are used to establish eligibility for Progresa, 'some people do not answer the census or give incorrect information because they feel ashamed to admit their poverty.' Likewise, Dutrey (2007: 9) argues that targeting can stigmatise beneficiaries.

Psycho-social costs depend critically on choices by programme designers. For example, a cash transfer to older people termed a 'social assistance scheme' will likely create more stigma than if it is called a 'social pension'. (Grosh and Leite 2009: 5) Sluchynsky (2009: 207) cautions that exploiting stigma deliberately for self-targeting can backfire, discouraging 
otherwise eligible claimants from taking up benefits they require. Lembani (2006: 22-23) reinforces this argument, adding that in-kind transfers that distribute 'inferior goods' leave participants at risk of social ridicule, increasing the likelihood they will drop out of the programme or not participate in the first place. Van der Berg, Siebrits and Lekezwa (2010: 13) find that some poor children refuse to participate in poverty-targeted school feeding programmes in South Africa due to the associated stigma, suggesting universal benefits better balance the trade-off between inclusion and exclusion errors.

Stigma sometimes arises in unexpected ways. Adato (2000: 14-15) finds that not being included in a programme can be stigmatising. This sentiment was articulated by a community member in Michoacán who was excluded from Progresa: 'In my community, let me tell you that the persons that were not chosen tell me that they are never lucky for anything, that people who were chosen were people who really have good luck. And I told them it wasn't true.' In other cases stigma simply is not an important issue. Castañeda (2005: 31) reports that community members make every effort to be included in the SISBEN programme and there is no associated stigma.

Appropriate design and effective implementation can reduce stigma. BRAC organizes beneficiaries into weekly meetings in order to reduce social isolation and build self-respect and self-confidence (Slater and Farrington 2009: 40). Geographic targeting automatically minimises the incidence of stigma, because everyone in local communities within targeted districts receives transfers. Similarly, Standing (2007: 29) argues that only universal schemes are non-stigmatising, because they do not single out the poor.

\subsection{Political costs}

Targeting the poor can also introduce political costs, primarily by excluding middle class beneficiaries who could lend their support to social transfers. Gelbach and Pritchett (1997) claim that the greater the degree of marginalisation of the poor, the more likely that effective poverty targeting will reduce the total resources transferred to the poor. As Sen argued: 'The beneficiaries of thoroughly targeted poverty-alleviation programmes are often quite weak politically and may lack the clout to sustain the programmes and maintain the quality of services offered. Benefits meant exclusively for the poor often end up being poor benefits' (Sen 1995: 14). Similarly, Benfield (2007: 7) warns that poverty targeting can cause political support to 'evaporate'.

It is extremely difficult to measure and quantify political costs, and there is little hard evidence to validate these assertions, most of which remain as untested hypotheses. Nonetheless, there is a strong consensus on the importance of political costs. Kakwani and Subbarao (2005: 43), quoting Subbarao et al. (1997), couches the issue in terms of the trade-off between inclusion and exclusion errors: 'Screening out the poorest is a bigger problem than including the non-poor in the targeting of any safety net transfer program; too much fine tuning in targeting may actually hurt the poor if the program loses political support.' Baulch (2002: 22) puts this in context of a compromise. 'A high level of inclusion/leakages to the non-poor may be necessary to secure sufficient political support for the anti-poverty intervention. As Pritchett (2005: 5) put it: "A leakier bucket may be better for redistribution of the poor".'

Various forms of poverty targeting yield different political impacts. Lembani (2006: 25) argues that community-based mechanisms can 'confer legitimacy on programmes that in turn may help to build political support for targeted approaches.' Grosh and Leite (2009: 5) point out that social pensions generally garner more political support than do general social assistance programmes. Van der Berg, Siebrits and Lekezwa (2010: 13) cite South Africa's social pension in making their point on political economy: 'The political support for a grant targeted only at very poor people may be less than that of a grant reaching a larger group, as is the 
case with the South African old age pension.' Slater and Farrington (2009: 35) reinforce these points: 'Whether means-tested or not, social pensions do enjoy strong and broad political support across different sectors of society.' They also suggest that 'self-targeting through public works programmes accompanied by targeting those who cannot work is frequently politically popular, in Africa, and elsewhere' (ibid:33). Elbers et al. (2004: 7) warns that very granular geographic targeting may be less politically popular than a more uniform scheme, which could lead to lower overall budgets for targeted transfers than would be the case under a more universal approach. Coady (2006: 14) highlights the issue of proxy means testing in Mexico in terms of it being 'the source of heated political conflict'. Not all poverty targeting approaches yield the same political costs.

Hodges et al. (2007) argue that the political costs of targeting severely undermined Mongolia's Child Money Programme. The electorate perceived the exclusion of some children as unfair, creating pressure for a universal distribution of benefits which began in mid-2006. The more categorical approach politically entrenched the programme, and they reported a widespread consensus against a return to poverty targeting. The Child Money Programme ultimately succumbed to a combination of forces, including the global economic downturn which hit Mongolia's mineral sector particularly hard. This experience highlights a potential trade-off between the political costs of targeting against the financial costs of universal provision.

Pritchett (2005: 31) encapsulates the dilemma into a question of how well the social budget responds to a larger beneficiary constituency. 'Electoral politics matter and doing the best for the poor requires taking a view on the "budget response function" - how will the support for the overall budget for transfers depend on the way in which it is targeted?' Grosh and Leite (2009: 164) pose the question in terms of budget optimism versus pessimism, as depending on whether or not 'the social unity resulting from a uniform provision of benefits will garner a sufficient budget (nationally financed in middle-income countries and donor assisted in lowincome countries) to provide meaningful protection.' Alternatively, proponents of poverty targeting are pessimistic because of both political and technical obstacles to budgets becoming sufficient to provide meaningful universal benefits. Conway (pers. comm.) suggests that a politically optimal strategy might lie somewhere between narrow poverty targeting and universal programmes - including the 'middle poor', for instance, to build a political constituency.

A second type of political cost results when beneficiary entitlements are not clear, leading to political manipulation of social priorities. This might be seen as a 'micro-political' set of costs. Sluchynsky (2009: 207) warns that 'significant discretion with respect to eligibility rules or decisions... placed in the hands of local politicians... could lead to patronage to gain popular support at the cost of exclusion of some needy and eligible individuals.' Pritchett (2005: 26) likewise warns that 'providing too much discretion, and particularly discretion without conditions for adequate local oversight, can lead to abuses.'

Chinsinga (2005: 14) finds that 'political patronage and capture of the interventions may lead to errors of inclusion'. Chinsinga (2005: 25) later argues: 'The fact that communities consistently pointed out to the need for external agents in the management of the transfers so as to ensure fairness, transparency and accountability is quite striking. It particularly underlined the increasing levels of distrust in the traditional power structures even though their role remains central in the socio-political activities of the villages.'

Appropriate design and effective implementation can increase the political benefits (and minimise the political costs) of targeting approaches. De Janvry and Sadoulet (2006: 9) highlight the importance of simplicity and transparency to ensure political acceptability. More broadly targeted programmes are assumed to generate greater political support (Ellis, 2012). 
As noted above, while this section summarises a wide range of assertions about political costs, their difficult-to-quantify nature means that rigorous evidence is hard to find, and credible conclusions about actual political impacts of different targeting mechanisms cannot be drawn. Although this is also true of other intangible (especially social and psycho-social) costs, political costs cannot be analysed in the same way that other types of costs are analysed. Randomised control trials face challenges to their external validity when trained on the central issues raised here, so definitive proof may prove elusive. Certainly, this topic will provide fertile ground for further research.

\subsection{Incentive-based costs}

Incentive costs may arise when beneficiaries change their behaviour in order to become eligible for the grant. Social pension eligibility criteria that exclude beneficiaries that receive investment income in excess of a specified threshold can create disincentives to save for one's retirement, particularly if the targeting test is blunt. Income thresholds for household benefits may undermine incentives to work and increase household earnings. Ravallion (2007: 5) raises the 'possibility that fine targeting will impose high marginal tax rates on recipients, possibly creating poverty traps.

Programmes that target individual demographic characteristics that are not readily subject to behavioural manipulation (such as gender and age) pose the least risk of negative incentive costs. One cannot grow older faster in order to qualify for a pension, although the risk of agemisreporting remains. Bobonis (2009: 24) finds that targeting women in Mexico's Oportunidades programme led to 'an increase in male partners' use of threats or of emotional abuse with no associated physical or sexual abuse - among beneficiary households as a result of the program. These are consistent with the model's predictions an increase in women's socioeconomic opportunities generate a greater incentive for male partners' to use emotional violence or threats of physical violence to extract rents from the wife's greater endowment and an associated reduction in the incidence of actual physical or sexual abuse.' The negative incentive effects do not just affect the direct beneficiary but can influence the behaviour of related parties.

Programmes that target outcome-type characteristics, however, are vulnerable to perverse behavioural responses. Jaspars and Maxwell (2008: 36), in their study of targeting malnourished children in complex food emergencies in Somalia, report a number of agencies concerned about families keeping 'their children malnourished as an extreme coping strategy to access general food rations... [and] that families will share malnourished children to access general rations.'

Though individual demographic characteristics cannot easily be manipulated, benefits categorically targeted on household structure may create perverse incentives for household re-formation. For example, if programmes target 'older persons without support', families may encourage older relatives to live alone rather than in extended family structures with earners and carers (Grosh and Leite, 2009: 5). A programme that targets femaleheaded households may undermine dual parent family structures, with greater costs in the long run to these households' well-being. Kakwani and Subbarao (2005) expresses similar concerns, cautioning that targeting on household structure may be difficult in practice because household re-formation is so fluid. Slater and Farrington (2009: 39) point out that Argentina's Jefes $Y$ Jefas cash-for-work programme targeted households with dependents, leading to the 'sharing' of children across households. Ellis (2012) expresses similar concerns about households restructuring to meet eligibility criteria, but apart from the Slater and Farrington study no empirical evidence could be found for these speculative effects.

Elbers et al. (2004: 8) warns that geographic targeting may induce inefficient and distortionary migration. Watkins (2008: 26) makes a similar point, pointing out that: 'The 
primary adverse incentives associated with geographic targeting are human migration from ineligible to eligible areas ... if the cost of migrating is less than the transfer.' The result will be otherwise unwarranted social dislocation. However neither study cites concrete evidence of this kind of distortion.

Lembani (2006: 22-23) argues that community-based targeting will likely create greater incentive costs - in terms of potential and current beneficiaries deliberately reducing their labour supply and earning capacities in order to qualify to be included in the group of beneficiaries - because community officials directly determine eligibility based on their perceptions of household means.

Perverse incentives may extend even to local and national authorities. Castañeda (2005:21) points out that local authorities, being closely connected to the problem of poverty in their communities, yet not bearing direct fiscal responsibility for the centrally funded Oportunidades programme, have an 'incentive to exaggerate the number of poor to get a greater amount of resources from central government. ... Abundant anecdotal evidence suggests that manipulation and or misuse of SISBEN may have in fact occurred, but unfortunately, there is no statistical evidence to quantify it and to determine the possible impact of such behavior.' Another type of higher level perverse incentive has been identified by national analysts in the Sudan, concerned that targeted food aid programmes act as 'a counter incentive for more proactive and appropriate government policies to address the livelihoods crisis in the region' (Pantuliano 2006: 8).

The impact of perverse incentives depends on the appropriate design and effective implementation of the programmes. Castañeda (2005) points out that poorly designed programmes can alter individual incentives. Pritchett (2005: 3) recommends 'targeting on observable characteristics [to] avoid incentive problems that arise when transfers are conditioned on outcomes like income or employment.' Ha, Chai and Alviar (2010: 6) speculate that proxy means tests, because they, focus on assets rather than income, should reduce the disincentive effect on work effort. Castañeda and Lindert (2005: 30), however, warn that: 'Empirical studies in the US also suggest that asset tests may reduce savings by lower-income families.'

Alternatively, limiting the timeframe for benefits targeted on outcome-type characteristics may dampen perverse incentives. The World Food Programme in Somalia would discharge families with malnourished children from the programme after three months if the child was not ill, to minimize the risk of families starving their children to gain access to food rations (Jaspars and Maxwell 2008: 36). Another approach is to limit the size of the benefit, since larger ones intensify any perverse incentive effect (Stecklov et al. 2006: 27-28).

While appropriate design and effective implementation can reduce incentive costs, only more universal approaches can eliminate them. Standing (2007: 29) argues that universal schemes are market neutral and do not create market distortions. Hodges et al. (2007: 3738) finds no clear evidence of negative incentive costs in Mongolia's Child Money Programme, but reports that 'some focus group participants suggested that it might reinforce a dependency "mindset"' in its targeted phase, since participants might reduce their income to become eligible or maintain their eligibility. They point out that such a 'dependency effect' should not arise with a universal programme. However, relatively generous benefits could reduce work effort, whether targeted or universal, though there is no empirical evidence for this effect in social transfer programmes. 


\section{Cost-effectiveness of targeting}

An assessment of the cost-effectiveness of targeting must weigh the benefits of targeting against the full range of costs, many of which, along with benefits, can only be quantified with great difficulty. The assessment should be quantitative as far as possible. However, policymakers make necessary judgements whether or not credible quantitative evidence exists. Systematic qualitative evidence provides a useful foundation for these complex judgements and may reflect the complexity of costing more effectively than necessarily arbitrary quantifications.

The decision to target should reflect an analysis that selects a targeting approach that minimises the full cost of targeting for a particular level of quantified benefit (costeffectiveness analysis), or maximises the rate of return - benefits in relation to costs (costbenefit analysis). The benefits of poverty targeting can be assessed in one of two ways: (1) for a given level of benefits delivered to poor households, effective poverty targeting reduces the fiscal cost of the programme; or alternatively, (2) for a given allocation to a benefit programme, effective poverty targeting increases the potential benefits to be delivered to poor households. The costs include the full set of components discussed in the previous section.

The challenge of assessing cost-effectiveness is constrained by data limitations and complexities that have hindered previous studies. The comprehensive literature review of Coady, Grosh and Hoddinott (2003) aimed to report targeting costs by programme, further classified by type of targeting methodology. However, of the 102 studies in their review, they identify $62(61 \%)$ for which information on targeting costs is 'not available'. Of the 40 studies for which they report references to targeting cost, only $8(8 \%)$ include specific quantitative information on the direct costs of targeting. The other 32 only reported total administrative expenses, which include payments systems and other delivery costs. This study faces the same constraints. A similarly small fraction of our studies have explicit information on direct administrative costs of targeting, and only two quantified just one other component of targeting costs.

The second constraint is the high degree of variability for each targeting methodology in the targeting performance. As mentioned in section 3.2 above, Coady et al.'s (2004: 2-3) study found that ' 80 percent of the variability in targeting performance was due to differences within targeting methods and only 20 percent was due to differences across methods'. While this review does not re-test this finding, qualitative analysis supports its ongoing applicability. This variability makes it impossible to draw strong conclusions from limited country studies or simulation analyses based primarily on design characteristics.

With limited cost data and a relatively weak explanatory role for the choice of targeting approach on targeting effectiveness, rigorous cost-benefit analysis is not always possible. Over half the studies highlighted one or more elements of the costs of targeting, and a third referenced costs other than administrative expenses. However, cost-effectiveness analysis may be possible with incomplete quantitative data, in combination with a judgement on unquantified costs and benefits. Also, cost-effectiveness analysis can be done that includes assumptions on targeting error.

Correlating the partial targeting cost estimates of Castañeda and Lindert (2005) summarised in the previous section with targeting errors provides some information about costeffectiveness. Their study reports the percentage of benefits received by the poorest quintile as an indicator of 'targeting efficiency'. Given this, one measure of inclusion error is the 
percentage of benefits received by beneficiaries not in this group. ${ }^{9}$ Figure 5.1 shows the correlation between interview costs and this measure of inclusion error for five Latin American programmes. (Castañeda and Lindert do not report the required targeting efficiency data for one of the programmes in their study.) The small sample does not permit significant inferences about the relationship, and in fact the correlation coefficient is not significantly different from zero. However, the coefficient has the expected negative sign, indicating that higher spending on targeting interviews is associated with lower inclusion error.

Figure 5.1. Targeting costs and inclusion "error" in Latin American cash transfer programmes

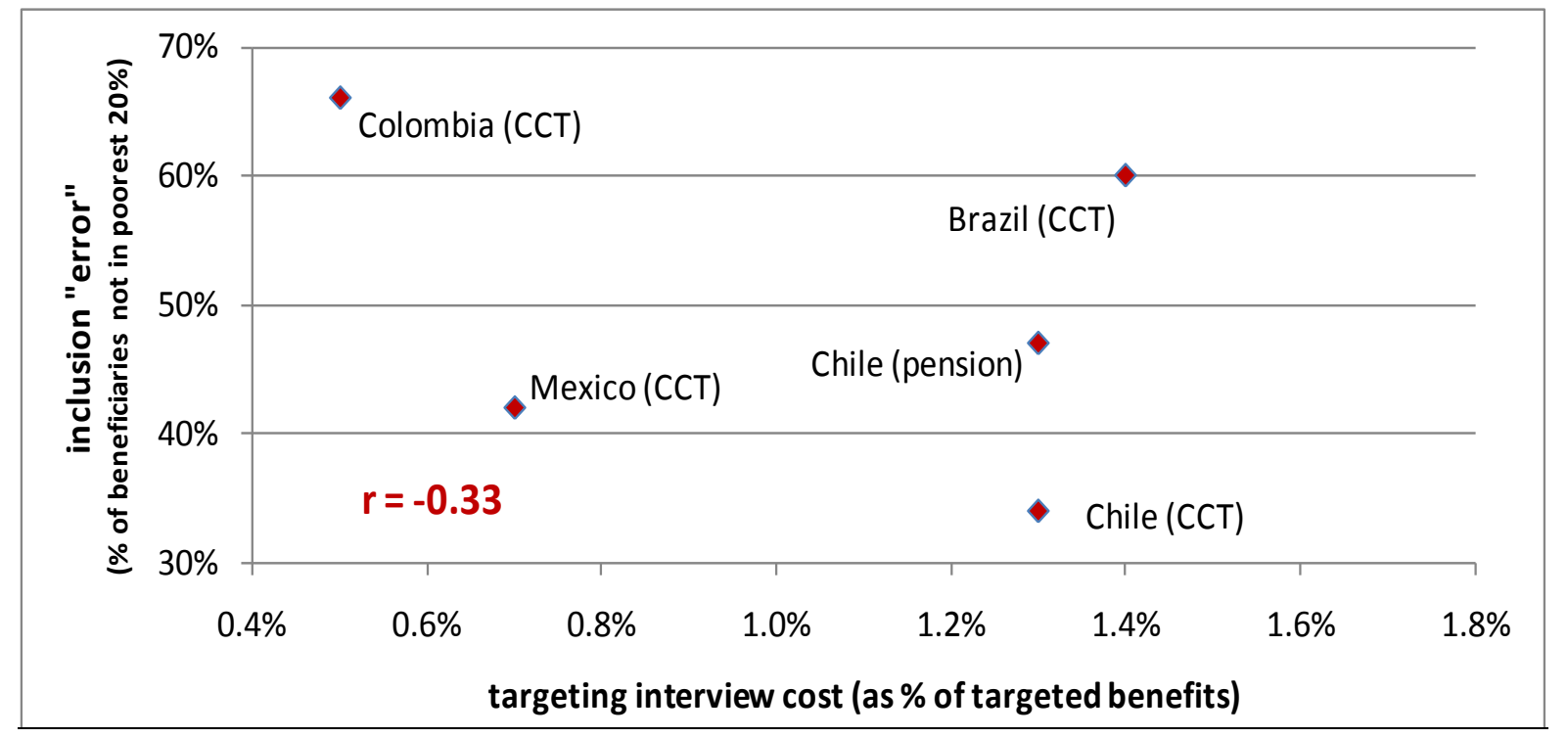

Source: Authors' calculations using data from Castañeda and Lindert (2005: 50).

A similar exercise provides some evidence on the relationship between exclusion error and targeting interview costs. Castañeda and Lindert (2005) report the percentage of the poorest quintile receiving benefits as an indicator of effective 'coverage'. Given this, one measure of exclusion error is the percentage of the poorest quintile excluded from receiving. ${ }^{10}$ Figure 5.2 shows the correlation between targeting interview costs and this measure of exclusion error for four Latin American programmes (Castañeda and Lindert do not report the required coverage data for two of the programmes in their study).

The even smaller sample again precludes significant inferences about the relationship. However, it is surprising that the correlation coefficient is positive and close to one, indicating that higher spending on targeting interviews is associated with higher exclusion error. This may reflect the negative relationship between inclusion and exclusion errors. A hypothesis for more rigorous testing is whether or not higher spending on the targeting process in fact reduces inclusion error but also increases exclusion error, perhaps because of the increased private costs for the poor. This hypothesis is consistent with the limited empirical evidence and the review of qualitative studies.

$9 \quad$ This is not necessarily the most appropriate measure, since different programmes have varying objectives and eligibility criteria, so receipt of programme benefits by households in higher quintiles is not necessarily 'error'. But this test provides an indication of how greater spending on the interview component of the targeting process is correlated with a greater concentration of benefits to the poorest quintile.

10 The same type of caveat expressed in the previous footnote for inclusion error applies in the case of exclusion error, since different programmes have varying objectives and eligibility criteria. Given the fairly high coverage in these programmes, a 'lowest quintile' threshold is a reasonable consistent level against which to assess exclusion. 
Figure 5.2. Targeting costs and exclusion "error" in Latin American cash transfer programmes

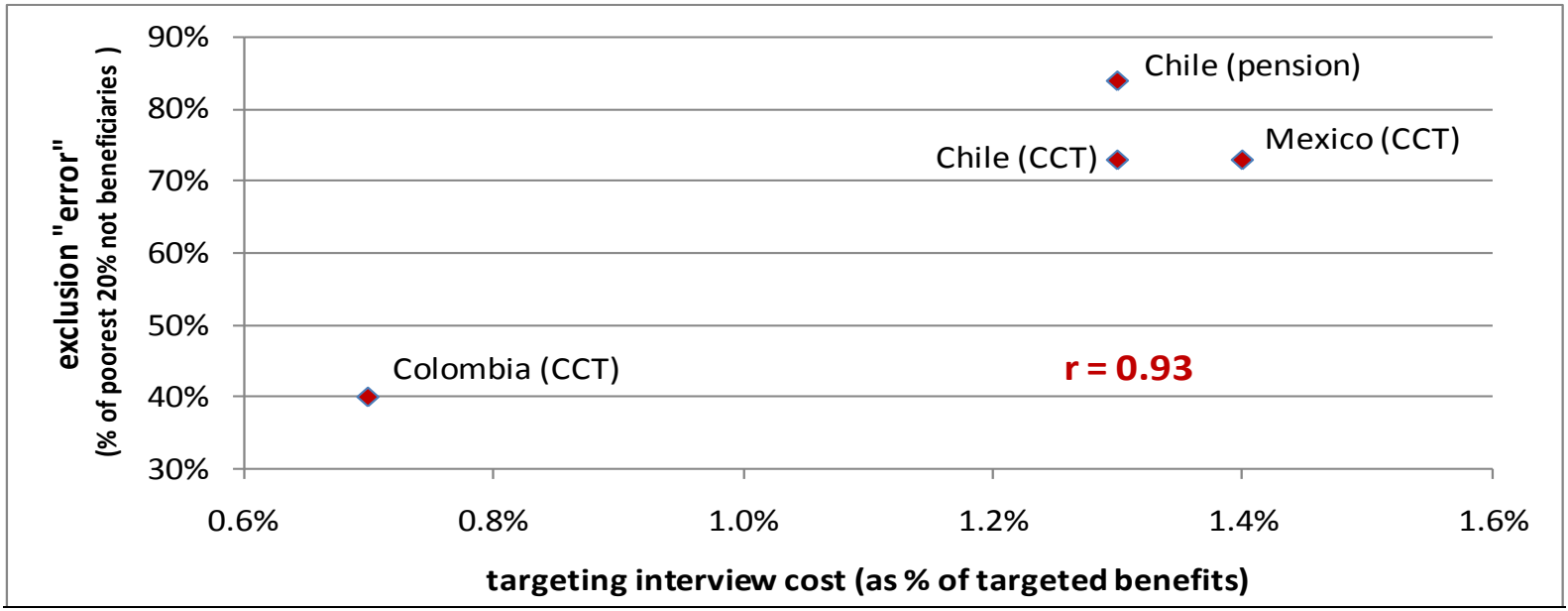

Source: Authors' calculations using data from Castañeda and Lindert (2005: 43, 50).

Watkins' (2008) simulation of targeting outcomes, using Zambian data on population demographics, household expenditure, etc., provides a further opportunity to explore the relationship between targeting effectiveness and cost. Figure 5.3 below illustrates the positive correlation between targeting effectiveness (as measured by the intervention's success in reducing the poverty gap) and a partial cost of targeting, which includes the direct financial cost of targeting to the government plus an estimate of opportunity costs for uncompensated officials and households. The costs exclude the social, psycho-social, political and incentive-based costs discussed above. Nonetheless, this represents the most comprehensive costing found among the studies included in this review.

\section{Figure 5.3 Targeting cost-effectiveness by methodology: simulations for Zambia}

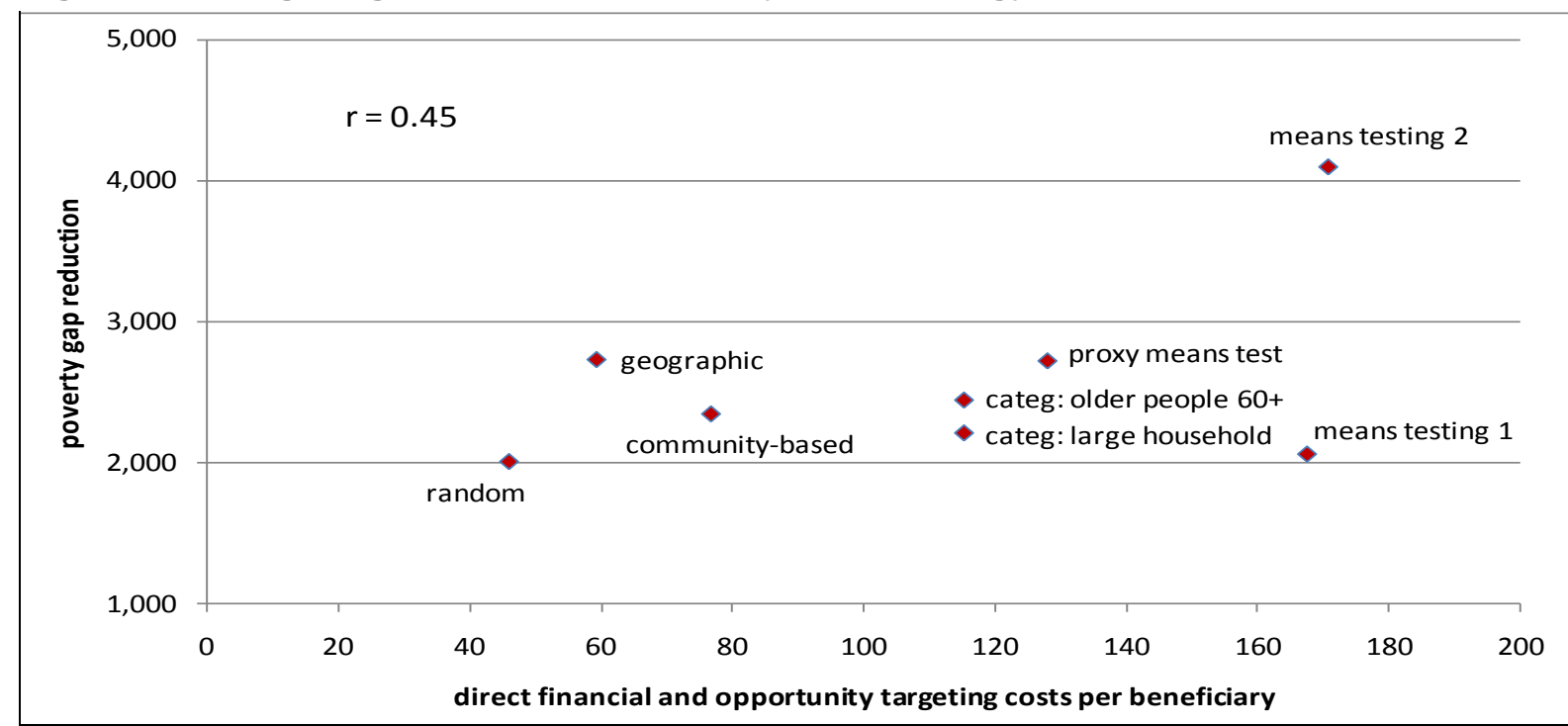

Source: Author's calculations using data from Watkins (2008: 52).

Watkins employs a random assignment targeting approach as a benchmark, and this demonstrates both the lowest cost and poorest impact. Means-testing with highly optimistic accuracy (85-90\%) demonstrates both the highest cost and greatest impact. Geographic targeting is the lowest cost realistic methodology, and yields the second-best targeting performance. Two categorical targeting methodologies (households with people 60 years and older, and households with 7 or more members) indicate unusually high targeting costs because of assumptions about the specific implementation approaches adopted. Proxy 
means testing is the next most expensive (after the means testing options), and yields the third best poverty gap reductions, but with optimistic assumptions about implementation errors. While the implications Watkins finds may not generalise easily to other countries because of the context-specific nature of the assumptions, his methodology shows promise for future research.

This review demonstrates insufficient evidence in the literature on information required for optimal decisions about whether or not to target and the choice of targeting methodology. The majority of studies recognised that there are important costs to targeting, and many of them identified components across a spectrum of costs - not just administrative costs to government but also private costs to individuals and households, as well as social, psychosocial, political and incentive-based costs. Given the data limitations, it is not possible to assert under what concrete circumstances poverty-targeting is appropriate, or specifically when one targeting methodology is better than another. Dutrey (2007: 8) encapsulates some of the key challenges.

There is still no coherent or standardized method to measure the costs of targeting (including administrative, identification and transfer costs), leakage, exclusion and overall efficiency. The costs of targeting are sometimes only reported in terms of the cost of identification of the beneficiaries, although there is clear evidence that the continuous administration of a targeted system requires more administrative resources than a universal programme.

Dutrey's review identifies significant problems with the existing literature on the costs of targeting, including imprecise calculations of administrative costs and the lack of acceptable studies even for the basic approaches of estimating unit costs of delivering benefits to the poor. The problem Dutrey identifies for administrative expenses is even more pronounced for the other components of targeting costs. While several studies in this review provide limited information about administrative expenses, only two studies provide estimates for other components of targeting costs. Coady et al. (2004) concluded their systematic review of targeting with an appeal for better data. In fact, data on targeting performance has improved, and the results in the previous sections make use of this data. However, data supporting analysis of cost effectiveness have not improved sufficiently for this review to make concrete conclusions about what is one of the most important (and controversial) challenges in social policy: the decision-making about whether and how to target. This should be based on a rigorous analysis of the full spectrum of costs, as far as possible.

While the lack of adequate quantitative data precludes a rigorous cost-benefit analysis for many programmes, DFID's value-for-money framework conceptualises an approach to evaluating the cost-effectiveness of poverty targeting (DFID 2011; Miller and Samson 2012), that allows for more systematic analysis of social transfer programmes and better decisionmaking on targeting choices, even with incomplete or unquantified information on targeting errors, costs and benefits. The diagram below illustrates the key linkages. Cost-effectiveness first requires the employment of the most economical inputs (for given outcomes), which implies adopting an appropriate targeting approach and taking account of non-targeting costs. The targeting cost might be measured as the average cost of identifying an eligible household. Cost efficiency requires minimising the cost of outputs. This may require attuning the design to achieve the appropriate trade-off between inclusion and exclusion errors while limiting targeting and other costs for the given output(s), recognising that some error is evitable with most programmes. One measure of efficiency is the money value of poverty gap reduction (the 'output') divided by the programme cost (the 'input') (Samson 2008; Samson et al. 2010; Samson 2011). ${ }^{11}$ Neither of these fully reflects the costs of excluding

11 However, this 'poverty-reducing efficiency' concept applies only if the aim of targeting is to reach poor households. If targeting aims for more categorical objectives, this efficiency measure may not be relevant. It is also arguable that poverty gap reduction is an outcome rather than an output. 
poor households from the programme, which constitutes an important element of targeting performance and effectiveness. Reaching the targeted group with minimal exclusion error can strengthen programme outcomes and impact. Achieving programme outcomes for lowest cost represents cost-effectiveness-that is, value-for-money.

Figure 5.4. Economy, efficiency and effectiveness in a value-for-money approach

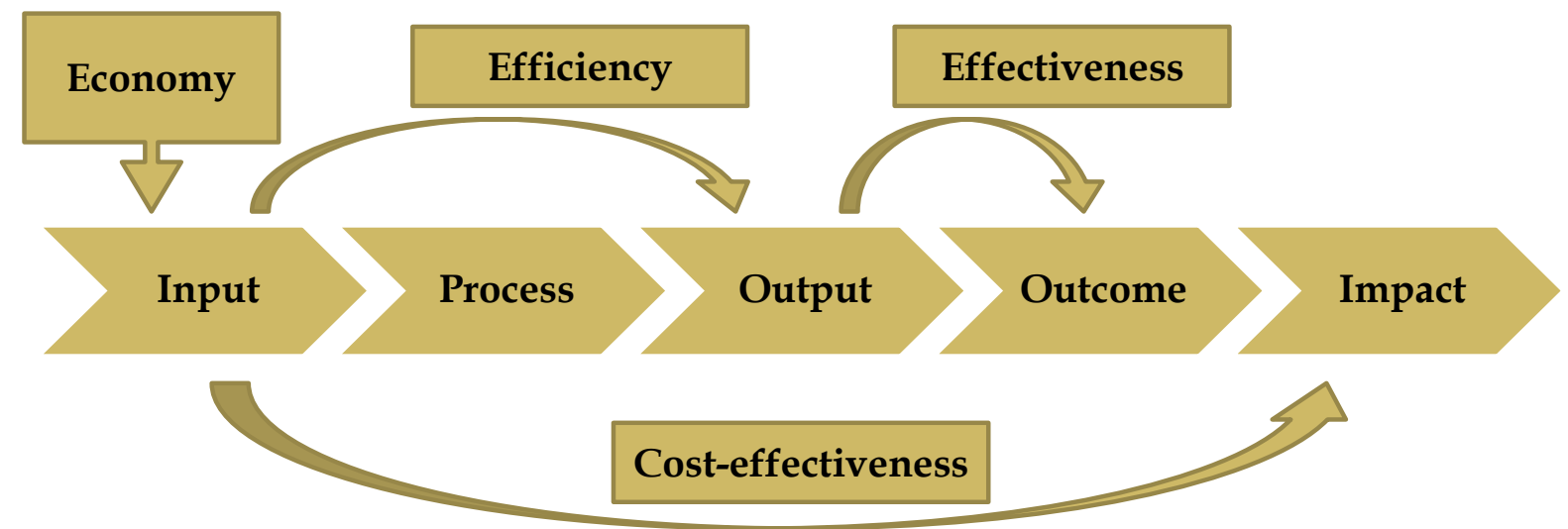

Source: DFID (2011: 4).

\section{Conclusions and implications for policy}

This review has shed light on the errors, costs and secondary consequences of targeting in actual social transfer programmes in a comparative way across different targeting mechanisms. The knowledge summarised by this review should be useful for informing the future selection, design and implementation of targeting mechanisms for social transfer programmes. However, some cautionary observations must be made.

First, while there are numerous studies reporting targeting errors and various costs, the range of targeting mechanisms reviewed means that once this analysis is performed by each targeting mechanism the evidence becomes less 'robust' and difficult to generalise. In terms of targeting errors, for instance, for community-based targeting we identified and reviewed only five documents, and only one document met our inclusion criteria for geographicallytargeted programmes, therefore we cannot draw strong conclusions based on these targeting mechanisms. Other targeting mechanisms were reviewed using more evidence. Nonetheless, it follows that it is extremely challenging to compare targeting outcomes across targeting mechanisms, from this limited evidence base.

Second, we have not disaggregated this analysis by the range of types of social transfer programme included in the documents, because different interventions often have very different, non-comparable objectives. For instance, the extent to which we can compare the accuracy of targeting a social pension using categorical targeting with a conditional cash transfer programme that targets poor households depends on intended outcomes. If both interventions aim to reduce poverty, their targeting outcomes are comparable, but if the social pension simply aims to transfer resources to older persons while the conditional cash transfer aims to reduce poverty then we have a comparability problem. Similarly, the variety of conditions and contexts (geographic, political and programme-specific) under which the different social transfers are made could also affect the comparability of targeting errors and costs. 
Earlier we summarised the key findings from the major targeting review conducted by Coady et al. (2004). This review asks different questions - we did not examine, for instance, whether targeted programmes deliver more resources to the poor than would random allocations - so our findings cannot be compared against those of Coady et al. We do endorse the conclusion that no single targeting mechanism works best in all contexts - the key factor is aligning the mechanism to programme objectives. We also agree with the Coady et al. finding that implementation is the single most important determinant of targeting success - this is evident from the range of outcomes in terms of targeting errors within a single mechanism. No targeting mechanism generates uniformly low or uniformly high inclusion and/or exclusion errors.

We believe this review is the first to synthesise evidence on the full range of targeting costs.

\subsection{Implications for practice and research}

\subsubsection{Targeting errors}

This review has identified several implications for social transfer practitioners and researchers. A fundamental conclusion is that, although most social transfers are intended to reduce poverty and vulnerability, it is unrealistic to expect any intervention to reach all poor people and exclude all non-poor people - perfect targeting is possible in theory but effectively impossible in reality. Firstly, some categorically targeted programmes reach discrete subgroups who are supported because they are socially vulnerable, not (only) because they are poor. In these cases, some inclusion and exclusion errors should be expected. But programme designers should carefully consider whether the scale of inclusion and exclusion errors (in terms of poverty) is justified, or whether alternative instruments should be considered that reduce these errors. Secondly, very few interventions attempt to reach all poor people - they display 'undercoverage by design' rather than 'exclusion error in implementation' - so a holistic assessment should aggregate errors across all components of a social protection system, rather than attributing a high 'exclusion error' to each component.

The main implication that can be drawn in comparing targeting mechanisms is that the effectiveness of each individual mechanism depends on the context, so the selection of an appropriate targeting mechanism should follow an assessment of the local context.

- Means tested programmes generally perform disappointingly in developing countries, reporting relatively high inclusion and exclusion errors in terms of reaching the poor, despite attempting to assess individual poverty status.

- Proxy means tests are highly sensitive to the proxies selected - the correlation with household income or consumption varies by indicator, so performance varies widely across programmes.

- Categorical targeting often achieves low inclusion and exclusion errors in terms of the eligibility criteria, but higher errors in terms of reaching the poor and screening out the non-poor, because the individual's poverty status is not directly assessed by the targeting mechanism.

- Geographically targeted programmes are sensitive to the spatial distribution of poverty, performing best where poverty is concentrated in discrete bounded areas, so geographic targeting might be best suited as the first stage of a multi-stage targeting process.

- Community-based targeting, either 'delegated' or 'devolved', requires specific conditions to be effective (e.g. social cohesion, no domination by elites) but can keep inclusion and exclusion errors in implementation relatively low, mainly because of local knowledge and intensive engagement in the targeting process. 
- Self-targeting requires lowering benefits and/or raising access costs to deter the nonpoor, but this is difficult to manipulate in contexts of high poverty - on public works programmes, exclusion errors are typically very high because of not enough employment opportunities, and job rationing has to be applied.

\subsubsection{Targeting costs}

This review examines evidence on the full range of costs associated with targeting, both to the programme and to beneficiaries or participants. Most of these costs are substantially under-researched. The trade-off between accuracy and (administrative) cost is confirmed by this review, but resolving this trade-off is ultimately a policy choice rather than a technical calculation.

- Administrative costs of targeting tend to increase as accuracy increases, and are by their nature higher for individual assessment methods (e.g. means testing), but lower for 'blanket coverage' (geographic) and 'universal' (i.e. categorical) approaches - but overall, administrative costs of targeting are not very high.

- $\quad$ Private costs to applicants - including transport, documentation, queuing time and opportunity costs of applying for social transfers - can be prohibitively high and inadvertently exclude eligible poor individuals, or they can be set high deliberately, as a self-targeting device.

- Social costs include the divisions within communities between beneficiaries and nonbeneficiaries, which can undermine social capital and cohesion - although these costs are often substantial, they are rarely investigated, but they do not appear to vary much by targeting mechanism.

- Psycho-social costs such as stigmatisation might be less significant than is often thought, and in some cases not being included in a social transfer programme is considered more stigmatising than being officially recognised as 'poor' - in fact, beneficiaries are sometimes positively empowered by their inclusion.

- Political costs of targeting can be significant, given the evidence that universal programmes generate broader political support than narrowly targeted social transfers for the poor; it is also important to avoid political manipulation of the targeting process, either to buy political support or to capture resource transfers.

- Incentive costs describe behavioural changes by applicants - e.g. in work effort or jobsearch, household composition, migration or fertility choices - and these (dis)incentives vary by targeting mechanism because different eligibility criteria invite different behavioural adjustments in order to qualify for benefits.

\subsubsection{Cost-effectiveness}

Quantifying the cost-effectiveness of alternative targeting mechanisms is complicated by the fact that many costs associated with targeting are 'qualitative' rather than 'quantitative' (e.g. psycho-social, political, and incentive costs). Most empirical evidence on targeting costeffectiveness limits the analysis to administrative costs. Analysis of the full spectrum of targeting costs is urgently needed for a more holistic understanding of the relative costeffectiveness of alternative targeting mechanisms.

Comparative evidence across several Latin American programmes finds that higher interview costs are associated with lower inclusion error (investing more in targeting reduces the selection of ineligible beneficiaries) but higher exclusion error (rigorous targeting tends to exclude more eligible people, perhaps because the private costs of applying are higher). 
Simulated cost data from Zambia (which might not be generalisable) confirms that means testing is the most expensive but (potentially) most accurate targeting mechanism, while geographic and categorical targeting are relatively inexpensive but are assumed to be relatively inaccurate. As with many decisions in the targeting process, a trade-off seems to be inevitable. Whether policy-makers have a bias towards (1) minimising 'leakages' to the ineligible or (2) ensuring that all 'needy' or eligible individuals are reached by a social transfer programme is a political judgement, not a calculation that can be solved by a technical formula.

\subsection{Conclusion}

This report has demonstrated that targeting social transfers is associated with various errors (inclusion and exclusion, by design and in implementation), costs (administrative and other), and secondary consequences (both positive and negative, some of which, such as incentive distortions, can be modelled as costs of targeting). Our hypothesis, as stated at the start of this literature review, was that 'different targeting mechanisms are associated with systematic differences in terms of inclusion and exclusion errors, financial costs and secondary consequences'.

An 'ideal' outcome would be to identify the most efficient and cost-effective targeting mechanisms - or perhaps to rank them - to provide an unambiguous answer to the policymaker's question: 'What is the 'best' mechanism for targeting social transfers to achieve the programme's objectives?' Having reached the end of this review of recent evidence, we conclude that no optimal mechanism exists. The choice of targeting mechanism is highly context-specific and depends on (1) the objectives of each social transfer programme, (2) how well the targeting strategy is designed and implemented. This conclusion resonates with that reached by Coady et al. (2004), who identified wider variation in targeting performance between programmes within each targeting mechanism than across targeting mechanisms.

This conclusion makes it difficult, if not impossible, to derive generalisable principles for comparative effectiveness across targeting mechanisms. Nonetheless, the evidence does suggest the following lessons for better more informed selection and better design and implementation of targeting mechanisms:

- Targeting errors: means testing is often relatively expensive and inaccurate; proxy means tests and categorical targeting give variable results depending on which proxies or categories are selected; geographical targeting performs best if poverty is concentrated in bounded areas; community-based targeting requires careful design and intensive supervision to avoid elite capture; self-targeting by raising access costs or lowering benefits can compromise the programme objectives.

- $\quad$ Targeting costs: there appears to be an unavoidable trade-off between targeting accuracy and targeting cost, but it is important to consider the full range of costs, not only administrative expenditure - but also private costs to applicants such as transport, social costs such as effects of targeting on social cohesion, incentive costs involving behavioural changes by applicants, psycho-social costs such as stigmatisation of beneficiaries, and political costs such as politicisation - but note also that some of these secondary effects can be positive rather than negative. 


\section{Appendix 1 Tables for targeting errors}

Table A1.1. Targeting errors on means tested programmes

\begin{tabular}{|c|c|c|c|c|c|}
\hline No. & Programme + Country & Eligibility criteria & $\begin{array}{l}\text { Exclusion } \\
\text { error }\end{array}$ & $\begin{array}{l}\text { Inclusion } \\
\text { error }\end{array}$ & Indicator/ (Comment) \\
\hline \multirow[t]{2}{*}{ \#3 } & \multirow[t]{2}{*}{$\begin{array}{l}\text { Social cash transfer } \\
\text { (Ndihme Ekonomika) } \\
\text { [Albania] }\end{array}$} & \multirow[t]{2}{*}{$\begin{array}{l}\text { Urban families with no other income } \\
\text { Rural households with small } \\
\text { landholdings }\end{array}$} & $\begin{array}{l}51.1 \% \\
62.6 \% \\
70.8 \%\end{array}$ & & $\begin{array}{l}\text { Proxy 1: Percentage of poorest } 10 \\
\text { percent not receiving assistance } \\
\text { Proxy 2: Percentage of poorest } 20 \\
\text { percent not receiving assistance } \\
\text { Proxy 3: Percentage of poorest } 40 \\
\text { percent not receiving assistance }\end{array}$ \\
\hline & & & & $\begin{array}{l}6.2 \% \\
10.1 \% \\
11.9 \%\end{array}$ & $\begin{array}{l}\text { Proxy 4: Percentage of richest } 60 \\
\text { percent receiving assistance } \\
\text { Proxy 5: Percentage of richest } 80 \\
\text { percent receiving assistance } \\
\text { Proxy 6: Percentage of richest } 90 \\
\text { percent receiving assistance } \\
\end{array}$ \\
\hline \multirow[t]{2}{*}{$\# 4$} & \multirow{2}{*}{$\begin{array}{l}\text { Minimum Livelihood Guarantee } \\
\text { Scheme, known as Di Bao } \\
\text { (DB). } \\
\text { [China] }\end{array}$} & \multirow{2}{*}{$\begin{array}{l}\text { Poor urban households } \\
\text { (means tested income below a } \\
\text { specified poverty line) }\end{array}$} & $71 \%$ & & $\begin{array}{l}\text { (Undercoverage rather than errors in } \\
\text { income assessment) }\end{array}$ \\
\hline & & & & $40 \%$ & $\begin{array}{l}\text { Recipients with incomes above the } \\
\text { income threshold for eligibility }\end{array}$ \\
\hline \#42 & $\begin{array}{l}\text { Unified Monthly Benefit } \\
\text { [Kyrgyz Republic] }\end{array}$ & $\begin{array}{l}\text { Household cash income }+ \text { imputed } \\
\text { farm income per capita }<\text { GMLC } \\
\text { (guaranteed minimal level of } \\
\text { consumption) }\end{array}$ & $69 \%$ & $35 \%$ & $\begin{array}{l}\text { "the program fails to protect } 69 \% \text { of the } \\
\text { individuals in the poorest quintile. At } \\
\text { the same time, more than half of the } \\
\text { beneficiaries are leaked to } \\
\text { households from richer quintiles" } \\
\text { [p33] }\end{array}$ \\
\hline \#45 & $\begin{array}{l}\text { Children Benefits } \\
\text { [Azerbaijan] }\end{array}$ & $\begin{array}{l}\text { "a categorical test to determine how } \\
\text { many children are in an applicant's } \\
\text { family and an income-test to } \\
\text { determine the salary of the applicant. } \\
\text { [lf] the family's income per capita for }\end{array}$ & $88.5 \%$ & $86.3 \%$ & $\begin{array}{l}\text { "Children Benefits is the only income- } \\
\text { tested social assistance program in } \\
\text { Azerbaijan and the only program with } \\
\text { an explicit poverty-reduction mandate. } \\
\text { The Children Benefits provides cash }\end{array}$ \\
\hline
\end{tabular}




\begin{tabular}{|l|l|l|l|l|l|}
\hline No. & Programme + Country & Eligibility criteria & $\begin{array}{c}\text { Exclusion } \\
\text { error }\end{array}$ & $\begin{array}{c}\text { Inclusion } \\
\text { error }\end{array}$ & Indicator/ (Comment) \\
\hline & & $\begin{array}{l}\text { the previous quarter is less that the } \\
\text { eligibility level of 16,500 AZM, the } \\
\text { applicant is eligible for the benefit." } \\
\text { [p3] }\end{array}$ & & & $\begin{array}{l}\text { income for families with children } \\
\text { assumed to be poor." [p3] }\end{array}$ \\
\hline
\end{tabular}


Table A1.2. Targeting errors on proxy means test programmes

\begin{tabular}{|c|c|c|c|c|c|}
\hline No. & Programme + Country & Eligibility criteria & $\begin{array}{l}\text { Exclusion } \\
\text { error }\end{array}$ & $\begin{array}{l}\text { Inclusion } \\
\text { error }\end{array}$ & Indicator/ (Comment) \\
\hline \multirow[t]{2}{*}{ \#19 } & \multirow[t]{2}{*}{$\begin{array}{l}\text { Conditional cash transfers } \\
\text { [Brazil, Ecuador] }\end{array}$} & \multirow[t]{2}{*}{$\begin{array}{l}\text { "we define the target population as the } \\
\text { poorest } 20 \text { percent of households" } \\
\text { [p.76] }\end{array}$} & $45 \%$ & & $\begin{array}{l}\text { Brazil: "Among those who are eligible } \\
\text { by income, enrolment is shown at just } \\
55 \text { percent" [p77] }\end{array}$ \\
\hline & & & $33 \%$ & & $\begin{array}{l}\text { Ecuador: "only } 67 \text { percent of the poor } \\
\text { end up receiving benefits" [p76] }\end{array}$ \\
\hline $\begin{array}{l}\# 35 \\
\# 64\end{array}$ & $\begin{array}{l}\text { Social welfare programmes } \\
\text { [Colombia] }\end{array}$ & $\begin{array}{l}\text { 1) housing quality and possession of } \\
\text { durables; } 2 \text { ) public utility services; 3) } \\
\text { human capital (education) levels; 4) } \\
\text { family demographics, unemployment, } \\
\text { dependency ratio and income per } \\
\text { capita }\end{array}$ & $19 \%$ & $31 \%$ & $\begin{array}{l}\text { SISBEN proxy means test database is } \\
\text { compared against the national } \\
\text { income distribution: } 81 \% \text { of poor are } \\
\text { correctly identified, } 69 \% \text { of those } \\
\text { classified as poor are poor. }\end{array}$ \\
\hline$\# 44$ & $\begin{array}{l}\text { Food subsidy } \\
\text { [Egypt] }\end{array}$ & $\begin{array}{l}\text { Modelling a proxy means test, based } \\
\text { on location, household composition, } \\
\text { social categories, housing quality, } \\
\text { ownership of assets and consumer } \\
\text { durables, employment and verifiable } \\
\text { income-related variables }\end{array}$ & $28 \%$ & $16 \%$ & $\begin{array}{l}\text { "nearly three-quarters of those defined } \\
\text { as poor using actual expenditure } \\
\text { were also predicted as being poor by } \\
\text { the model, giving an error of } \\
\text { exclusion of } 28 \% \text { " } \\
\text { " } 16 \% \text { of the actual non-poor were } \\
\text { predicted as poor, representing the } \\
\text { error of inclusion" [p35] }\end{array}$ \\
\hline
\end{tabular}




\begin{tabular}{|c|c|c|c|c|c|}
\hline No. & Programme + Country & Eligibility criteria & $\begin{array}{l}\text { Exclusion } \\
\text { error }\end{array}$ & $\begin{array}{l}\text { Inclusion } \\
\text { error }\end{array}$ & Indicator/ (Comment) \\
\hline \multirow[t]{3}{*}{ \#46 } & $\begin{array}{l}\text { Child Money Programme } \\
\text { (conditional cash transfer) } \\
\text { [Mongolia] } \\
\text { Proxy means test (ex ante) } \\
\text { (predicted exclusion and } \\
\text { inclusion errors in design } \\
\text { based on the PMT formula) }\end{array}$ & \multirow{2}{*}{$\begin{array}{l}11 \text { indicators: } \\
\text { location, } \\
\text { household size, } \\
\text { household head's level of education, } \\
\text { household members' employment, } \\
\text { housing conditions, } \\
\text { household assets, } \\
\text { number of livestock owned, } \\
\text { means of transport owned, } \\
\text { support and assistance received, } \\
\text { the presence of household members } \\
\text { with physical disabilities, elderly } \\
\text { members (aged } 70+) \text {, full orphans, } \\
\text { and single mothers or fathers with } \\
\text { four or more children. [p10] }\end{array}$} & $42 \%$ & $38 \%$ & $\begin{array}{l}\text { "even without taking into account the } \\
\text { CMP's implementation problems, the } \\
\text { targeted CMP had a high ex ante } \\
\text { inclusion error due to the properties of } \\
\text { the formula used in the proxy means } \\
\text { test. Analysis of the formula ... } \\
\text { reveals that } 38 \% \text { of the beneficiary } \\
\text { households could be expected to be } \\
\text { non-poor" [p14] }\end{array}$ \\
\hline & $\begin{array}{l}\text { Proxy means test (ex post) } \\
\text { (actual exclusion and inclusion } \\
\text { errors in implementation) }\end{array}$ & & $20.7 \%$ & $56.9 \%$ & $\begin{array}{l}\text { "actual performance revealed a much } \\
\text { higher inclusion error than the } 38 \% \\
\text { expected from ex ante simulation, } \\
\text { which means that the targeted } \\
\text { programme suffered not only from } \\
\text { technical problems concerning the } \\
\text { formula used for proxy means testing } \\
\text { but also from serious shortcomings in } \\
\text { implementation. ... } 56.9 \% \text { of } \\
\text { beneficiary households and } 51.3 \% \text { of } \\
\text { beneficiary children were 'non-poor', } \\
\text { i.e. living above the Minimum } \\
\text { Subsistence Level." }\end{array}$ \\
\hline & "Universal" (categorical) & $\begin{array}{l}\text { In } 2006 \text {, "the parliament adopted a new } \\
\text { law which made the provision of 'child } \\
\text { money' a universal entitlement, to } \\
\text { which all children under } 18 \text { years of } \\
\text { age would be eligible" [p11] }\end{array}$ & $8 \%$ & $65 \%$ & $\begin{array}{l}\text { The 'universal' child benefit programme } \\
\text { still has some exclusion errors } \\
\text { because } 8 \% \text { of "households below } \\
\text { the MSL do not have children and } \\
\text { therefore are automatically excluded. } \\
\text {... some children were still not } \\
\text { reached by the 'universal' } \\
\text { programme, either because of self- } \\
\text { exclusion by wealthier families or } \\
\text { because of barriers to access [e.g. } \\
\text { "lack of documents"] by extremely } \\
\text { vulnerable and marginalized poor } \\
\text { families and by children living outside }\end{array}$ \\
\hline
\end{tabular}




\begin{tabular}{|c|c|c|c|c|c|}
\hline No. & Programme + Country & Eligibility criteria & $\begin{array}{c}\text { Exclusion } \\
\text { error }\end{array}$ & $\begin{array}{c}\text { Inclusion } \\
\text { error }\end{array}$ & \multicolumn{1}{|l|}{ Indicator/ (Comment) } \\
\hline & & & & & $\begin{array}{l}\text { a family framework [e.g. street } \\
\text { children]." [p15] }\end{array}$ \\
\hline
\end{tabular}


Table A1.3. Targeting errors on categorically targeted programmes

\begin{tabular}{|c|c|c|c|c|c|}
\hline No. & Programme + Country & Eligibility criteria & $\begin{array}{c}\text { Exclusion } \\
\text { error }\end{array}$ & $\begin{array}{l}\text { Inclusion } \\
\text { error }\end{array}$ & Indicator/ (Comment) \\
\hline \multirow[t]{8}{*}{ \#15 } & \multirow{8}{*}{$\begin{array}{l}\text { Social pension } \\
\text { [several countries] }\end{array}$} & \multirow[t]{2}{*}{ Age ("universal” old age pension) } & $23 \%$ & & Nepal \\
\hline & & & $13 \%$ & & Brunei \\
\hline & & \multirow{6}{*}{$\begin{array}{l}\text { (Exclusion error measured only by } \\
\text { age eligibility, not poverty status) } \\
\text { (secondary sources cited) }\end{array}$} & $7 \%$ & & Namibia \\
\hline & & & $6 \%$ & & Mexico City \\
\hline & & & $4 \%$ & & Botswana \\
\hline & & & $0 \%$ & & Bolivia \\
\hline & & & $0 \%$ & & Mauritius \\
\hline & & & $0 \%$ & & Samoa \\
\hline \#36 & $\begin{array}{l}\text { Social pension } \\
\text { (Old Age Allowance) } \\
\text { [Bangladesh] }\end{array}$ & $\begin{array}{l}\text { Age (over } 60 \text { years) } \\
\text { (Inclusion error measured by age } \\
\text { eligibility) }\end{array}$ & & $24 \%$ & $\begin{array}{l}\text { "24\% of households receiving the old } \\
\text { age allowance did not have a } \\
\text { household member aged } 60 \text { or } \\
\text { above" [para.47] }\end{array}$ \\
\hline \#45 & $\begin{array}{l}\text { Social pension } \\
\text { [Azerbaijan] }\end{array}$ & $\begin{array}{l}\text { Age } \\
\text { (Errors measured by poverty status, not } \\
\text { age eligibility) }\end{array}$ & $95.2 \%$ & $86.1 \%$ & $\begin{array}{l}\text { "Social Pensions provide protection for } \\
\text { the elderly who do not qualify for a } \\
\text { social insurance pension bec-ause of } \\
\text { the lack of contribution to the Pay-As- } \\
\text { You-Go scheme." [p3] }\end{array}$ \\
\hline \#45 & $\begin{array}{l}\text { Disability grant } \\
\text { [Azerbaijan] }\end{array}$ & $\begin{array}{l}\text { "households with disabled members } \\
\text { during the Karabakh conflict with } \\
\text { Armenia" [p3] }\end{array}$ & $99.8 \%$ & $47.7 \%$ & Karabakh benefits \\
\hline \#45 & $\begin{array}{l}\text { Disability grant } \\
\text { [Azerbaijan] }\end{array}$ & $\begin{array}{l}\text { "households with disabled members ... } \\
\text { from the Chernobyl nuclear accident } \\
\text { in Ukraine in 1986." [p3] }\end{array}$ & $100.0 \%$ & $100.0 \%$ & Chernobyl benefits \\
\hline \#45 & $\begin{array}{l}\text { Disability grant } \\
\text { [Azerbaijan] }\end{array}$ & "households with disabled children" [p3] & $100.0 \%$ & $83.5 \%$ & Child Disability \\
\hline \#45 & $\begin{array}{l}\text { Student grants } \\
\text { [Azerbaijan] }\end{array}$ & "full-time students" [p3] & $97.9 \%$ & $91.1 \%$ & Scholarships \\
\hline \#45 & $\begin{array}{l}\text { Grants for war veterans, } \\
\text { decorated civilians, military } \\
\text { and government personnel } \\
\text { [Azerbaijan] }\end{array}$ & $\begin{array}{l}\text { - } \quad \text { war and labour veterans } \\
\text { - } \text { citizens decorated with orders and } \\
\text { medals } \\
\text { - } \quad \text { personnel of civil, security and } \\
\text { military services }\end{array}$ & $94.9 \%$ & $90.1 \%$ & $\begin{array}{l}\text { "Other Benefits [includes] merit-based } \\
\text { privileges for war and labor veterans, } \\
\text { and citizens decorated with orders } \\
\text { and medals. Another category is } \\
\text { occupa-tional benefits for personnel }\end{array}$ \\
\hline
\end{tabular}




\begin{tabular}{|c|c|c|c|c|c|}
\hline No. & Programme + Country & Eligibility criteria & $\begin{array}{l}\text { Exclusion } \\
\text { error }\end{array}$ & $\begin{array}{l}\text { Inclusion } \\
\text { error }\end{array}$ & Indicator/ (Comment) \\
\hline & & $\begin{array}{ll} & \text { personnel of some other } \\
\text { government organizations }\end{array}$ & & & $\begin{array}{l}\text { of civil, security and military services, } \\
\text { and some other government } \\
\text { organizations" [p3] }\end{array}$ \\
\hline \multirow[t]{5}{*}{$\# 40$} & \multirow{5}{*}{$\begin{array}{l}\text { Social assistance programmes } \\
\text { (child allowances, subsidies } \\
\text { on public services) } \\
\text { [Eastern Europe] }\end{array}$} & \multirow{5}{*}{$\begin{array}{l}\text { "Categorical benefits such as child } \\
\text { allowances, and subsidies on public } \\
\text { services for the aging or for public } \\
\text { workers and their dependents" } \\
\text { [p19] }\end{array}$} & $94 \%$ & $36 \%$ & Poland \\
\hline & & & $57 \%$ & $86 \%$ & Hungary \\
\hline & & & $90 \%$ & $92 \%$ & Bulgaria \\
\hline & & & $87 \%$ & $84 \%$ & Russian Federation \\
\hline & & & $90 \%$ & $65 \%$ & Estonia \\
\hline \multirow[t]{3}{*}{ \#22 } & \multirow{3}{*}{$\begin{array}{l}\text { Cash and food transfer } \\
\text { programmes } \\
\text { [Bangladesh] } \\
\text { (many eligibility criteria) } \\
\text { (Inclusion error if "beneficiaries } \\
\text { failed to meet this criterion but } \\
\text { were selected for the programs" } \\
\text { [p81]) }\end{array}$} & (1) Female-headed household & & $\begin{array}{l}78 \% \\
70 \% \\
64 \% \\
21 \% \\
\end{array}$ & $\begin{array}{l}\text { Food Security Vulnerable Group } \\
\text { Development (FSVGD) } \\
\text { Income-Generating Vulnerable Group } \\
\text { Development (IGVGD) } \\
\text { Food for Asset Creation (FFA) } \\
\text { Rural Maintenance Program (RMP) }\end{array}$ \\
\hline & & (2) Age range (18-49 years) & & $\begin{array}{l}11 \% \\
11 \% \\
6 \% \\
3 \%\end{array}$ & $\begin{array}{l}\text { FSVGD } \\
\text { IGVGD } \\
\text { FFA } \\
\text { RMP }\end{array}$ \\
\hline & & (3) Illiteracy & & $9 \%$ & RMP (only a criterion on RMP) \\
\hline \multirow[t]{2}{*}{$\# 59$} & \multirow[t]{2}{*}{$\begin{array}{l}\text { Livelihood Empowerment } \\
\text { Against Poverty (LEAP) } \\
\text { [Ghana] }\end{array}$} & $\begin{array}{l}\text { "people over } 65 \text { in ultra-poor } \\
\text { households, households containing } \\
\text { orphans and vulnerable children, and } \\
\text { persons with severe disabilities" [p4] }\end{array}$ & $35.9 \%$ & & Rural exclusion error \\
\hline & & (analysis of GLSS data) & & $73.4 \%$ & Urban inclusion error \\
\hline
\end{tabular}


Table A1.4. Targeting errors on geographically targeted programmes

\begin{tabular}{|l|c|c|c|c|c|}
\hline No. & Programme + Country & Eligibility criteria & $\begin{array}{c}\text { Exclusion } \\
\text { error }\end{array}$ & $\begin{array}{c}\text { Inclusion } \\
\text { error }\end{array}$ & Indicator/ (Comment) \\
\hline$\# 27$ & $\begin{array}{c}\text { Social assistance programmes } \\
\text { [Vietnam] }\end{array}$ & "poor and remote communes" & $80.5 \%$ & $7.7 \%$ & $\begin{array}{c}\text { "the vast majority of poor people in } \\
\text { Vesignated not live in an officially } \\
\text { [p36] }\end{array}$ \\
\hline
\end{tabular}


Table A1.5. Targeting errors on community-based targeting programmes

\begin{tabular}{|c|c|c|c|c|c|}
\hline No. & Programme + Country & Eligibility criteria & $\begin{array}{l}\text { Exclusion } \\
\text { error }\end{array}$ & $\begin{array}{l}\text { Inclusion } \\
\text { error }\end{array}$ & Indicator/ (Comment) \\
\hline \multirow[t]{2}{*}{ \#2 } & \multirow[t]{2}{*}{$\begin{array}{l}\text { Social cash transfer } \\
\text { [Malawi] }\end{array}$} & $\begin{array}{l}\text { Ultra-poor + labour-constrained } \\
\text { (3 proxies of ultra-poverty tested) }\end{array}$ & $\begin{array}{l}5.6 \% \\
9.4 \% \\
10.3 \%\end{array}$ & & $\begin{array}{l}\text { Proxy 1: Households that take only one } \\
\text { meal per day } \\
\text { Proxy 2: Households in the lowest } 20 \% \\
\text { expenditure category } \\
\text { Proxy } 3: \text { Households below the food } \\
\text { poverty line }\end{array}$ \\
\hline & & $\begin{array}{l}\text { Labour-constrained: dependency } \\
\text { ratio>3 or no working aged adult, or } \\
\text { working aged adult has chronic illness } \\
\text { or disability }\end{array}$ & & $24 \%$ & $\begin{array}{l}\text { Household is receiving transfers but is } \\
\text { not labour-constrained }\end{array}$ \\
\hline$\# 12$ & $\begin{array}{l}\text { 'Glass of Milk' subsidy } \\
\text { programme } \\
\text { [Peru] } \\
\text { (Delegated CBT) }\end{array}$ & $\begin{array}{l}\text { Poor children (44\% of households with } \\
\text { children aged } 3-11 \text { ) } \\
\text { Households with pregnant/ lactating } \\
\text { women } \\
\text { People with tuberculosis (TB) }\end{array}$ & $\begin{array}{l}51.4 \% \\
38.2 \% \\
36.5 \%\end{array}$ & $\begin{array}{l}16.8 \% \\
27.0 \% \\
39.6 \%\end{array}$ & $\begin{array}{l}\text { Targeting based on poverty among all } \\
\text { households } \\
\text { Targeting based on poverty among } \\
\text { households with children aged }<7 \\
\text { Targeting based on child malnutrition }\end{array}$ \\
\hline \multirow[t]{2}{*}{ \#50 } & \multirow[t]{2}{*}{$\begin{array}{l}\text { General food distribution } \\
\text { [Tanzania, Zimbabwe] }\end{array}$} & $\begin{array}{l}<=3 \text { acres (=poorest) or >3 acres of } \\
\text { "unproductive" land (=poor); } \\
<=2 \text { cattle; zero or low-income- } \\
\text { generating activities [p54] }\end{array}$ & & $5-12 \%$ & Tanzania \\
\hline & & $\begin{array}{l}\text { Land }<=2-3 \text { hectares; }<=2-3 \text { cattle; no } \\
\text { permanent salaried employment [p61] }\end{array}$ & & $10-13 \%$ & Zimbabwe \\
\hline$\# 51$ & $\begin{array}{l}\text { Agricultural Input Subsidy } \\
\text { Programme } \\
\text { [Malawi] } \\
\text { (Devolved CBT) }\end{array}$ & $\begin{array}{l}\text { Communities identified vulnerable } \\
\text { members; criteria included: } \\
\text { being elderly, weak and vulnerable; } \\
\text { orphans, widows + female-headed } \\
\text { households keeping orphans; } \\
\text { "households with multiple problems"; } \\
\text { disabled, chronically ill household } \\
\text { head or keeping sick people }\end{array}$ & $67 \%$ & $5 \%$ & $\begin{array}{l}\text { "95\% of the targeted households for } \\
\text { agricultural inputs were poor" and } \\
\text { food insecure. [p84] } \\
\text { "67\% food insecure households ... } \\
\text { were excluded. Ideally these } \\
\text { households should have been } \\
\text { included because they satisfy the } \\
\text { selection criteria. However, due to } \\
\text { limited quota only } 33 \% \text { of the } \\
\text { deserving households were targeted." } \\
\text { [p84] }\end{array}$ \\
\hline \#94 & $\begin{array}{l}\text { Vision } 2020 \text { Umurenge } \\
\text { Programme }\end{array}$ & $\begin{array}{l}\text { Bottom } 2 \text { "social poverty" 'Ubudehe' } \\
\text { categories }\end{array}$ & $60.0 \%$ & $21.1 \%$ & $\begin{array}{l}\text { "Social poverty" assessed against } \\
\text { "extreme income poverty" and }\end{array}$ \\
\hline
\end{tabular}




\begin{tabular}{|c|c|c|c|c|c|}
\hline No. & Programme + Country & Eligibility criteria & $\begin{array}{c}\text { Exclusion } \\
\text { error }\end{array}$ & $\begin{array}{c}\text { Inclusion } \\
\text { error }\end{array}$ & Indicator/ (Comment) \\
\hline & $\begin{array}{l}\text { Rwanda] } \\
\text { (Devolved CBT) }\end{array}$ & $\begin{array}{l}\text { + Land constrained }<=0.25 \mathrm{ha} \\
\text { + Adult labour in the household } \\
(0=\text { Direct Support; } 1+=\text { Public Works) }\end{array}$ & & & "human income poverty" lines \\
\hline
\end{tabular}


Table A1.6. Targeting errors on self-targeted programmes

\begin{tabular}{|c|c|c|c|c|c|}
\hline No. & Programme + Country & Eligibility criteria & $\begin{array}{c}\text { Exclusion } \\
\text { error }\end{array}$ & $\begin{array}{c}\text { Inclusion } \\
\text { error }\end{array}$ & Indicator/ (Comment) \\
\hline$\# 96$ & $\begin{array}{l}\text { Productive Safety Net } \\
\begin{array}{l}\text { Programme (PSNP) - } \\
\text { Public Works component } \\
\text { [Ethiopia] }\end{array}\end{array}$ & $\begin{array}{l}\text { Food insecure rural households: } \\
\text { 3+ months of food shortage in the } \\
\text { previous year }\end{array}$ & $69.9 \%$ & $12.5 \%$ & $\begin{array}{l}\text { "88\% of beneficiaries and 70\% of non- } \\
\text { beneficiaries reported experiencing } \\
\text { three or more months of food } \\
\text { shortage in the preceding year" [p23] }\end{array}$ \\
\hline
\end{tabular}

Table A1.7. Targeting errors on programmes using multiple targeting mechanisms

\begin{tabular}{|c|c|c|c|c|c|}
\hline No. & Programme + Country & Eligibility criteria & $\begin{array}{l}\text { Exclusion } \\
\text { error }\end{array}$ & $\begin{array}{c}\text { Inclusion } \\
\text { error }\end{array}$ & Indicator/ (Comment) \\
\hline \#5 & $\begin{array}{l}\text { Social cash transfer } \\
\text { National Social Emergency } \\
\text { Plan } \\
\text { [Uruguay] }\end{array}$ & $\begin{array}{l}\text { Means test: Household income below } \\
\text { poverty line } \\
+ \text { Proxy means test: "Critical needs } \\
\text { index" based on household } \\
\text { characteristics }\end{array}$ & $21.6 \%$ & & $\begin{array}{l}\text { (Eligible households did not apply for } \\
\text { programme benefits) }\end{array}$ \\
\hline \multirow[t]{2}{*}{$\# 11$} & \multirow{2}{*}{$\begin{array}{l}\text { Disability Grant } \\
\text { [South Africa] }\end{array}$} & \multirow{2}{*}{$\begin{array}{l}\text { Means test: Income and assets } \\
+\underline{\text { Categorical: }} \text { "Disability test": inability } \\
\text { to work }\end{array}$} & $38 \%-46 \%$ & $34 \%$ & Income + disability tests together \\
\hline & & & $49 \%$ & $17 \%$ & Disability test alone \\
\hline \multirow[t]{2}{*}{$\# 14$} & \multirow[t]{2}{*}{$\begin{array}{l}\text { Conditional cash transfer } \\
\text { Red de Proteccion Social } \\
\text { [Nicaragua] }\end{array}$} & \multirow{2}{*}{$\begin{array}{l}\text { Geographic: Localities with high } \\
\text { marginality index scores in } \\
\text { municipalities with good institutional } \\
\text { capacity and schools, in extremely } \\
\text { poor departments } \\
+ \text { Proxy means test: Household assets, } \\
\text { land, economic resources, business } \\
\text { enterprises }\end{array}$} & $3 \%-10 \%$ & & $\begin{array}{l}\text { (Low levels of undercoverage in } \\
\text { programme areas) }\end{array}$ \\
\hline & & & & $6 \%-15 \%$ & $\begin{array}{l}\text { (Low levels of leakage in programme } \\
\text { areas) }\end{array}$ \\
\hline \multirow[t]{2}{*}{ \#20 } & \multirow{2}{*}{$\begin{array}{l}\text { Red de Proteccion Social } \\
\text { [Nicaragua] } \\
\text { ( } 2 \text { targeting methods applied in } \\
\text { different areas) }\end{array}$} & $\begin{array}{l}\text { Geographic: Poor districts (all } \\
\text { households in poorest districts) }\end{array}$ & $3 \%$ & $14 \%$ & Poor households \\
\hline & & $\begin{array}{l}\text { Proxy means test: Poor households in } \\
\text { less poor districts) }\end{array}$ & $\begin{array}{c}3 \% \\
10 \% \\
\end{array}$ & $\begin{array}{l}17 \% \\
6 \% \\
\end{array}$ & $\begin{array}{l}\text { Extremely poor households } \\
\text { Poor households }\end{array}$ \\
\hline \#38 & $\begin{array}{l}\text { Food-for-School Programme } \\
\text { (FSP) }\end{array}$ & $\begin{array}{l}\text { Geographic: (1) poorest provinces; (2) } \\
\text { poorer municipalities within each of }\end{array}$ & $80 \%$ & $62 \%$ & Primary schools \\
\hline
\end{tabular}




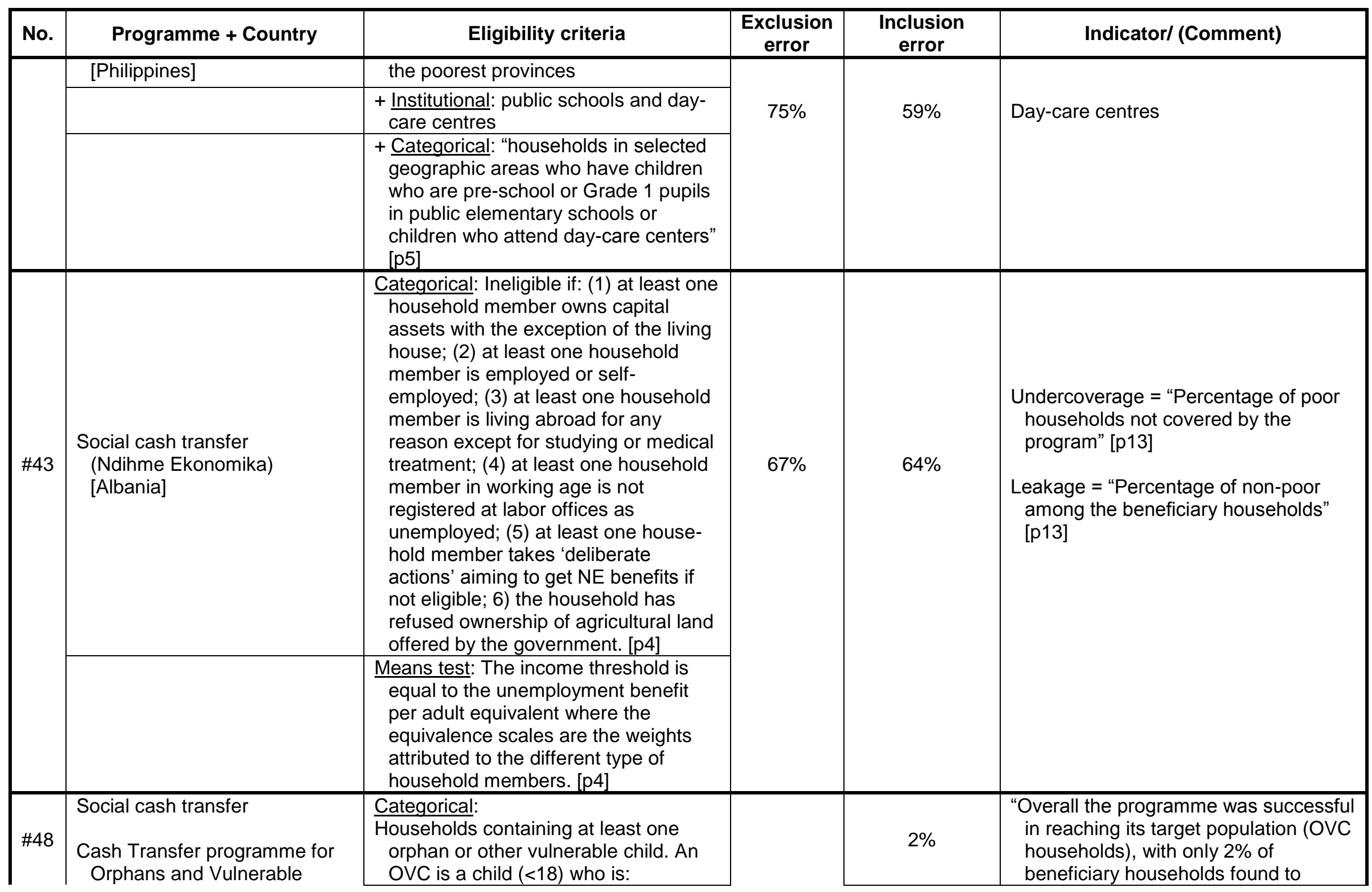




\begin{tabular}{|c|c|c|c|c|c|}
\hline No. & Programme + Country & Eligibility criteria & $\begin{array}{l}\text { Exclusion } \\
\text { error }\end{array}$ & $\begin{array}{l}\text { Inclusion } \\
\text { error }\end{array}$ & Indicator/ (Comment) \\
\hline & \multirow[t]{2}{*}{$\begin{array}{l}\text { Children (CT-OVC) } \\
\text { [Kenya] }\end{array}$} & $\begin{array}{l}\text { - an orphan (single or double); or } \\
\text { - chronically ill; or } \\
\text { - looked after by chronically ill carer. }\end{array}$ & \multirow[b]{2}{*}{$78 \%$} & & $\begin{array}{l}\text { contain no OVCs and } 21 \% \text { of OVC } \\
\text { households being supported by the } \\
\text { programme in the programme areas } \\
\text { covered by the evaluation." [p23] }\end{array}$ \\
\hline & & $\begin{array}{l}\text { +Proxy means test: } \\
\text { Household meets at least } 8 \text { of } 17 \\
\text { poverty characteristics: (1) No adult } \\
\text { reached standard 8; (2) Caregiver is } \\
\text { not working or is a farmer or labourer; } \\
\text { (3) Caregiver has <2 acres of land; } \\
\text { (4) Walls are mud/ cow-dung or } \\
\text { grass/sticks; (5) Floor is mud or cow- } \\
\text { dung; (6) Roof is mud or cow-dung; } \\
\text { (7) No toilet or pan/ bucket; (8) } \\
\text { Drinking water is river, lake or pond; } \\
\text { (9) Lighting fuel is firewood; (10) } \\
\text { Cooking fuel is firewood or residue/ } \\
\text { animal waste/ grass; (11) Owns no } \\
\text { real estate property; (12) Owns } 2 \text { or } \\
\text { less zebu cattle; (13) Owns no hybrid } \\
\text { cattle; (14) Owns } 5 \text { or less goats; (15) } \\
\text { Owns } 5 \text { or less sheep; (16) Owns no } \\
\text { pigs; (17) Owns no camels. [p22] }\end{array}$ & & $2 \%$ & $\begin{array}{l}\text { "The basis on which these poverty } \\
\text { characteristics were chosen is not } \\
\text { clear, and the analysis presented } \\
\text { below demonstrates that they do not } \\
\text { perform well in identifying the poorest } \\
\text { households (in fact } 95 \% \text { of OVC } \\
\text { households in treatment locations are } \\
\text { defined as poor according to these } \\
\text { criteria)." [p23] } \\
\text { "'”xclusion errors in implementation } \\
\text { were inevitable because, due to } \\
\text { budget limitations, only } 21 \% \text { of OVC } \\
\text { households and } 22 \% \text { of eligible OVC } \\
\text { households could be supported, and } \\
\text { should therefore not be interpreted as } \\
\text { a failure of the programme's } \\
\text { implementation systems as they } \\
\text { would be for a universal rights-based } \\
\text { programme." [p26] }\end{array}$ \\
\hline \multirow[t]{2}{*}{$\# 61$} & \multirow[t]{2}{*}{$\begin{array}{l}\text { Conditional cash transfer } \\
\text { PROGRESA } \\
\text { [Mexico] }\end{array}$} & \multirow{2}{*}{$\begin{array}{l}\text { Geographic (communities) } \\
\text { + Means test (households) } \\
\text { "First, communities are selected using } \\
\text { a marginality index based on census } \\
\text { data. Second, within the selected } \\
\text { communities, households are chosen } \\
\text { using survey data collected at the } \\
\text { household level." [p1771] }\end{array}$} & $6.6 \%$ & & $\begin{array}{l}\text { "approximately seven out of } 100 \\
\text { households classified as extreme } \\
\text { poor by the 'perfect' targeting method } \\
\text { based on consumption are not } \\
\text { classified as poor by PROGRESA" } \\
\text { [p1775] }\end{array}$ \\
\hline & & & & $70.1 \%$ & $\begin{array}{l}\text { "when the low poverty line is applied } \\
\text { the leakage rate is high by } \\
\text { construction" [p1775] }\end{array}$ \\
\hline \#72 & $\begin{array}{l}\text { Old Age Allowance } \\
\text { [Bangladesh] }\end{array}$ & $\begin{array}{l}\text { Categorical (older persons) } \\
+ \text { CBT (delegated) } \\
\text { A committee of local elites identifies }\end{array}$ & & $60.4 \%$ & $\begin{array}{l}\text { "community selection does a good job } \\
\text { in distinguishing between poor and } \\
\text { non-poor older persons but it is much }\end{array}$ \\
\hline
\end{tabular}




\begin{tabular}{|c|c|c|c|c|c|}
\hline No. & Programme + Country & Eligibility criteria & $\begin{array}{l}\text { Exclusion } \\
\text { error }\end{array}$ & $\begin{array}{l}\text { Inclusion } \\
\text { error }\end{array}$ & Indicator/ (Comment) \\
\hline & & poor older persons & & & $\begin{array}{l}\text { less accurate in selecting the poorest } \\
\text { among the poor" [p77] }\end{array}$ \\
\hline$\# 97$ & $\begin{array}{l}\text { Social cash transfer } \\
\text { Cash Transfer programme for } \\
\text { Orphans and Vulnerable } \\
\text { Children (CT-OVC) } \\
\text { [Kenya] }\end{array}$ & $\begin{array}{l}\text { Target group: Ultra-poor house-holds } \\
\text { with orphans or vulnerable children } \\
\text { (1) Geographic: Districts by poverty + } \\
\text { HIV rates } \\
\text { (2) Community-based (delegated): } \\
\text { Committees identify beneficiaries by } \\
\text { eligibility criteria } \\
\text { (3) Proxy means test: PMT + ranking = } \\
\text { quota }\end{array}$ & & $22 \%$ & $\begin{array}{l}\text { "total household poverty is ...78 } \\
\text { percent among CT-OVC program } \\
\text { recipients" [p6] }\end{array}$ \\
\hline
\end{tabular}




\section{References 12}

\#20 Adato, M. (2008) Integrating survey and ethnographic methods to evaluate conditional cash transfer programs. Washington DC: IFPRI. (810): 1-36.

\#66 Adato, M. (2000) The Impact of PROGRESA on Community Social Relationships. Washington DC: IFPRI.

\#22 Ahmed, A.; Quisumbing, A.; Nasreen, M.; Hoddinott, J. and Bryan, E. (2009) Comparing food and cash transfers to the ultra poor in Bangladesh. Washington DC: IFPRI.

\#03 Alderman, H. (2001) 'Multi-Tier Targeting of Social Assistance: The Role of Intergovernmental Transfers', World Bank Economic Review. 15(1): 33-53.

\#94 Asselin, L-M. (2010) VUP Targeting and Poverty Surveys 2009. Kigali, Rwanda: MINALOC

\#72 Barrientos, A. (2009) 'Social Pensions in Low-Income Countries', Chapter 5 in R. Holzmann, D. Robalino and N. Takayama (2009) Closing the coverage gap: role of social pensions and other retirement income transfers. Washington DC: World Bank.

\#26 Baulch, B. (2002) Poverty monitoring and targeting using ROC curves: examples from Vietnam. Brighton: Institute of Development Studies.

\#87 Benfield, W. (2007) Indicator targeting: The Jamaica Food Stamp Programme. http://uwivet.edu/conferences/salises/documents/Benfield W.pdf.

Besley, T. and Kanbur, R. (1990) The Principles of Targeting, Policy, Research, and External Affairs Working Papers. Washington DC: World Bank.

\#07 Bobonis, G. (2009) The Impact of Conditional Cash Transfers on Marriage and Divorce. University of Toronto, Department of Economics, Working Papers.

\#05 Burdin, G. and de Melo, G. (2009) Social Benefits in Uruguay: Why Do Some Potential Beneficiaries Not Apply? Revista Cepal (98): 141-58.

Case, A. and Deaton, A. (1998) 'Large cash transfers to the elderly in South Africa', Economic Journal 108 (450):1330-1361.

\#64 Castañeda, T. (2005) Targeting Social Spending to the Poor with Proxy-Means Testing: Colombia's SISBEN System. Washington DC: Social Protection Unit, Human Development Network, World Bank.

Castañeda, T.; Lindert, K. with de la Brière, B.; Fernandez, L.; Hubert, C.; Larrañaga, O.; Orozco, M. and Viquez, R. (2005) Designing and Implementing Household Targeting Systems: Lessons from Latin America and the United States. Washington DC: Social Protection Unit, Human Development Network, World Bank.

\#69 Chinsinga, B. (2005) 'Targeting Safety Net Interventions in Developing Countries: Some Insights from a Qualitative Simulation Study from Malawi', European Journal of Development Research 17(4): 706-734.

\#25 Coady, D. (2006) 'The welfare returns to finer targeting: The case of the Progresa program in Mexico', International Tax and Public Finance 13(2-3): 217-239.

\#06 Coady, D. and Parker, S. (2009) Targeting Social Transfers to the Poor in Mexico, IMF Working Papers: 09/60. Washington DC: International Monetary Fund.

Coady, D.; Grosh, M. and Hoddinott, J. (2004) 'Targeting outcomes redux', World Bank Research Observer 19 (1):61-85.

12 The number ("\#”) assigned to each document referenced is an identifier code used in the Appendix tables above. Documents with no identifier codes are referenced in the main text but not in the Appendix tables. 
\#92 Coady, D.; Grosh, M. and Hoddinott, J. (2003) Targeted anti-poverty interventions: A selected annotated bibliography. Washington DC: World Bank Publications.

\#18 Conning, J. and Kevane, M. (2002) 'Community-based targeting mechanisms for social safety nets: A critical review', World Development 30(3): 375-394.

Cornia, G. and Stewart, F. (1993) 'Two Errors of Targeting', Journal of International Development 5 (5):459-496.

\#80 de Janvry, A. and Sadoulet, E. (2006) 'Making Conditional Cash Transfer Programs More Efficient: Designing for Maximum Effect of the Conditionality', World Bank Economic Review. (1): 1-29.

DFID (Department for International Development) (2011) DFID's Approach to Value for Money (VfM). London: DFID.

\#57 Dutrey, A. (2007) Successful Targeting? Reporting Efficiency and Costs in Targeted Poverty Alleviation Programmes. Geneva: United Nations Research Institute for Social Development (UNRISD).

\#24 Elbers, C.; Fujii, T.; Lanjouw, P.; Özler, B. and Yin, W. (2004) Poverty alleviation through geographic targeting: how much does disaggregation help? Policy Research Working Paper 3419. Washington DC: World Bank.

\#58 Ellis, F. (2012) “We Are All Poor Here”: Economic Difference, Social Divisiveness, and Targeting Cash Transfers in Sub-Saharan Africa', Journal of Development Studies 48(2): 201-14.

\#59 Ellis, F. (2009) Poverty targeting: New evidence on spatial and distributional impacts. Frontiers of Social Protection Brief Number 2. Johannesburg: Regional Hunger and Vulnerability Programme.

\#44 Falkingham, J. and Namazie, C. (2002) Measuring health and poverty: a review of approaches to identifying the poor. DFID Health Systems Resource Centre.

\#21 Ferreira-Coimbra, N. and Forteza, A. (2005) 'Can Latin America protect the elderly with non-contributory programmes? The case of Uruguay', Development Policy Review 23(6): 683-702.

\#19 Fiszbein, A.; Schady, N. and Ferreira, F. [et al.] (2009) Conditional cash transfers: reducing present and future poverty. Washington DC: World Bank.

\#40 Fox, L. (2003) Safety Nets in Transition Economies: A Primer. Washington DC: World Bank.

Gelbach, J. and Pritchett, L. (1997) More for the poor is less for the poor: the politics of targeting. Policy Research Working Paper 1799. Washington DC: World Bank.

\#74 Grosh, M. and Leite, P. (2009) 'Defining Eligibility for Social Pensions: A View from a Social Assistance Perspective', Chapter 12 in R. Holzmann, D. Robalino and N. Takayama (2009) Closing the coverage gap: role of social pensions and other retirement income transfers. Washington DC: World Bank.

Grosh, M.; del Ninno, C.; Tesliuc, E. and Ouerghi, A. (2008) From Protection to Promotion: The Design and Implementation of Effective Safety Nets. Washington DC: World Bank.

Ha, W.; Chai, J. and Alviar, C. (2010) Targeting in Kenya's Cash Transfer Programme for OVC. Working Paper. African Development Bank.

Habibov, N. and Fan, L. (2006) 'Social Assistance and the Challenges of Poverty and Inequality in Azerbaijan, a Low-Income Country in Transition', Journal of Sociology and Social Welfare 33(1): 203-226.

\#10 Handa, S. and Davis, B. (2006) The experience of conditional cash transfers in Latin America and the Caribbean. ESA Working Paper (FAO). no. 06-07: Rome: FAO. 
\#46 Hodges, A.; Dufay, A-C.; Dashdorj, K.; Jong, K. and Budragchaa, U. (2007) Child Benefits and Poverty Reduction: Evidence from Mongolia's Child Money Programme. United Nations Children's Fund.

\#23 Hunter, N. and Adato, M. (2007) The child support grant in Kwazulu-Natal: perceptions and experience inside the household. Research Report 73. Durban: School of Development Studies, University of KwaZulu-Natal.

Hurrell, A. (2009) Effective Targeting of Poverty-focused programmes. OPM Briefing Notes 2009-01. Oxford: Oxford Policy Management.

\#48 Hurrell, A. and MacAuslan, I. (2009) 'Effective targeting of cash transfer programmes in an African context: Lessons learned from the on-going evaluation of two cash transfer programmes in Kenya', paper prepared for the Centre for the Study of African Economies 2009 Conference, Oxford, 22-24 March.

\#49 Jaspars, S. and Maxwell, D. (2008) Targeting in Complex Emergencies: Somalia Country Case Study. Medford MA: Feinstein International Center.

Kakwani, N. and Subbarao, K. (2005) Aging and Poverty in Africa and the Role of Social Pensions. Social Protection Discussion Paper Series 0521. Washington DC: World Bank.

Kidd, S. and Wylde, E. (2011) Targeting the Poorest: An assessment of the proxy means test methodology. Canberra: Australian Agency for International Development (AusAID).

\#76 Lembani, M. (2006) Assessing the Effectiveness and Efficiency of Targeting Methods in Public Works Programmes in Malawi: The Case of MASAF and CARE managed programmes in the Central Region of Malawi. Cape Town: University of Western Cape.

\#43 Lucia, M. and Paolo, V. (2009) Impact Evaluation of an Anti-Poverty Program in Albania: Is a Negative Effect Due to Targeting failures? Perugia: Università di Perugia.

\#14 Maluccio, J. (2009) 'Household Targeting in Practice: the Nicaraguan Red de Proteccion Social', Journal of International Development 21(1): 1-23.

\#38 Manasan, R. and Cuenca, J. (2007) 'Who Benefits from the Food-For-School Program and Tindahan Natin Program: Lessons in Targeting', Social Welfare and Development Journal 2(1): 1-60.

Mangiavacchi, L. and Verme, P. (2009) Impact Evaluation of an Anti-Poverty Program in Albania: Is a Negative Effect due to Targeting Failures? Working Paper. Washington DC: World Bank.

\#63 Mansuri, G. and Rao, V. (2004) Community-Based and-Driven Development: A Critical Review. Policy Research Working Paper 3209. Washington DC: World Bank.

\#50 Mathys, E. (2004) Community-Managed Targeting and Distribution of Food Aid: A review of the experience of Save the Children UK in sub-Saharan Africa. London: Save the Children UK.

\#51 Mgemezulu, O. (2008) The social impact of community based targeting mechanisms for safety nets: A qualitative study of the targeted agricultural input subsidy programme in Malawi. Durban: School of Development Studies, University of KwaZulu-Natal.

Miller, E. and Samson, M. (2012) HIV-Sensitive Social Protection: State of the evidence 2012 in sub-Saharan Africa. Working Paper commissioned by UNICEF. Cape Town: Economic Policy Research Institute.

\#02 Miller, C.; Tsoka, M. and Reichert, K. (2010) 'Targeting Cash to Malawi's Ultra-poor: A Mixed Methods Evaluation', Development Policy Review (4): 481-502. 
\#27 Minot, N. and Baulch, B. (2002) The spatial distribution of poverty in Vietnam and the potential for targeting. Washington DC: World Bank.

\#11 Mitra, S. (2010) Disability Cash Transfers in the Context of Poverty and Unemployment: the Case of South Africa. Fordham University, Department of Economics, Fordham Economics Discussion Paper Series.

Mkandawire, T. (2005) Targeting and Universalism in Poverty Reduction. Social Policy and Development Programme Paper No. 23. Geneva: United Nations Research Institute for Social Development (UNRISD).

\#45 Nazim, N. and Lida, F. (2006) 'Social Assistance and the Challenges of Poverty and Inequality in Azerbaijan, a Low-Income Country in Transition', Journal of Sociology and Social Welfare 1-14.

\#01 Pantuliano, S. (2006) 'From food aid to livelihoods support: rethinking the role of WFP in eastern Sudan', Disasters 31 Suppl 1: S77-90.

\#52 Pritchett, L. (2005) The Political Economy of Targeted Safety Nets. Washington DC: Social Protection Unit, Human Development Network, World Bank.

\#53 Pritchett, L.; Sumarto, S. and Suryahadi, A. (2002) Targeted Programs in an Economic Crisis: Empirical Findings from Indonesia's Experience. Cambridge: Harvard University.

\#04 Ravallion, M. (2007) How Relevant is Targeting to the Success of an Antipoverty Program? Policy Research Working Paper 4385. Washington DC: World Bank.

Samson, M. (2011) Micro-simulation Analysis of Social Protection Intervention in Pacific Island Countries. Commissioned by the Australian Agency for International Development (AusAID). Cape Town: Economic Policy Research Institute.

Samson, M. (2008) Targeting options for social protection in Nepal. Policy brief commissioned by the U.K. Department for International Development. Cape Town: Economic Policy Research Institute.

Samson, M.; Mac Quene, K. and van Niekerk, I. (2010) Designing and Implementing Social Transfer Programmes (Second Edition). Cape Town: Economic Policy Research Institute.

\#31 Samson, M.; van Niekerk, I. and MacQuene, K. (2006) Designing and Implementing Social Transfer Programmes. Cape Town: Economic Policy Research Institute.

\#17 Schady, N. (2002) 'Picking the poor: Indicators for geographic targeting in Peru', Review of Income and Wealth (3): 417-433.

Sen, A. (1995) 'The Political Economy of Targeting', in D. van de Walle and K. Nead (eds), Public Spending and the Poor: Theory and Evidence. Baltimore: Johns Hopkins University Press.

\#96 Sharp, K.; Brown, T. and Teshome, A. (2006) Targeting Ethiopia's Productive Safety Net Programme (PSNP). London: Overseas Development Institute.

\#61 Skoufias, E.; Davis, B. and de la Vega, S. (2001) 'Targeting the Poor in Mexico: An Evaluation of the Selection of Households into PROGRESA', World Development 29(10): 1769-1784.

\#36 Slater, R. and Farrington, J. (2009) Targeting of Social Transfers: A Review for DFID. London: ODI.

Slater, R. and Mphale, M. (2008) Cash transfers, gender and generational relations: evidence from a pilot project in Lesotho. A report commissioned by World Vision International. London: Humanitarian Policy Group Overseas Development Institute.

\#75 Sluchynsky, O. (2009) 'Administration of Social Pension Programs', Chapter 14 in R. Holzmann, D. Robalino and N. Takayama (2009) Closing the coverage gap: role of social pensions and other retirement income transfers. Washington DC: World Bank. 
\#32 Standing, G. (2007) How Cash Transfers Boost Work and Economic Security. United Nations Department of Economic and Social Affairs.

\#65 Stecklov, G.; Winters, P.; Todd, J. and Regalia, F. (2006) Demographic Externalities from Poverty Programs in Developing Countries: Experimental Evidence from Latin America. Washington DC: Department of Economics, American University.

\#12 Stifel, D. and Alderman, H. (2003) The 'Glass of Milk' Subsidy Program and Malnutrition in Peru. World Bank Policy Research Working Paper 3089. Washington DC: World Bank.

\#42 Tesliuc (2004) Mitigating Social Risks in Kyrgyz Republic. Washington DC: Social Protection Unit, Human Development Network, World Bank.

van de Walle, D. (1998) 'Targeting Revisited', World Bank Research Observer 13 (2).

\#33 van der Berg, S.; Siebrits, K. and Lekezwa, B. (2010) Efficiency and equity effects of social grants in South Africa. Stellenbosch: Department of Economics, University of Stellenbosch.

\#56 Watkins, B. (2008) Alternative Methods for Targeting Social Assistance to Highly Vulnerable Groups. Washington DC: Kimetrica.

\#15 Willmore, L. (2007) 'Universal pensions for developing countries', World Development 35(1): 24-51. 